\title{
Crónica
}

\section{Cuadro sinóptico de obras de compositores chilenos interpretadas durante el segundo semestre (octubre, 2010 - marzo, 2011) ${ }^{1}$}

\section{Abreviaturas}

BAFONA Ballet Folclórico Nacional

CECODA Central Coordinadora de Difusión Artística, actualmente colectivo Catarsis

DUOC Instituto Profesional DUOC-UC de la Pontificia Universidad Católica de Chile, ex Departamento Universitario Obrero Campesino.

GAM Centro Cultural Gabriela Mistral, Santiago

GAMUS Grupo Archivo de Música, Biblioteca Nacional.

IMUC Instituto de Música de la Pontificia Universidad Católica de Chile.

IMUS Instituto de Música, Pontificia Universidad Católica de Valparaíso.

PUC Pontificia Universidad Católica de Chile.

PUCV Pontificia Universidad Católica de Valparaíso.

TDL Tierra de Larry.

UMCE Universidad Metropolitana de Ciencias de la Educación.

UNMSM Universidad Mayor de San Marcos, Perú.

UPLA Universidad de Playa Ancha.

USACH Universidad de Santiago de Chile.

USS Universidad San Sebastián.

\begin{tabular}{|c|c|c|c|c|}
\hline $\begin{array}{l}\text { Nombre del } \\
\text { Compositor }\end{array}$ & Titulo de la obra & $\begin{array}{l}\text { Fecha de } \\
\text { Interpretación }\end{array}$ & Lugar & Intérpretes \\
\hline \multirow[t]{5}{*}{$\begin{array}{l}\text { Abalo, Juan } \\
\text { Pablo }\end{array}$} & $\begin{array}{l}\text { *Paisaje soleado (2010) para } \\
\text { flauta, clarinete, trompeta, } \\
\text { trombón, percusión, piano, violín, } \\
\text { viola, violoncello y contrabajo. }\end{array}$ & $8 / 11 / 2010$ & $\begin{array}{l}\text { XX Festival de Música } \\
\text { Contemporánea, PUC, } \\
\text { Sala GAM. }\end{array}$ & $\begin{array}{l}\text { Ensamble Contemporáneo, } \\
\text { Aliocha Solovera, director. }\end{array}$ \\
\hline & $\begin{array}{l}\text { Vista a la casa de Ives (2011) } \\
\text { para orquesta de cámara. }\end{array}$ & $16 / 03 / 2011$ & $\begin{array}{l}\text { Parroquia Santa Elena, } \\
\text { Las Condes, Santiago. }\end{array}$ & $\begin{array}{l}\text { Orquesta de Cámara de } \\
\text { Chile, Víctor Hugo Toro, } \\
\text { director. }\end{array}$ \\
\hline & & $17 / 03 / 2011$ & $\begin{array}{l}\text { Teatro Caja Los Andes, } \\
\text { Santiago. }\end{array}$ & $\begin{array}{l}\text { Orquesta de Cámara de } \\
\text { Chile, Víctor Hugo Toro, } \\
\text { director. }\end{array}$ \\
\hline & & $18 / 03 / 2011$ & $\begin{array}{l}\text { Teatro Municipal de } \\
\text { Nuñoa, Santiago. }\end{array}$ & $\begin{array}{l}\text { Orquesta de Cámara de } \\
\text { Chile, Víctor Hugo Toro, } \\
\text { director. }\end{array}$ \\
\hline & & $19 / 03 / 2011$ & $\begin{array}{l}\text { Teatro Municipal de San } \\
\text { Joaquín, Santiago. }\end{array}$ & $\begin{array}{l}\text { Orquesta de Cámara de } \\
\text { Chile, Víctor Hugo Toro, } \\
\text { director. }\end{array}$ \\
\hline
\end{tabular}




\begin{tabular}{|c|c|c|c|c|}
\hline $\begin{array}{l}\text { Nombre del } \\
\text { Compositor }\end{array}$ & Titulo de la obra & $\begin{array}{l}\text { Fecha de } \\
\text { Interpretación }\end{array}$ & Lugar & Intérpretes \\
\hline $\begin{array}{l}\text { Abarzúa, } \\
\text { Andrés }\end{array}$ & $\begin{array}{l}\text { *Free Will is a Sweet Illusion } \\
\text { (2009) para soprano, percusión, } \\
\text { piano y contrabajo. }\end{array}$ & $12 / 01 / 2011$ & $\begin{array}{l}\text { XI Festival de Música } \\
\text { Contemporánea de la } \\
\text { Universidad de Chile, } \\
\text { Facultad de Artes, Sala } \\
\text { Isidora Zegers. }\end{array}$ & $\begin{array}{l}\text { Camila García, soprano; } \\
\text { Leonardo Mandujano, } \\
\text { percusión; Daniela } \\
\text { Saavedra, piano; Camilo } \\
\text { Gaete, contrabajo. }\end{array}$ \\
\hline \multirow[t]{7}{*}{ Aburto, Diego } & $\begin{array}{l}\text { Transición para vibráfono y } \\
\text { piano. }\end{array}$ & $03 / 02 / 2011$ & $\begin{array}{l}\text { Música escénica para } \\
\text { percusiones, Sala Manuel } \\
\text { Enríquez, Facultad de } \\
\text { Música de la Universidad } \\
\text { de Tamaulipas, Tampico, } \\
\text { México. }\end{array}$ & $\begin{array}{l}\text { Dúo de Percusiones A } \\
\text { Dois y músicos invitados. }\end{array}$ \\
\hline & & 04/02/2011 & $\begin{array}{l}\text { Música escénica } \\
\text { para percusiones, } \\
\text { Master Class, Salón } \\
\text { de percusiones de } \\
\text { la Universidad de } \\
\text { Tamaulipas, Tampico, } \\
\text { México. }\end{array}$ & $\begin{array}{l}\text { Dúo de Percusiones A } \\
\text { Dois y músicos invitados. }\end{array}$ \\
\hline & & $08 / 02 / 2011$ & $\begin{array}{l}\text { Música escénica para } \\
\text { percusiones, Auditorio de } \\
\text { la Casa de la Marimba, } \\
\text { Ciudad de México. }\end{array}$ & $\begin{array}{l}\text { Dúo de Percusiones A } \\
\text { Dois y músicos invitados. }\end{array}$ \\
\hline & & $10 / 02 / 2011$ & $\begin{array}{l}\text { Música escénica para } \\
\text { percusiones, } 2^{\circ} \text { Festival } \\
\text { de la Marimba Maestro } \\
\text { Zeferino Nandayapa en la } \\
\text { Plaza Central de Chiapas } \\
\text { de Corzo, México. }\end{array}$ & $\begin{array}{l}\text { Dúo de Percusiones A Doi } \\
\text { y músicos invitados. }\end{array}$ \\
\hline & & $11 / 02 / 2011$ & $\begin{array}{l}\text { Música escénica para } \\
\text { percusiones, Master } \\
\text { Class, Escuela de Música } \\
\text { de la Universidad de } \\
\text { Chiapas, México. }\end{array}$ & $\begin{array}{l}\text { Dúo de Percusiones A } \\
\text { Dois y músicos invitados. }\end{array}$ \\
\hline & & $12 / 02 / 2011$ & $\begin{array}{l}\text { Música escénica para } \\
\text { percusiones, Auditorio de } \\
\text { la Fundación Sebastián, } \\
\text { Ciudad de México. }\end{array}$ & $\begin{array}{l}\text { Dúo de Percusiones A } \\
\text { Dois y músicos invitados. }\end{array}$ \\
\hline & & $12 / 02 / 2011$ & $\begin{array}{l}\text { Música escénica para } \\
\text { percusiones, Master } \\
\text { Class Auditorio de la } \\
\text { Fundación Sebastián, } \\
\text { Ciudad de México. }\end{array}$ & $\begin{array}{l}\text { Dúo de Percusiones A } \\
\text { Dois y músicos invitados. }\end{array}$ \\
\hline $\begin{array}{l}\text { Acevedo, } \\
\text { Claudio }\end{array}$ & $\begin{array}{l}\text { Viento del sur (2002) para flauta, } \\
\text { oboe, cuatro, guitarra, contrabajo } \\
\text { y maracas. }\end{array}$ & $19 / 11 / 2010$ & $\begin{array}{l}\text { Centro de Extensión de } \\
\text { la Universidad Católica } \\
\text { del Maule. }\end{array}$ & $\begin{array}{l}\text { Ensamble Serenata: } \\
\text { Hernán Jara, flauta; } \\
\text { Guillermo Milla, oboe; } \\
\text { Claudio Acevedo, } \\
\text { cuatro; Gonzalo Ramos, } \\
\text { percusión; Pablo } \\
\text { Seguel, bajo; Mauricio } \\
\text { Valdebenito, guitarra. }\end{array}$ \\
\hline
\end{tabular}




\begin{tabular}{|c|c|c|c|c|}
\hline $\begin{array}{l}\text { Nombre del } \\
\text { Compositor }\end{array}$ & Titulo de la obra & $\begin{array}{l}\text { Fecha de } \\
\text { Interpretación }\end{array}$ & Lugar & Intérpretes \\
\hline & \multirow{5}{*}{$\begin{array}{l}\text { Violeta María (2008) para flauta, } \\
\text { oboe, cuatro, contrabajo, maracas } \\
\text { y batá. }\end{array}$} & $20 / 11 / 2010$ & $\begin{array}{l}\text { Salón Balmaceda de } \\
\text { Linares. }\end{array}$ & Ensamble Serenata. \\
\hline & & $21 / 11 / 2010$ & $\begin{array}{l}\text { Teatro Municipal de San } \\
\text { Clemente. }\end{array}$ & Ensamble Serenata. \\
\hline & & $19 / 11 / 2010$ & $\begin{array}{l}\text { Centro de Extensión de } \\
\text { la Universidad Católica } \\
\text { del Maule. }\end{array}$ & Ensamble Serenata. \\
\hline & & $20 / 11 / 2010$ & $\begin{array}{l}\text { Salón Balmaceda de } \\
\text { Linares. }\end{array}$ & Ensamble Serenata. \\
\hline & & $21 / 11 / 2010$ & $\begin{array}{l}\text { Teatro Municipal de San } \\
\text { Clemente. }\end{array}$ & Ensamble Serenata. \\
\hline & \multirow[t]{3}{*}{$\begin{array}{l}\text { Por las calles (2009) para flauta, } \\
\text { oboe, guitarra, tiple, contrabajo, } \\
\text { bombo, caja y platillos. }\end{array}$} & $19 / 11 / 2010$ & $\begin{array}{l}\text { Centro de Extensión de } \\
\text { la Universidad Católica } \\
\text { del Maule. }\end{array}$ & Ensamble Serenata. \\
\hline & & $20 / 11 / 2010$ & $\begin{array}{l}\text { Salón Balmaceda de } \\
\text { Linares. }\end{array}$ & Ensamble Serenata. \\
\hline & & $21 / 11 / 2010$ & $\begin{array}{l}\text { Teatro Municipal de San } \\
\text { Clemente }\end{array}$ & Ensamble Serenata. \\
\hline \multirow[t]{4}{*}{ Advis, Luis } & $\begin{array}{l}\text { Cantata de Santa Maria de } \\
\text { Iquique (1969) para coro y } \\
\text { orquesta. }\end{array}$ & $6 / 10 / 2010$ & $\begin{array}{l}\text { Sala Isidora Zegers, } \\
\text { Facultad de Artes, } \\
\text { Universidad de Chile. }\end{array}$ & $\begin{array}{l}\text { Coro y conjunto } \\
\text { instrumental de la } \\
\text { Universidad Católica Raúl } \\
\text { Silva Henríquez, Germán } \\
\text { Greene, director general. }\end{array}$ \\
\hline & $\begin{array}{l}\text { Preludio } \mathrm{N}^{0} 1, \text { Andante mosso } \\
\text { (1965) para piano. }\end{array}$ & $23 / 11 / 2010$ & $\begin{array}{l}\text { XXIV Ciclo de } \\
\text { Pianistas Jóvenes 2010, } \\
\text { Auditorium Instituto } \\
\text { Chileno- Norteamericano } \\
\text { de Cultura. }\end{array}$ & Giselle Moraga, pianista. \\
\hline & $\begin{array}{l}\text { Preludio } \mathrm{N}^{0} 15 \text {, Adagio pesaroso } \\
\text { (1960) para piano. }\end{array}$ & $23 / 11 / 2010$ & $\begin{array}{l}\text { XXIV Ciclo de } \\
\text { Pianistas Jóvenes 2010, } \\
\text { Auditorium Instituto } \\
\text { Chileno Norteamericano } \\
\text { de Cultura. }\end{array}$ & Giselle Moraga, pianista. \\
\hline & $\begin{array}{l}\text { Vamos mujer (Cantata Santa } \\
\text { María de Iquique) (1969). }\end{array}$ & $15 / 02 / 2011$ & $\begin{array}{l}\text { Teatro Municipal Lord } \\
\text { Cochrane, Valdivia. }\end{array}$ & Roberto Bravo, piano. \\
\hline $\begin{array}{l}\text { Ahumada } \\
\text { Leonardo y } \\
\text { Andrea Paz } \\
\text { Miranda }\end{array}$ & $\begin{array}{l}\text { Nagual en vivo (2010) } \\
\text { improvisación audiovisual. }\end{array}$ & $13 / 10 / 2010$ & $\begin{array}{l}\text { X Festival } \\
\text { Internacional de } \\
\text { Música Electroacústica } \\
\text { Ai-Maako, Auditorio } \\
\text { Fundación Telefónica, } \\
\text { Santiago. }\end{array}$ & \\
\hline
\end{tabular}




\begin{tabular}{|c|c|c|c|c|}
\hline $\begin{array}{l}\text { Nombre del } \\
\text { Compositor }\end{array}$ & Titulo de la obra & $\begin{array}{l}\text { Fecha de } \\
\text { Interpretación }\end{array}$ & Lugar & Intérpretes \\
\hline $\begin{array}{l}\text { Albornoz, } \\
\text { Alejandro }\end{array}$ & $\begin{array}{l}\text { Radio tarro chilena (2010), } \\
\text { medios electrónicos. }\end{array}$ & $15 / 10 / 2010$ & $\begin{array}{l}\text { X Festival } \\
\text { Internacional de } \\
\text { Música Electroacústica } \\
\text { Ai-Maako, Auditorio } \\
\text { Fundación Telefónica, } \\
\text { Santiago. }\end{array}$ & \\
\hline Albornoz, Paulo & $\begin{array}{l}\text { Tonada por encargo (2005) para } \\
\text { guitarra. }\end{array}$ & $25 / 02 / 2011$ & $\begin{array}{l}\text { Del Mapocho al Illimani, } \\
\text { concierto de guitarra } \\
\text { clásica, } \\
\text { Museo de Arte } \\
\text { Contemporáneo Plaza (El } \\
\text { Prado), La Paz, Bolivia. }\end{array}$ & $\begin{array}{l}\text { Alejandro Escobar, } \\
\text { guitarra. }\end{array}$ \\
\hline Alcalde, Andrés & $\begin{array}{l}\text { Der Mondbach (1985) para } \\
\text { violoncello. }\end{array}$ & $28 / 10 / 2010$ & $\begin{array}{l}\text { Concierto-Bicentenario, } \\
\text { Sala Alte Feuerwache de } \\
\text { Colonia, Alemania. }\end{array}$ & Celso López, violoncello. \\
\hline \multirow[t]{3}{*}{$\begin{array}{l}\text { Aldea Dávila, } \\
\text { Sebastián }\end{array}$} & $\begin{array}{l}\text { **Díada (2010) para dúo de } \\
\text { guitarras y conjunto. }\end{array}$ & $1 / 12 / 2010$ & $\begin{array}{l}\text { Prismas Festival } \\
\text { de Creación } \\
\text { Latinoamericana, } \\
\text { Proyecto Germina. } \\
\text { Cciones...Primaveras } \\
\text { latinoamericanas, GAM. }\end{array}$ & $\begin{array}{l}\text { Dúo Ramallo (Cecilia y } \\
\text { Carlos Salvador Ramallo } \\
\text { Díaz), guitarras. }\end{array}$ \\
\hline & & $12 / 02 / 2011$ & $\begin{array}{l}\text { "Guitarras } \\
\text { Latinoamericanas } \\
\text { en Lima", UNMSM, } \\
\text { Estivalia Perú 2011, } \\
\text { Festival Musical de } \\
\text { Verano de la UNMSM. }\end{array}$ & $\begin{array}{l}\text { Dúo Ramallo (Cecilia y } \\
\text { Carlos Salvador Ramallo } \\
\text { Díaz), guitarras. }\end{array}$ \\
\hline & & $18 / 02 / 2011$ & $\begin{array}{l}\text { Música entre historia y } \\
\text { madera. Conservatorio } \\
\text { Nacional de Música de } \\
\text { La Paz, Bolivia. }\end{array}$ & $\begin{array}{l}\text { Dúo Ramallo (Cecilia y } \\
\text { Carlos Salvador Ramallo } \\
\text { Díaz), guitarras. }\end{array}$ \\
\hline \multirow[t]{3}{*}{$\begin{array}{l}\text { Allende, Pedro } \\
\text { Humberto }\end{array}$} & $\begin{array}{l}\text { Tonadas } \mathrm{N}^{0} 5 \text { (1920) y No } 6(1921) \\
\text { para piano. }\end{array}$ & $17 / 10 / 2010$ & $\begin{array}{l}\text { VII Festival } \\
\text { Internacional de Música } \\
\text { Contemporánea Darwin } \\
\text { Vargas, Instituto de } \\
\text { Música, PUCV. }\end{array}$ & Samuel Quezada, piano. \\
\hline & $\begin{array}{l}\text { Seis miniaturas griegas (1918- } \\
\text { 1928) en versión para orquesta } \\
\text { de cámara. }\end{array}$ & $15 / 11 / 2010$ & $\begin{array}{l}\text { Sala América de la } \\
\text { Biblioteca Nacional. }\end{array}$ & $\begin{array}{l}\text { Orquesta de Cámara del } \\
\text { Departamento de Música } \\
\text { de la UMCE, Daniel } \\
\text { Miranda, director. }\end{array}$ \\
\hline & Tonada $\mathrm{N}^{\circ} 9$ (1921) para piano. & $25 / 11 / 2010$ & $\begin{array}{l}\text { XXIV Ciclo de } \\
\text { Pianistas Jóvenes 2010, } \\
\text { Auditorium Instituto } \\
\text { Chileno Norteamericano } \\
\text { de Cultura. }\end{array}$ & Pedro Robert, pianista. \\
\hline
\end{tabular}




\begin{tabular}{|c|c|c|c|c|}
\hline $\begin{array}{l}\text { Nombre del } \\
\text { Compositor }\end{array}$ & Titulo de la obra & $\begin{array}{l}\text { Fecha de } \\
\text { Interpretación }\end{array}$ & Lugar & Intérpretes \\
\hline & $\begin{array}{l}\text { Estudio en Re menor } \mathrm{N}^{0} 7 \text { (1932) } \\
\text { para piano. }\end{array}$ & $1 / 12 / 2010$ & $\begin{array}{l}\text { XXIV Ciclo de } \\
\text { Pianistas Jóvenes 2010, } \\
\text { Auditorium Instituto } \\
\text { Chileno Norteamericano } \\
\text { de Cultura. }\end{array}$ & $\begin{array}{l}\text { Javier Valenzuela, } \\
\text { pianista. }\end{array}$ \\
\hline & $\begin{array}{l}\text { Cinco tonadas de carácter } \\
\text { popular chileno (1918-1922) } \\
\text { para piano. }\end{array}$ & $22 / 03 / 2011$ & $\begin{array}{l}\text { Cathédrale St. Louis des } \\
\text { Invalides, París. }\end{array}$ & $\begin{array}{l}\text { María Paz Santibañez, } \\
\text { piano. }\end{array}$ \\
\hline \multirow[t]{5}{*}{ Alvarado, Boris } & \multirow[t]{2}{*}{$\begin{array}{l}\text { Exmesure (2010) para una } \\
\text { bailarina, flauta, clarinete, violín, } \\
\text { viola, violoncello, percusión y } \\
\text { piano. }\end{array}$} & $14 / 10 / 2010$ & $\begin{array}{l}\text { VII Festival } \\
\text { Internacional de Música } \\
\text { Contemporánea Darwin } \\
\text { Vargas, Instituto de } \\
\text { Música, PUCV. }\end{array}$ & $\begin{array}{l}\text { Ensemble E-Mex de } \\
\text { Colonia, Alemania, } \\
\text { Ramón Gorigoitía, } \\
\text { director, Alejandra Caro, } \\
\text { bailarina invitada. }\end{array}$ \\
\hline & & $15 / 10 / 2010$ & $\begin{array}{l}\text { Sala Isidora Zegers, } \\
\text { Facultad de Artes, } \\
\text { Universidad de Chile. }\end{array}$ & $\begin{array}{l}\text { Ensemble E-Mex de } \\
\text { Colonia, Alemania, } \\
\text { Ramón Gorigoitía, } \\
\text { director, Alejandra Caro, } \\
\text { bailarina invitada. }\end{array}$ \\
\hline & $\begin{array}{l}\text { MaipúCampana, Alma de } \\
\text { Chilenía (2010), sinfonía sacra } \\
\text { para danza, teatro, solistas } \\
\text { vocales, coro femenino, tape y } \\
\text { orquesta, sobre textos del padre } \\
\text { Joaquín Alliende Luco. }\end{array}$ & $\begin{array}{l}11,12,13 \\
14 / 11 / 2010\end{array}$ & $\begin{array}{l}\text { Santuario Nacional de } \\
\text { Maipú. }\end{array}$ & $\begin{array}{l}\text { Actores: Héctor Noguera, } \\
\text { Francisca Imboden, } \\
\text { Fernanda Márquez } \\
\text { Sidharta Corvalán, } \\
\text { Constanza Gómez y } \\
\text { Emilia Noguera. } \\
\text { Solistas vocales: } \\
\text { Madgalena Matthey, } \\
\text { Pascuala Ilabaca y María } \\
\text { Paz Mera, Illie Castillo, } \\
\text { Francisco Astorga, } \\
\text { Compañía de Danza Viaje } \\
\text { al infinito, Coro Femenino } \\
\text { de Cámara de la PUCV, } \\
\text { Orquesta para la obra, } \\
\text { dirección general: Boris } \\
\text { Alvarado. }\end{array}$ \\
\hline & \multirow[t]{2}{*}{$\begin{array}{l}\text { Double Rock (2001) para dos } \\
\text { marimbas. }\end{array}$} & 03/02/2011 & $\begin{array}{l}\text { Música escénica para } \\
\text { percusiones, Sala Manuel } \\
\text { Enríquez, Facultad de } \\
\text { Música de la Universidad } \\
\text { de Tamaulipas, Tampico, } \\
\text { México. }\end{array}$ & $\begin{array}{l}\text { Dúo de Percusiones A } \\
\text { Dois. }\end{array}$ \\
\hline & & $04 / 02 / 2011$ & $\begin{array}{l}\text { Música escénica } \\
\text { para percusiones, } \\
\text { Master Class, Salón } \\
\text { de percusiones de } \\
\text { la Universidad de } \\
\text { Tamaulipas, Tampico, } \\
\text { México. }\end{array}$ & $\begin{array}{l}\text { Dúo de Percusiones A } \\
\text { Dois. }\end{array}$ \\
\hline
\end{tabular}




\begin{tabular}{|c|c|c|c|c|}
\hline $\begin{array}{l}\text { Nombre del } \\
\text { Compositor }\end{array}$ & Titulo de la obra & $\begin{array}{l}\text { Fecha de } \\
\text { Interpretación }\end{array}$ & Lugar & Intérpretes \\
\hline & & $08 / 02 / 2011$ & $\begin{array}{l}\text { Música escénica para } \\
\text { percusiones, Auditorio de } \\
\text { la Casa de la Marimba, } \\
\text { Ciudad de México. }\end{array}$ & $\begin{array}{l}\text { Dúo de Percusiones A } \\
\text { Dois. }\end{array}$ \\
\hline & & $10 / 02 / 2011$ & $\begin{array}{l}\text { Música escénica para } \\
\text { percusiones, } 2^{\circ} \text { Festival } \\
\text { de la Marimba Maestro } \\
\text { Zeferino Nandayapa en la } \\
\text { Plaza Central de Chiapas } \\
\text { de Corzo, México. }\end{array}$ & $\begin{array}{l}\text { Dúo de Percusiones A } \\
\text { Dois. }\end{array}$ \\
\hline & & $11 / 02 / 2010$ & $\begin{array}{l}\text { Música escénica para } \\
\text { percusiones, Master } \\
\text { Class, Escuela de Música } \\
\text { de la Universidad de } \\
\text { Chiapas }\end{array}$ & $\begin{array}{l}\text { Dúo de Percusiones A } \\
\text { Dois. }\end{array}$ \\
\hline & & $12 / 02 / 2011$ & $\begin{array}{l}\text { Música escénica para } \\
\text { percusiones, Auditorio de } \\
\text { la Fundación Sebastián, } \\
\text { Ciudad de México. }\end{array}$ & $\begin{array}{l}\text { Dúo de Percusiones A } \\
\text { Dois. }\end{array}$ \\
\hline & & $12 / 02 / 2011$ & $\begin{array}{l}\text { Música escénica para } \\
\text { percusiones, Master } \\
\text { Class, Auditorio de la } \\
\text { Fundación Sebastián, } \\
\text { Ciudad de México. }\end{array}$ & $\begin{array}{l}\text { Dúo de Percusiones A } \\
\text { Dois. }\end{array}$ \\
\hline $\begin{array}{l}\text { Alvarado Gaete, } \\
\text { Cristopher }\end{array}$ & $\begin{array}{l}\text { **Un poco más allá (2010) para } \\
\text { flauta. }\end{array}$ & $3 / 12 / 2010$ & $\begin{array}{l}\text { Prismas Festival } \\
\text { de Creación } \\
\text { Latinoamericana, } \\
\text { Proyecto Germina. } \\
\text { Cciones...Primaveras } \\
\text { latinoamericanas, GAM. }\end{array}$ & Leonardo Vargas, flauta. \\
\hline $\begin{array}{l}\text { Amenábar, } \\
\text { Juan }\end{array}$ & $\begin{array}{l}\text { A la orilla del estero de } \\
\text { Tres composiciones corales } \\
\text { (1950-53), texto de Miguel } \\
\text { Arteche. }\end{array}$ & $7 / 10 / 2010$ & $\begin{array}{l}\text { Aula Magna de la } \\
\text { USACH. }\end{array}$ & $\begin{array}{l}\text { Coro de la USACH, } \\
\text { Santiago Marín, director. }\end{array}$ \\
\hline \multirow[t]{4}{*}{ Aranda, Pablo } & \multirow[t]{2}{*}{$\begin{array}{l}\text { Ale (2002) para piano y medios } \\
\text { electrónicos. }\end{array}$} & $7 / 10 / 2010$ & $\begin{array}{l}\text { X Festival Ai-Maako, } \\
\text { Teatro Municipal Lord } \\
\text { Cochrane, Valdivia. }\end{array}$ & Fernanda Ortega, piano. \\
\hline & & $29 / 11 / 2010$ & $\begin{array}{l}\text { Sala América de la } \\
\text { Biblioteca Nacional. }\end{array}$ & Fernanda Ortega, piano. \\
\hline & $\begin{array}{l}\text { *Parphe II (2010) para flauta, } \\
\text { clarinete, violín, violoncello, } \\
\text { piano y marimba. }\end{array}$ & $10 / 11 / 2010$ & $\begin{array}{l}\text { XX Festival de Música } \\
\text { Contemporánea, PUC, } \\
\text { Sala GAM. }\end{array}$ & $\begin{array}{l}\text { Taller de Música } \\
\text { Contemporánea, Pablo } \\
\text { Aranda, director. }\end{array}$ \\
\hline & $\begin{array}{l}\text { *Aleridaga (Fragmento I) (2011), } \\
\text { encargada por el ViktoriaQuartett } \\
\text { Berlin. }\end{array}$ & $7 / 01 / 2011$ & $\begin{array}{l}\text { Aula Magna Universidad } \\
\text { San Sebastián, Campus } \\
\text { General Lagos, Valdivia. }\end{array}$ & $\begin{array}{l}\text { Ensamble ViktoriaQuartett } \\
\text { Berlin, Álvaro Parra, } \\
\text { violín; Gabriel Adorján, } \\
\text { violín; Daniel Röhn, } \\
\text { viola; Christopher Jepson, } \\
\text { violoncello. }\end{array}$ \\
\hline
\end{tabular}




\begin{tabular}{llll}
\hline $\begin{array}{l}\text { Nombre del } \\
\text { Compositor }\end{array}$ & Titulo de la obra & $\begin{array}{l}\text { Fecha de } \\
\text { Interpretación }\end{array}$ & Lugar \\
\hline & $8 / 01 / 2011$ & Teatro del Lago, Frutillar. & $\begin{array}{l}\text { Ensamble ViktoriaQuartett } \\
\text { Berlin, Álvaro Parra, } \\
\text { violín; Gabriel Adorján, } \\
\text { violín; Daniel Röhn, } \\
\text { viola; Christopher Jepson, } \\
\text { violoncello. }\end{array}$ \\
& & &
\end{tabular}

$11 / 01 / 201$

$13 / 01 / 2011$
XI Festival de Música

Contemporánea de la

Universidad de Chile,

Facultad de Artes, Sala

Isidora Zegers.
Goethe Institut, Santiago. Ensamble ViktoriaQuartett

Berlin.

Álvaro Parra, violín;

Gabriel Adorján, violín;

Daniel Röhn, viola;

Christopher Jepson,

violoncello.

Ensamble ViktoriaQuartett

Berlin.

Álvaro Parra, violín;

Gabriel Adorján, violín;

Daniel Röhn, viola;

Christopher Jepson, violoncello.

\begin{tabular}{|c|c|c|c|c|}
\hline \multirow[t]{2}{*}{$\begin{array}{l}\text { Arenas Fuentes, } \\
\text { Mauricio }\end{array}$} & $\begin{array}{l}\text { La caja mágica (2007) para } \\
\text { piano. }\end{array}$ & $22 / 03 / 2011$ & $\begin{array}{l}\text { Cathédrale St. Louis des } \\
\text { Invalides, París. }\end{array}$ & $\begin{array}{l}\text { María Paz Santibañez, } \\
\text { piano. }\end{array}$ \\
\hline & $\begin{array}{l}\text { Variaciones sobre Gracias a la } \\
\text { vida }(2005) \text { para piano. }\end{array}$ & $22 / 03 / 2011$ & $\begin{array}{l}\text { Cathédrale St. Louis des } \\
\text { Invalides, París. }\end{array}$ & $\begin{array}{l}\text { María Paz Santibañez, } \\
\text { piano. }\end{array}$ \\
\hline \multirow[t]{4}{*}{$\begin{array}{l}\text { Asuar, José } \\
\text { Vicente }\end{array}$} & $\begin{array}{l}\text { Elegía (1982), composición } \\
\text { electroacústica, estéreo. }\end{array}$ & $8 / 10 / 2010$ & $\begin{array}{l}\text { X Festival } \\
\text { Internacional de Música } \\
\text { Electroacústica Ai- } \\
\text { Maako, Teatro Municipal } \\
\text { Lord Cochrane, Valdivia. }\end{array}$ & $\begin{array}{l}\text { Concierto carta blanca de } \\
\text { José Vicente Asuar. }\end{array}$ \\
\hline & & $16 / 10 / 2010$ & $\begin{array}{l}\text { X Festival } \\
\text { Internacional de } \\
\text { Música Electroacústica } \\
\text { Ai-Maako, Auditorio } \\
\text { Fundación Telefónica, } \\
\text { Santiago. }\end{array}$ & $\begin{array}{l}\text { Concierto carta blanca de } \\
\text { José Vicente Asuar. }\end{array}$ \\
\hline & $\begin{array}{l}\text { En el jardin (1985), } \\
\text { composición electroacústica, } \\
\text { estéreo. }\end{array}$ & $8 / 10 / 2010$ & $\begin{array}{l}\text { X Festival } \\
\text { Internacional de Música } \\
\text { Electroacústica Ai- } \\
\text { Maako, Teatro Municipal } \\
\text { Lord Cochrane, Valdivia. }\end{array}$ & $\begin{array}{l}\text { Concierto carta blanca de } \\
\text { José Vicente Asuar. }\end{array}$ \\
\hline & & $16 / 10 / 2010$ & $\begin{array}{l}\text { X Festival } \\
\text { Internacional de } \\
\text { Música Electroacústica } \\
\text { Ai-Maako, Auditorio } \\
\text { Fundación Telefónica, } \\
\text { Santiago. }\end{array}$ & $\begin{array}{l}\text { Concierto carta blanca de } \\
\text { José Vicente Asuar. }\end{array}$ \\
\hline
\end{tabular}




\begin{tabular}{|c|c|c|c|c|}
\hline $\begin{array}{l}\text { Nombre del } \\
\text { Compositor }\end{array}$ & Titulo de la obra & $\begin{array}{l}\text { Fecha de } \\
\text { Interpretación }\end{array}$ & Lugar & Intérpretes \\
\hline & \multirow[t]{2}{*}{$\begin{array}{l}\text { Cuatro piezas instrumentales } \\
\text { (1989), composición } \\
\text { electroacústica, estéreo. }\end{array}$} & $8 / 10 / 2010$ & $\begin{array}{l}\text { X Festival } \\
\text { Internacional de Música } \\
\text { Electroacústica Ai- } \\
\text { Maako, Teatro Municipal } \\
\text { Lord Cochrane, Valdivia. }\end{array}$ & $\begin{array}{l}\text { Concierto carta blanca de } \\
\text { José Vicente Asuar. }\end{array}$ \\
\hline & & $16 / 10 / 2010$ & $\begin{array}{l}\text { X Festival } \\
\text { Internacional de } \\
\text { Música Electroacústica } \\
\text { Ai-Maako, Auditorio } \\
\text { Fundación Telefónica, } \\
\text { Santiago. }\end{array}$ & $\begin{array}{l}\text { Concierto carta blanca de } \\
\text { José Vicente Asuar. }\end{array}$ \\
\hline \multirow[t]{2}{*}{ Atria, Jaime } & La consentida (1961), para coro. & $5 / 10 / 2010$ & Aula Magna USACH. & $\begin{array}{l}\text { Coro de Cámara de la } \\
\text { UPLA, Carlos Hernández, } \\
\text { director. }\end{array}$ \\
\hline & $\begin{array}{l}\text { La violeta y la parra }(1970) \\
\text { para coro. }\end{array}$ & $5 / 10 / 2010$ & Aula Magna USACH. & $\begin{array}{l}\text { Coro de Cámara de la } \\
\text { UPLA, Carlos Hernández, } \\
\text { director. }\end{array}$ \\
\hline \multirow[t]{2}{*}{$\begin{array}{l}\text { Barrientos, } \\
\text { Gustavo }\end{array}$} & *Tirana Rit (2011), ópera. & $7 / 02 / 2011$ & $\begin{array}{l}\text { Teatro del Lago, Semanas } \\
\text { Musicales de Frutillar. }\end{array}$ & $\begin{array}{l}\text { Solistas: Carolina Muñoz } \\
\text { Coloma, Arturo Jiménez } \\
\text { de Santiago y Carlos } \\
\text { Campos de Puerto Montt; } \\
\text { Coro de la Pontificia } \\
\text { Universidad Católica; } \\
\text { Coro de la Universidad de } \\
\text { Los Lagos. Bailarines de } \\
\text { la compañía "Danzahora" } \\
\text { y } 4 \text { actores de la } \\
\text { Agrupación de Actores, } \\
\text { todos de Puerto Montt. }\end{array}$ \\
\hline & & & & $\begin{array}{l}\text { El ensamble orquestal } \\
\text { estuvo integrado por } \\
\text { solistas en violín, viola, } \\
\text { violoncello y contrabajo, } \\
\text { flautas, clarinete, saxofón, } \\
\text { corno, trompeta, trombón, } \\
\text { timbales, marimba, } \\
\text { accesorios de percusión, } \\
\text { guitarra y un músico } \\
\text { electrónico. Dirección: } \\
\text { Gustavo Barrientos. }\end{array}$ \\
\hline \multirow[t]{2}{*}{$\begin{array}{l}\text { Becerra- } \\
\text { Schmidt, } \\
\text { Gustavo }\end{array}$} & Sonata (1953) para flauta y piano. & $1 / 10 / 2010$ & $\begin{array}{l}\text { Sala Isidora Zegers, } \\
\text { Facultad de Artes, } \\
\text { Universidad de Chile. }\end{array}$ & $\begin{array}{l}\text { Wilson Padilla, flauta; } \\
\text { Miguel Ángel Jiménez, } \\
\text { piano. }\end{array}$ \\
\hline & $\begin{array}{l}\text { *Poemas corales (2008), texto } \\
\text { de Elicura Chihuailaf, para coro } \\
\text { femenino, obra dedicada a Coral } \\
\text { Femenina de Viña del Mar. }\end{array}$ & $17 / 10 / 2010$ & $\begin{array}{l}\text { VII Festival } \\
\text { Internacional de Música } \\
\text { Contemporánea Darwin } \\
\text { Vargas, Instituto de } \\
\text { Música de la PUCV, Sala } \\
\text { DUOC de Viña del Mar. }\end{array}$ & $\begin{array}{l}\text { Coral Femenina Viña del } \\
\text { Mar, Jessica Quezada, } \\
\text { directora. }\end{array}$ \\
\hline
\end{tabular}




\begin{tabular}{|c|c|c|c|c|}
\hline $\begin{array}{l}\text { Nombre del } \\
\text { Compositor }\end{array}$ & Titulo de la obra & $\begin{array}{l}\text { Fecha de } \\
\text { Interpretación }\end{array}$ & Lugar & Intérpretes \\
\hline & \multirow[t]{6}{*}{$\begin{array}{l}\text { Concierto (1950) para violín y } \\
\text { orquesta. }\end{array}$} & $3 / 11 / 2010$ & Aula Magna USACH. & $\begin{array}{l}\text { Orquesta de la } \\
\text { Universidad de Santiago } \\
\text { de Chile, David del Pino } \\
\text { Klinge, director; Oriana } \\
\text { Silva, violín. }\end{array}$ \\
\hline & & $3 / 11 / 2010$ & $\begin{array}{l}\text { Parroquia Santa Elena, } \\
\text { Las Condes. }\end{array}$ & $\begin{array}{l}\text { Orquesta de Cámara de } \\
\text { Chile, Julio Doggenweiler, } \\
\text { director invitado; Isidro } \\
\text { Rodríguez, violín. }\end{array}$ \\
\hline & & $4 / 11 / 2010$ & $\begin{array}{l}\text { Estación Mapocho, Sala } \\
\text { de las Artes. }\end{array}$ & $\begin{array}{l}\text { Orquesta de Cámara de } \\
\text { Chile, Julio Doggenweiler, } \\
\text { director invitado; Isidro } \\
\text { Rodríguez, violín. }\end{array}$ \\
\hline & & $5 / 11 / 2010$ & $\begin{array}{l}\text { Teatro Municipal de } \\
\text { Ñuñoa, Santiago. }\end{array}$ & $\begin{array}{l}\text { Orquesta de Cámara de } \\
\text { Chile, Julio Doggenweiler, } \\
\text { director invitado; Isidro } \\
\text { Rodríguez, violín. }\end{array}$ \\
\hline & & $6 / 11 / 2010$ & $\begin{array}{l}\text { Colegio San Esteban, Lo } \\
\text { Barnechea, Santiago. }\end{array}$ & $\begin{array}{l}\text { Orquesta de Cámara de } \\
\text { Chile, Julio Doggenweiler, } \\
\text { director invitado; Isidro } \\
\text { Rodríguez, violín. }\end{array}$ \\
\hline & & $11 / 11 / 2010$ & $\begin{array}{l}\text { XX Festival de Música } \\
\text { Contemporánea, PUC, } \\
\text { Sala GAM. }\end{array}$ & $\begin{array}{l}\text { Orquesta de Cámara } \\
\text { Universidad Católica, } \\
\text { David Núñez, director. }\end{array}$ \\
\hline & $\begin{array}{l}\text { Ballet sobre un cuento de } \\
\text { brujas (1963) para dos pianos y } \\
\text { percusión. }\end{array}$ & $10 / 12 / 2010$ & $\begin{array}{l}\text { Concierto homenaje } \\
\text { a Gustavo Becerra- } \\
\text { Schmidt, } \\
\text { Aula de la Universidad } \\
\text { de Oldenburgo. }\end{array}$ & $\begin{array}{l}\text { Intérpretes de diversos } \\
\text { ensambles de Oldenburgo } \\
\text { y del Norte de Alemania. }\end{array}$ \\
\hline & $\begin{array}{l}\text { Agua dormida (1971) para } \\
\text { soprano y piano. }\end{array}$ & $10 / 12 / 2010$ & $\begin{array}{l}\text { Concierto homenaje } \\
\text { a Gustavo Becerra- } \\
\text { Schmidt, } \\
\text { Aula de la Universidad } \\
\text { de Oldenburgo. }\end{array}$ & $\begin{array}{l}\text { Intérpretes de diversos } \\
\text { ensambles de Oldenburgo } \\
\text { y del Norte de Alemania. }\end{array}$ \\
\hline & $\begin{array}{l}\text { Charivari (1979) para flauta, } \\
\text { piano y percusión. }\end{array}$ & $10 / 12 / 2010$ & $\begin{array}{l}\text { Concierto homenaje } \\
\text { a Gustavo Becerra- } \\
\text { Schmidt, } \\
\text { Aula de la Universidad } \\
\text { de Oldenburgo. }\end{array}$ & $\begin{array}{l}\text { Intérpretes de diversos } \\
\text { ensambles de Oldenburgo } \\
\text { y del Norte de Alemania. }\end{array}$ \\
\hline & $\begin{array}{l}\text { Preludio y Balistocata (1979) } \\
\text { para piano. }\end{array}$ & $10 / 12 / 2010$ & $\begin{array}{l}\text { Concierto homenaje } \\
\text { a Gustavo Becerra- } \\
\text { Schmidt, } \\
\text { Aula de la Universidad } \\
\text { de Oldenburgo. }\end{array}$ & $\begin{array}{l}\text { Intérpretes de diversos } \\
\text { ensambles de Oldenburgo } \\
\text { y del Norte de Alemania. }\end{array}$ \\
\hline & $\begin{array}{l}\text { Revolución (1980) para coro } \\
\text { mixto. }\end{array}$ & $10 / 12 / 2010$ & $\begin{array}{l}\text { Concierto homenaje } \\
\text { a Gustavo Becerra- } \\
\text { Schmidt, } \\
\text { Aula de la Universidad } \\
\text { de Oldenburgo. }\end{array}$ & $\begin{array}{l}\text { Coro Bundschuh, Robert } \\
\text { Brüll, director. }\end{array}$ \\
\hline
\end{tabular}




\begin{tabular}{|c|c|c|c|c|}
\hline $\begin{array}{l}\text { Nombre del } \\
\text { Compositor }\end{array}$ & Titulo de la obra & $\begin{array}{l}\text { Fecha de } \\
\text { Interpretación }\end{array}$ & Lugar & Intérpretes \\
\hline & $\begin{array}{l}\text { Singen wann? (¿Cantar, cuándo?) } \\
\text { (1988) para coro mixto a cuatro } \\
\text { voces. }\end{array}$ & $10 / 12 / 2010$ & $\begin{array}{l}\text { Concierto homenaje } \\
\text { a Gustavo Becerra- } \\
\text { Schmidt, } \\
\text { Aula de la Universidad } \\
\text { de Oldenburgo. }\end{array}$ & $\begin{array}{l}\text { Coro Bundschuh, Robert } \\
\text { Brüll, director. }\end{array}$ \\
\hline & $\begin{array}{l}\text { Wenn ich einmal nicht schlafen } \\
\text { kann (2003) para canto y piano. }\end{array}$ & $10 / 12 / 2010$ & $\begin{array}{l}\text { Concierto homenaje } \\
\text { a Gustavo Becerra- } \\
\text { Schmidt, } \\
\text { Aula de la Universidad } \\
\text { de Oldenburgo. }\end{array}$ & $\begin{array}{l}\text { Intérpretes de diversos } \\
\text { ensambles de Oldenburgo } \\
\text { y del Norte de Alemania. }\end{array}$ \\
\hline & $\begin{array}{l}\text { Gehörtes Eigentum para coro } \\
\text { mixto. }\end{array}$ & $10 / 12 / 2010$ & $\begin{array}{l}\text { Concierto Homenaje } \\
\text { a Gustavo Becerra- } \\
\text { Schmidt. } \\
\text { Aula de la Universidad } \\
\text { de Oldenburgo. }\end{array}$ & $\begin{array}{l}\text { Coro Bundschuh, Robert } \\
\text { Brüll, director. }\end{array}$ \\
\hline & $\begin{array}{l}\text { Las Pascualas (1957) para } \\
\text { guitarra. }\end{array}$ & $25 / 02 / 2011$ & $\begin{array}{l}\text { Del Mapocho al Illimani, } \\
\text { concierto de guitarra } \\
\text { clásica, } \\
\text { Museo de Arte } \\
\text { Contemporáneo Plaza (El } \\
\text { Prado) La Paz, Bolivia. }\end{array}$ & $\begin{array}{l}\text { Alejandro Escobar, } \\
\text { guitarra. }\end{array}$ \\
\hline $\begin{array}{l}\text { Benavides, } \\
\text { Jorge }\end{array}$ & $\begin{array}{l}\text { Manifiesto de un angelito a su } \\
\text { madre (2010) para voz, violín } \\
\text { y cello. }\end{array}$ & $7 / 10 / 2010$ & $\begin{array}{l}\text { VI Concurso de } \\
\text { Composición Luis Advis, } \\
\text { GAM. }\end{array}$ & $\begin{array}{l}\text { Jorge Benavides, violín; } \\
\text { Catalina Fuentes, cantante; } \\
\text { Daygoro Serón, cello. }\end{array}$ \\
\hline Bernal, César & $\begin{array}{l}\text { **Viejo lobo membrillo (2010) } \\
\text { para contrabajo y percusión. }\end{array}$ & $29 / 11 / 2010$ & $\begin{array}{l}\text { Prismas Festival } \\
\text { de Creación } \\
\text { Latinoamericana, } \\
\text { Proyecto Germina. } \\
\text { Cciones...Primaveras } \\
\text { latinoamericanas, } \\
\text { Universidad de } \\
\text { Valparaíso. }\end{array}$ & $\begin{array}{l}\text { César Bernal, contrabajo; } \\
\text { Pablo Rivera, percusión. }\end{array}$ \\
\hline \multirow[t]{3}{*}{ Botto, Carlos } & $\begin{array}{l}\text { Tres preludios op. } 3 \text { (1952) para } \\
\text { piano. }\end{array}$ & $17 / 10 / 2010$ & $\begin{array}{l}\text { VII Festival } \\
\text { Internacional de Música } \\
\text { Contemporánea Darwin } \\
\text { Vargas, Instituto de } \\
\text { Música de la PUCV. }\end{array}$ & Patricia Escobar, piano. \\
\hline & $\begin{array}{l}\text { Seis piezas breves (1992) para } \\
\text { orquesta de cámara. }\end{array}$ & $15 / 11 / 2010$ & $\begin{array}{l}\text { Sala América de la } \\
\text { Biblioteca Nacional. }\end{array}$ & $\begin{array}{l}\text { Orquesta de Cámara del } \\
\text { Departamento de Música } \\
\text { de la UMCE, Daniel } \\
\text { Miranda, director. }\end{array}$ \\
\hline & $\begin{array}{l}\text { Cantos al amor y la muerte } \\
\text { (1956) para orquesta de cuerdas } \\
\text { y tenor. }\end{array}$ & $17 / 11 / 2010$ & $\begin{array}{l}\text { Iglesia San Francisco, } \\
\text { Santiago. }\end{array}$ & $\begin{array}{l}\text { Orquesta de Cámara } \\
\text { de Chile, Juan Pablo } \\
\text { Izquierdo, director, Iván } \\
\text { Rodríguez, tenor. }\end{array}$ \\
\hline $\begin{array}{l}\text { Brnčić, } \\
\text { Gabriel }\end{array}$ & $\begin{array}{l}\text { Ergon - Rondeau II (2000), } \\
\text { versión para violoncello } \\
\text { amplificado e imágenes de la } \\
\text { pintora Gabriela Vargas. }\end{array}$ & $13 / 10 / 2010$ & $\begin{array}{l}\text { VII Festival } \\
\text { Internacional de Música } \\
\text { Contemporánea Darwin } \\
\text { Vargas, Instituto de } \\
\text { Música de la PUCV. }\end{array}$ & Mircea Ticu, violoncello. \\
\hline
\end{tabular}




\section{$\begin{array}{llll}\text { Nombre del } & \text { Titulo de la obra } & \text { Fecha de } & \text { Lugar } \\ \text { Compositor } & \text { Interpretación } & \text { Intérpretes }\end{array}$}

$\begin{array}{ll}\text { Cáceres, } & * * \text { Por Corrientes y Florida } \\ \text { Eduardo } & \text { (2010) para flauta y guitarra }\end{array}$

$5 / 10 / 2010$

El viento en la isla (1982) para

9/10/2010

voz y piano.

Y cómo están? Están Flor

(2010) para piano.

La otra Concertación (1989) para voz femenina, bajo eléctrico, tablas hindúes y medios electroacústicos.

Antisonata chilótica (1984) para orquesta sinfónica, piano y percusión.

Fantasiica araucánica (1984) para piano.

$04 / 11 / 2010$

Fantasias ritmicas (2006) para piano. $5^{\circ}$ Ciclo de Música Dúo "FrameDuo",

Contemporánea, Sala Michela Caser (flauta),

Carlos Guastavino,

Biblioteca Nacional,

Centro Nacional de

la Música, Instituto

Nacional de Musicología

Carlos Vega, Buenos

Aires, Argentina.

Argentina.

Aula de la Universidad ARTIK DUO: Tania de Lund, Suecia.

Naranjo-Golborne, piano; Rocío Olalde (soprano).

Homenaje a Robert Jorge Pepi-Alos, piano.

Schumann: 200 años,

Sala Isidora Zegers,

Facultad de Artes,

Universidad de Chile.

15/10/2010 VII Festival Pascuala Ilabaca, voz;

Internacional de Música Jaime Frez, tablas

Contemporánea Darwin

Vargas, Instituto de

Música de la PUCV,

Teatro Auditorium

DUOC, Sede Viña del

Mar.

19/10/2010 III Festival Internacional de Música de Medellín:

Grandes Percusionistas

del Mundo, Teatro Pablo

Tobón Uribe.

hindúes; Jaime Frez, bajo

eléctrico; Rodrigo Rivera,

voz, tabla, bajo eléctrico

y tape; Boris Alvarado,

director.

Orquesta Sinfónica de Medellín, Alejandro

Posada, director;

Alexander Ziborov,

percusión; Victoria

Ziborova, piano.

Retrospectiva de la

Música Chilena en

Patricia Castro, piano.

el Bicentenario, Sala

América de la Biblioteca

Nacional, Colectivo

Catarsis (ex CECODA).

16/11/2010 Ciclo de Música de Patricia Castro, piano.

Cámara,

Goethe Institut, Santiago.

Retrospectiva de la

Patricia Castro, piano

Música Chilena en

el Bicentenario, Sala

América de la Biblioteca

Nacional, Colectivo

Catarsis (ex CECODA).

24/11/2010 Semana de la Música, Fernanda Ortega, piano.

Sala América de la

Biblioteca Nacional,

GAMUS. 


\begin{tabular}{|c|c|c|c|c|}
\hline $\begin{array}{l}\text { Nombre del } \\
\text { Compositor }\end{array}$ & Titulo de la obra & $\begin{array}{l}\text { Fecha de } \\
\text { Interpretación }\end{array}$ & Lugar & Intérpretes \\
\hline & Contratiempo (1978) para piano. & $18 / 12 / 2010$ & Grigny, Francia. & Ian Quiao Xing, piano. \\
\hline & $\begin{array}{l}\text { **Septiembre (2002) para } \\
\text { conjunto instrumental. }\end{array}$ & $10 / 01 / 2011$ & $\begin{array}{l}\text { XI Festival de Música } \\
\text { Contemporánea de la } \\
\text { Universidad de Chile, } \\
\text { Facultad de Artes, Sala } \\
\text { Isidora Zegers. }\end{array}$ & $\begin{array}{l}\text { Celso López, violoncello; } \\
\text { Miguel Villafruela, } \\
\text { saxofón alto; Wilson } \\
\text { Padilla, flauta; Manuel } \\
\text { Jiménez, arpa; Aliocha } \\
\text { Solovera, director. }\end{array}$ \\
\hline
\end{tabular}

\begin{tabular}{|c|c|c|c|c|}
\hline \multirow[t]{6}{*}{ Cádiz, Rodrigo } & $\begin{array}{l}\text { eHarpsichord (2005) para piano y } \\
\text { medios electrónicos. }\end{array}$ & $7 / 10 / 2010$ & $\begin{array}{l}\text { X Festival } \\
\text { Internacional de Música } \\
\text { Electroacústica } \\
\text { Ai-Maako, Teatro } \\
\text { Municipal Lord Cochrane } \\
\text { de Valdivia. }\end{array}$ & Fernanda Ortega, piano. \\
\hline & $\begin{array}{l}\text { iCons (2007) para sistema de } \\
\text { sensores gestuados. }\end{array}$ & $9 / 10 / 2010$ & $\begin{array}{l}\text { X Festival } \\
\text { Internacional de Música } \\
\text { Electroacústica } \\
\text { Ai-Maako, Teatro } \\
\text { Municipal Lord } \\
\text { Cochrane, Valdivia. }\end{array}$ & \\
\hline & $\begin{array}{l}\text { eRecorder (2008) para flauta } \\
\text { contrabaja Paetzold y medios } \\
\text { electrónicos. }\end{array}$ & $9 / 10 / 2010$ & $\begin{array}{l}\text { X Festival } \\
\text { Internacional de Música } \\
\text { Electroacústica Ai- } \\
\text { Maako, Teatro Municipal } \\
\text { Lord Cochrane, Valdivia. }\end{array}$ & $\begin{array}{l}\text { Terri Hron, flauta } \\
\text { dulce, Rodrigo Cádiz, } \\
\text { electrónica. }\end{array}$ \\
\hline & & $14 / 10 / 2010$ & $\begin{array}{l}\text { X Festival } \\
\text { Internacional de } \\
\text { Música Electroacústica } \\
\text { Ai-Maako, Auditorio } \\
\text { Fundación Telefónica, } \\
\text { Santiago. }\end{array}$ & $\begin{array}{l}\text { Terri Hron, flauta } \\
\text { dulce, Rodrigo Cádiz, } \\
\text { electrónica. }\end{array}$ \\
\hline & $\begin{array}{l}\text { G-3 (2001) para trío de guitarras } \\
\text { y cinta. }\end{array}$ & $14 / 10 / 2010$ & $\begin{array}{l}\text { X Festival } \\
\text { Internacional de Música } \\
\text { Electroacústica } \\
\text { Ai-Maako, Auditorio } \\
\text { Fundación Telefónica, } \\
\text { Santiago. }\end{array}$ & $\begin{array}{l}\text { Aksak Tacet Ensamble: } \\
\text { Andrés Pantoja, Cristián } \\
\text { Alvear y Fernando } \\
\text { Sandoval, guitarras. }\end{array}$ \\
\hline & $\begin{array}{l}\text { **Extensiones }(2010) \text { para } \\
\text { percusión solista, orquesta y } \\
\text { computador. }\end{array}$ & 22 y $23 / 10 / 2010$ & $\begin{array}{l}\text { Teatro de la Universidad } \\
\text { de Chile. }\end{array}$ & $\begin{array}{l}\text { Orquesta Sinfónica } \\
\text { de Chile, Michal } \\
\text { Nesterowicz, director; } \\
\text { Gerardo Salazar, } \\
\text { percusión. }\end{array}$ \\
\hline
\end{tabular}




\begin{tabular}{|c|c|c|c|c|}
\hline $\begin{array}{l}\text { Nombre del } \\
\text { Compositor }\end{array}$ & Titulo de la obra & $\begin{array}{l}\text { Fecha de } \\
\text { Interpretación }\end{array}$ & Lugar & Intérpretes \\
\hline & $\begin{array}{l}\text { *Divergencias (2010) para } \\
\text { glockenspiel, xilófono, vibráfono, } \\
\text { marimba. }\end{array}$ & $14 / 11 / 2010$ & $\begin{array}{l}\text { XX Festival de Música } \\
\text { Contemporánea, Salón } \\
\text { Fresno, Centro de } \\
\text { Extensión PUC. }\end{array}$ & $\begin{array}{l}\text { Ensamble de Percusión } \\
\text { IMUC, Gerardo Salazar, } \\
\text { director. }\end{array}$ \\
\hline
\end{tabular}

\begin{tabular}{|c|c|c|c|c|}
\hline $\begin{array}{l}\text { Candela, José } \\
\text { Miguel }\end{array}$ & $\begin{array}{l}\text { Qué tarde (2007) para flauta y } \\
\text { computador. }\end{array}$ & $13 / 10 / 2010$ & $\begin{array}{l}\text { X Festival } \\
\text { Internacional de } \\
\text { Música Electroacústica } \\
\text { Ai-Maako, Auditorio } \\
\text { Fundación Telefónica, } \\
\text { Santiago. }\end{array}$ & $\begin{array}{l}\text { Randall Ledermann, } \\
\text { flauta. }\end{array}$ \\
\hline $\begin{array}{l}\text { Cantón } \\
\text { Edgardo, } \\
\text { Leonardo } \\
\text { Cendoyya, } \\
\text { Rolando } \\
\text { Cori, Juan } \\
\text { Pablo Aguayo } \\
\text { y Cristián } \\
\text { Errandonea } \\
\end{array}$ & $\begin{array}{l}\text { *Improvisación "Tierra de Larry } \\
\text { (2010) para conjunto instrumental } \\
\text { y medios electrónicos. }\end{array}$ & $19 / 10 / 2010$ & $\begin{array}{l}\text { Campos abiertos, Sede } \\
\text { Las Encinas, ciclo de } \\
\text { conciertos Facultad de } \\
\text { Artes, Universidad de } \\
\text { Chile. }\end{array}$ & $\begin{array}{l}\text { TDL: Edgardo Cantón, } \\
\text { piano PC; Leonardo } \\
\text { Cendoyya, piano PC; } \\
\text { Rolando Cori, guitarra } \\
\text { PC; Juan Pablo Aguayo, } \\
\text { flauta/flautín, Cristián } \\
\text { Errandonea, contrabajo. }\end{array}$ \\
\hline \multirow[t]{2}{*}{$\begin{array}{l}\text { Cantón } \\
\text { Edgardo, Oscar } \\
\text { Carmona, } \\
\text { Fernando } \\
\text { Carrasco, } \\
\text { Antonio } \\
\text { Carvallo, } \\
\text { Rolando Cori, } \\
\text { Eduardo } \\
\text { Cáceres, } \\
\text { Rafael Díaz, } \\
\text { Andrés Ferrari, } \\
\text { Miguel Letelier, } \\
\text { Andrés } \\
\text { Maupoint, } \\
\text { Mario Mora, } \\
\text { Jorge Pepi- } \\
\text { Alos y Juan } \\
\text { Quinteros. }\end{array}$} & $\begin{array}{l}\text { *Eusebius (adagio) y Florestan } \\
\text { (vivace) }(2010), \text { homenaje a } \\
\text { Robert Schumann, creación } \\
\text { colectiva real. }\end{array}$ & $13 / 10 / 2010$ & $\begin{array}{l}\text { Sala Isidora Zegers, } \\
\text { Facultad de Artes, } \\
\text { Universidad de Chile. }\end{array}$ & $\begin{array}{l}\text { Creación colectiva real de } \\
\text { profesores y un estudiante } \\
\text { del área de composición } \\
\text { del Departamento de } \\
\text { Música y Sonología, } \\
\text { Facultad de Artes, } \\
\text { Universidad de Chile. } \\
\text { La intervención de cada } \\
\text { participante consistió en } \\
\text { un trozo de un minuto de } \\
\text { duración. }\end{array}$ \\
\hline & & $10 / 01 / 2011$ & $\begin{array}{l}\text { XI Festival de Música } \\
\text { Contemporánea de la } \\
\text { Universidad de Chile, } \\
\text { Facultad de Artes, Sala } \\
\text { Isidora Zegers. }\end{array}$ & Jorge Pepi-Alos, pianista. \\
\hline
\end{tabular}




\begin{tabular}{|c|c|c|c|c|}
\hline $\begin{array}{l}\text { Nombre del } \\
\text { Compositor }\end{array}$ & Titulo de la obra & $\begin{array}{l}\text { Fecha de } \\
\text { Interpretación }\end{array}$ & Lugar & Intérpretes \\
\hline Cárdenas, Félix & $\begin{array}{l}\text { Sikchá (2010) para electroacústica } \\
\text { e imagen. }\end{array}$ & $15 / 10 / 2010$ & $\begin{array}{l}\text { VII Festival } \\
\text { Internacional de Música } \\
\text { Contemporánea Darwin } \\
\text { Vargas, Instituto de } \\
\text { Música de la PUCV. }\end{array}$ & $\begin{array}{l}\text { Claudia Miranda, } \\
\text { electroacústica e imagen. }\end{array}$ \\
\hline \multirow[t]{2}{*}{$\begin{array}{l}\text { Carmona, } \\
\text { Oscar }\end{array}$} & $\begin{array}{l}\text { *Art of Improvisation III (2010) } \\
\text { para piano y medios electrónicos. }\end{array}$ & $12 / 11 / 2010$ & $\begin{array}{l}\text { XX Festival de Música } \\
\text { Contemporánea, PUC, } \\
\text { Sala GAM. }\end{array}$ & $\begin{array}{l}\text { Oscar Carmona, piano y } \\
\text { electrónica. }\end{array}$ \\
\hline & $\begin{array}{l}\text { Nebula VII (2002-2004) para } \\
\text { violín amplificado. }\end{array}$ & $28 / 10 / 2010$ & $\begin{array}{l}\text { Concierto-Bicentenario, } \\
\text { Sala Alte Feuerwache de } \\
\text { Colonia, Alemania. }\end{array}$ & Davor Miric, violín. \\
\hline $\begin{array}{l}\text { Carrasco, } \\
\text { Fernando }\end{array}$ & $\begin{array}{l}{ }^{*} \text { LORO (2010) para duo de } \\
\text { guitarras. }\end{array}$ & $10 / 01 / 2011$ & $\begin{array}{l}\text { XI Festival de Música } \\
\text { Contemporánea de la } \\
\text { Universidad de Chile, } \\
\text { Facultad de Artes, Sala } \\
\text { Isidora Zegers. }\end{array}$ & $\begin{array}{l}\text { Luis Orlandini y Romilio } \\
\text { Orellana, guitarras. }\end{array}$ \\
\hline
\end{tabular}

\begin{tabular}{|c|c|c|c|c|}
\hline $\begin{array}{l}\text { Carrasco, } \\
\text { Sebastián }\end{array}$ & $\begin{array}{l}\text { Aak }(2010) \text { para guitarra solista } \\
\text { y orquesta. }\end{array}$ & $6 / 10 / 2010$ & $\begin{array}{l}\text { VI Concurso de } \\
\text { Composición Luis Advis, } \\
\text { Sala GAM. }\end{array}$ & $\begin{array}{l}\text { Orquesta de Cámara del } \\
\text { Consejo Nacional de } \\
\text { la Cultura y las Artes, } \\
\text { Alejandro Reyes, director } \\
\text { invitado; Diego Castro, } \\
\text { guitarra. }\end{array}$ \\
\hline \multirow[t]{5}{*}{$\begin{array}{l}\text { Carvallo, } \\
\text { Antonio }\end{array}$} & \multirow[t]{2}{*}{ Una corda (2008) para piano. } & $7 / 10 / 2010$ & $\begin{array}{l}\text { X Festival } \\
\text { Internacional de Música } \\
\text { Electroacústica Ai- } \\
\text { Maako, Teatro Municipal } \\
\text { Lord Cochrane de } \\
\text { Valdivia. }\end{array}$ & Fernanda Ortega, piano. \\
\hline & & $29 / 11 / 2010$ & $\begin{array}{l}\text { Sala América de la } \\
\text { Biblioteca Nacional. }\end{array}$ & Fernanda Ortega, piano. \\
\hline & $\begin{array}{l}\text { Giverny, Nuit (2000) para medios } \\
\text { electroacústicos. }\end{array}$ & $13 / 10 / 2010$ & $\begin{array}{l}\text { X Festival } \\
\text { Internacional de } \\
\text { Música Electroacústica } \\
\text { Ai-Maako, Auditorio } \\
\text { Fundación Telefónica, } \\
\text { Santiago. }\end{array}$ & \\
\hline & \multirow[t]{2}{*}{$\begin{array}{l}\text { Monocromos (2005) para sonidos } \\
\text { electrónicos y danza. }\end{array}$} & $22 / 10 / 2010$ & $\begin{array}{l}\text { Goethe Institute, } \\
\text { Santiago. }\end{array}$ & Lillian Pizarro, danza. \\
\hline & & $26 / 10 / 2010$ & $\begin{array}{l}\text { Campos abiertos, Sede } \\
\text { Las Encinas, ciclo de } \\
\text { conciertos, Facultad de } \\
\text { Artes, Universidad de } \\
\text { Chile. }\end{array}$ & Lillian Pizarro, danza. \\
\hline
\end{tabular}




\begin{tabular}{|c|c|c|c|c|}
\hline $\begin{array}{l}\text { Nombre del } \\
\text { Compositor }\end{array}$ & Titulo de la obra & $\begin{array}{l}\text { Fecha de } \\
\text { Interpretación }\end{array}$ & Lugar & Intérpretes \\
\hline & $\begin{array}{l}\text { Ecos presentes (2010) para } \\
\text { conjunto instrumental y } \\
\text { electrónica en tiempo real. }\end{array}$ & $10 / 01 / 2011$ & $\begin{array}{l}\text { XI Festival de Música } \\
\text { Contemporánea de la } \\
\text { Universidad de Chile, } \\
\text { Facultad de Artes, Sala } \\
\text { Isidora Zegers. }\end{array}$ & $\begin{array}{l}\text { Ensamble Taller de } \\
\text { Música Contemporánea: } \\
\text { Fernanda Ortega, piano; } \\
\text { Natalia Martorell, flauta; } \\
\text { Miguel Angel Múñoz, } \\
\text { violín; Noemí Alegria, } \\
\text { viola; Cristián Gutiérrez, } \\
\text { violoncello; Alejandro } \\
\text { Ortiz, clarinete; Pablo } \\
\text { Aranda, director. }\end{array}$ \\
\hline $\begin{array}{l}\text { Clerc, } \\
\text { Miguelangel }\end{array}$ & *Eufótica (2010) para percusión. & $14 / 11 / 2010$ & $\begin{array}{l}\text { XX Festival de Música } \\
\text { Contemporánea, PUC, } \\
\text { Sala GAM. }\end{array}$ & $\begin{array}{l}\text { Ensamble de Percusión } \\
\text { IMUC, Gerardo Salazar, } \\
\text { director. }\end{array}$ \\
\hline Coger, Gabriel & **Baraka (2010) para piano. & $3 / 12 / 2010$ & $\begin{array}{l}\text { Prismas Festival } \\
\text { de Creación } \\
\text { Latinoamericana, } \\
\text { Proyecto Germina. } \\
\text { Cciones...Primaveras } \\
\text { latinoamericanas, GAM. }\end{array}$ & Aina Sandoval, piano. \\
\hline \multirow[t]{3}{*}{$\begin{array}{l}\text { Coloma, } \\
\text { Eleonora }\end{array}$} & $\begin{array}{l}\text { *Canciones del agua negra } \\
(2010) \text { para voz femenina, violín } \\
\text { y piano. }\end{array}$ & $22 / 10 / 2010$ & $\begin{array}{l}\text { Sala Alameda, Instituto } \\
\text { Cultural Banco Estado, } \\
\text { Santiago. }\end{array}$ & $\begin{array}{l}\text { Geraldine Compagnon } \\
\text { (voz); Ángela Sánchez, } \\
\text { violín; Eleonora Coloma, } \\
\text { piano. }\end{array}$ \\
\hline & $\begin{array}{l}\text { *Los pájaros }(2010) \\
\text { para piano y fotografía } \\
\text { experimental. }\end{array}$ & $22 / 10 / 2010$ & $\begin{array}{l}\text { Sala Alameda, Instituto } \\
\text { Cultural Banco Estado, } \\
\text { Santiago. }\end{array}$ & Eleonora Coloma, piano. \\
\hline & $\begin{array}{l}\text { *Oditnes (2010) para saxo alto, } \\
\text { guitarra eléctrica, batería y piano. }\end{array}$ & $22 / 10 / 2010$ & $\begin{array}{l}\text { Sala Alameda, Instituto } \\
\text { Cultural Banco Estado, } \\
\text { Santiago. }\end{array}$ & $\begin{array}{l}\text { David Espinoza, saxo } \\
\text { alto; Mauricio Contreras, } \\
\text { guitarra eléctrica; Nicolás } \\
\text { Ríos, batería; Elenora } \\
\text { Coloma, piano. }\end{array}$ \\
\hline Cori, Rolando & $\begin{array}{l}\text { Coral de la usinas (1974- rev. } \\
\text { 1996) para coro mixto, texto de } \\
\text { Juan Enrique Coeymans. }\end{array}$ & $7 / 10 / 2010$ & $\begin{array}{l}\text { Aula Magna de la } \\
\text { USACH. }\end{array}$ & $\begin{array}{l}\text { Coro USACH, Santiago } \\
\text { Marín, director. }\end{array}$ \\
\hline $\begin{array}{l}\text { Cornejo Purán, } \\
\text { Marcelo }\end{array}$ & $\begin{array}{l}\text { **Pugeñun (pajarillos de libertad) } \\
\text { (2010) para cuarteto de guitarras. }\end{array}$ & $2 / 12 / 2010$ & $\begin{array}{l}\text { Prismas Festival } \\
\text { de Creación } \\
\text { Latinoamericana, } \\
\text { Proyecto Germina. } \\
\text { Cciones...Primaveras } \\
\text { latinoamericanas, GAM. }\end{array}$ & $\begin{array}{l}\text { Gonzálo Cáceres, } \\
\text { Benjamín Espinoza, José } \\
\text { Riquelme, Felipe Vallejos, } \\
\text { guitarras. }\end{array}$ \\
\hline Correa, Esteban & $\begin{array}{l}\text { *Alas (2010) para guitarra } \\
\text { eléctrica, bajo eléctrico, } 2 \\
\text { violines, violoncello, trompeta, } \\
\text { corno, vibráfono y piano. }\end{array}$ & $13 / 11 / 2010$ & $\begin{array}{l}\text { XX Festival de Música } \\
\text { Contemporánea, PUC, } \\
\text { Sala GAM. }\end{array}$ & $\begin{array}{l}\text { Taller de Lejos, Alejandro } \\
\text { Meléndez, director. }\end{array}$ \\
\hline Cortés, Renán & $\begin{array}{l}\text { Serie de movimientos breves de } \\
\text { danza }(1979,1984) \text { para piano. }\end{array}$ & $29 / 11 / 2010$ & $\begin{array}{l}\text { Semana de la Música, } \\
\text { Sala América de la } \\
\text { Biblioteca Nacional. }\end{array}$ & Fernanda Ortega, piano. \\
\hline
\end{tabular}




\begin{tabular}{|c|c|c|c|c|}
\hline $\begin{array}{l}\text { Nombre del } \\
\text { Compositor }\end{array}$ & Titulo de la obra & $\begin{array}{l}\text { Fecha de } \\
\text { Interpretación }\end{array}$ & Lugar & Intérpretes \\
\hline $\begin{array}{l}\text { Cortés } \\
\text { Rodríguez, } \\
\text { David }\end{array}$ & $\begin{array}{l}\text { **Violin, VI micropiezas } \\
\text { (Violentar, Ilusión; Olvido) } \\
\text { (2010) para violín solo. }\end{array}$ & $3 / 12 / 2010$ & $\begin{array}{l}\text { Prismas Festival } \\
\text { de Creación } \\
\text { Latinoamericana, } \\
\text { Proyecto Germina. } \\
\text { Cciones...Primaveras } \\
\text { latinoamericanas, GAM. }\end{array}$ & Jorge Maraboli, violín. \\
\hline Délano, Pablo & Estudio $\mathrm{N}^{\circ} 1$ (1966) para guitarra. & $2 / 11 / 2010$ & $\begin{array}{l}\text { Auditorium Cirilo } \\
\text { Vila, Facultad de Artes, } \\
\text { Universidad de Chile. }\end{array}$ & $\begin{array}{l}\text { Maximiliano Jofré, } \\
\text { guitarra. }\end{array}$ \\
\hline Díaz, Antonio & $\begin{array}{l}\text { Naturaleza humana (2010), live } \\
\text { electronics. }\end{array}$ & $7 / 10 / 2010$ & $\begin{array}{l}\text { Teatro Municipal Lord } \\
\text { Cochrane de Valdivia. }\end{array}$ & \\
\hline Díaz, Daniel & $\begin{array}{l}\text { Al horitaña de la montazonte } \\
\text { (2008-2010) para coro femenino, } \\
\text { texto de Vicente Huidobro. }\end{array}$ & $15 / 10 / 2010$ & $\begin{array}{l}\text { VII Festival } \\
\text { Internacional de Música } \\
\text { Contemporánea Darwin } \\
\text { Vargas, Instituto de } \\
\text { Música de la PUCV, Sala } \\
\text { DUOC de Viña del Mar. }\end{array}$ & $\begin{array}{l}\text { Coral Femenina Viña del } \\
\text { Mar, Jéssica Quezada, } \\
\text { directora; Nicolás } \\
\text { Eyzaguirre, actor; Daniel } \\
\text { Díaz, director general. }\end{array}$ \\
\hline $\begin{array}{l}\text { Díaz, Juan } \\
\text { Pablo }\end{array}$ & $\begin{array}{l}\text { **Bifurcaciones (2010) para } \\
\text { violoncello. }\end{array}$ & $3 / 12 / 2010$ & $\begin{array}{l}\text { Prismas Festival } \\
\text { de Creación } \\
\text { Latinoamericana, } \\
\text { Proyecto Germina. } \\
\text { Cciones...Primaveras } \\
\text { latinoamericanas, GAM. }\end{array}$ & $\begin{array}{l}\text { Daniel Ramírez, } \\
\text { violoncello. }\end{array}$ \\
\hline
\end{tabular}

\begin{tabular}{|c|c|c|c|c|}
\hline \multirow[t]{5}{*}{ Díaz, Rafael } & $\begin{array}{l}\text { El cautiverio feliz Pascual Coña } \\
\text { (1996-2010) para narrador, solista } \\
\text { y coro. }\end{array}$ & $15 / 10 / 2010$ & $\begin{array}{l}\text { VII Festival } \\
\text { Internacional de Música } \\
\text { Contemporánea Darwin } \\
\text { Vargas, Instituto de } \\
\text { Música de la PUCV. }\end{array}$ & $\begin{array}{l}\text { Camerata IMUS, Bernardo } \\
\text { Zamora, tenor; María } \\
\text { Angélica Luzzi, narradora; } \\
\text { Gonzalo Venegas, director. }\end{array}$ \\
\hline & $\begin{array}{l}\text { Kyrie Mwuono (2006), adaptación } \\
\text { para solista y coro femenino. }\end{array}$ & $18 / 10 / 2010$ & $\begin{array}{l}\text { Sala de Eventos Codelco, } \\
\text { Santiago. }\end{array}$ & $\begin{array}{l}\text { Coral Femenina Viña del } \\
\text { Mar, Jessica Quezada, } \\
\text { directora; Carolina Matus, } \\
\text { soprano. }\end{array}$ \\
\hline & $\begin{array}{l}\text { Barcarola para un poema de } \\
\text { Jorge Teiller (1998) para guitarra. }\end{array}$ & $20 / 10 / 2010$ & $\begin{array}{l}\text { Ciclo Guitarrístico, } \\
\text { Instituto Cervantes } \\
\text { de Manchester, Reino } \\
\text { Unido. }\end{array}$ & $\begin{array}{l}\text { Mauricio Valdebenito, } \\
\text { guitarra. }\end{array}$ \\
\hline & & $21 / 10 / 2010$ & $\begin{array}{l}\text { Universidad John Moores } \\
\text { de Liverpool, Reino } \\
\text { Unido. }\end{array}$ & $\begin{array}{l}\text { Mauricio Valdebenito, } \\
\text { guitarra. }\end{array}$ \\
\hline & $\begin{array}{l}\text { *El ángel de la guarda se le } \\
\text { aparece a Matías Catrileo } \\
\text { Quezada (2010) para violín y } \\
\text { piano. }\end{array}$ & 6,7 y $8 / 11 / 2010$ & $\begin{array}{l}37^{\circ} \text { Concurso } \\
\text { Internacional de Música, } \\
\text { Dr. Luis Sigall, Hotel } \\
\text { O’Higgins, Salón } \\
\text { Independencia, Viña } \\
\text { del Mar. }\end{array}$ & $\begin{array}{l}\text { Alexandra Myriam Aubert, } \\
\text { piano; participantes del } \\
\text { concurso internacional } \\
\text { de violín; Paula Sumane, } \\
\text { violín (destacada por la } \\
\text { mejor interpretación de la } \\
\text { obra de R. Díaz). }\end{array}$ \\
\hline
\end{tabular}




\begin{tabular}{|c|c|c|c|c|}
\hline $\begin{array}{l}\text { Nombre del } \\
\text { Compositor }\end{array}$ & Titulo de la obra & $\begin{array}{l}\text { Fecha de } \\
\text { Interpretación }\end{array}$ & Lugar & Intérpretes \\
\hline & $\begin{array}{l}\text { *Retorna para siempre Matías } \\
\text { Catrileo Quezada (2010). } 1 . \\
\text { Canción de cuna, 2. El ángel } \\
\text { de la iluminación, 3. Canción } \\
\text { de cuna, 4. El ángel comunero, } \\
\text { 5. Canción del regreso, 6. El } \\
\text { ángel de Temuco, 7. El ángel de } \\
\text { Vilcún, 8. El ángel del olvido } \\
\text { para mezzosoprano, flauta, violín, } \\
\text { violoncello y piano. }\end{array}$ & $10 / 11 / 2010$ & $\begin{array}{l}\text { XX Festival de Música } \\
\text { Contemporánea, PUC, } \\
\text { Sala GAM. }\end{array}$ & $\begin{array}{l}\text { Taller de Música } \\
\text { Contemporánea, Pablo } \\
\text { Aranda, director; Nancy } \\
\text { Gómez, mezzosoprano. }\end{array}$ \\
\hline & $\begin{array}{l}\text { *Pewenmapu. Requiem azul para } \\
\text { Jaime Mendoza Collio (2009) } \\
\text { para flauta traversa. }\end{array}$ & $11 / 01 / 2011$ & $\begin{array}{l}\text { XI Festival de Música } \\
\text { Contemporánea de la } \\
\text { Universidad de Chile, } \\
\text { Facultad de Artes, Sala } \\
\text { Isidora Zegers. }\end{array}$ & $\begin{array}{l}\text { Wilson Padilla, flauta } \\
\text { traversa. }\end{array}$ \\
\hline $\begin{array}{l}\text { Domínguez } \\
\text { Mosciatti, } \\
\text { Fabrizio }\end{array}$ & $\begin{array}{l}\text { **Dance en la Araucanía (2010) } \\
\text { para contrabajo. }\end{array}$ & $3 / 12 / 2010$ & $\begin{array}{l}\text { Prismas Festival } \\
\text { de Creación } \\
\text { Latinoamericana, } \\
\text { Proyecto Germina. } \\
\text { Cciones...Primaveras } \\
\text { latinoamericanas, GAM. }\end{array}$ & $\begin{array}{l}\text { María Francisca Moraga, } \\
\text { contrabajo. }\end{array}$ \\
\hline $\begin{array}{l}\text { Dupuy Abiuso, } \\
\text { Jorge }\end{array}$ & $\begin{array}{l}\text { **Transbordo (2010) para } \\
\text { guitarra. }\end{array}$ & $3 / 12 / 2010$ & $\begin{array}{l}\text { Prismas Festival } \\
\text { de Creación } \\
\text { Latinoamericana, } \\
\text { Proyecto Germina. } \\
\text { Cciones...Primaveras } \\
\text { latinoamericanas, GAM. }\end{array}$ & $\begin{array}{l}\text { Rodrigo Guerrero, } \\
\text { guitarra. }\end{array}$ \\
\hline $\begin{array}{l}\text { Errázuriz, } \\
\text { Sebastián }\end{array}$ & $\begin{array}{l}\text { Busco una estirpe nueva (2006) } \\
\text { para soprano y orquesta de } \\
\text { cuerdas. }\end{array}$ & 10 y $11 / 01 / 2011$ & $\begin{array}{l}\text { Teatro Municipal de } \\
\text { Santiago. }\end{array}$ & $\begin{array}{l}\text { Orquesta Filarmónica de } \\
\text { Santiago, Rani Calderón, } \\
\text { director; Patricia } \\
\text { Cifuentes, soprano. }\end{array}$ \\
\hline \multirow[t]{3}{*}{$\begin{array}{l}\text { Escobar, } \\
\text { Alejandro }\end{array}$} & \multirow[t]{2}{*}{$\begin{array}{l}\text { Tres aires nortinos (2010) para } \\
\text { guitarra. }\end{array}$} & $23 / 11 / 2010$ & $\begin{array}{l}\text { Sala Isidora Zegers, } \\
\text { Facultad de Artes, } \\
\text { Universidad de Chile. }\end{array}$ & $\begin{array}{l}\text { Alejandro Escobar, } \\
\text { guitarra. }\end{array}$ \\
\hline & & $25 / 02 / 2011$ & $\begin{array}{l}\text { Del Mapocho al Illimani, } \\
\text { concierto de guitarra } \\
\text { clásica, Museo de Arte } \\
\text { Contemporáneo Plaza (El } \\
\text { Prado) La Paz, Bolivia. }\end{array}$ & $\begin{array}{l}\text { Alejandro Escobar, } \\
\text { guitarra. }\end{array}$ \\
\hline & $\begin{array}{l}\text { Tonada para tu regreso }(2010) \\
\text { para guitarra. }\end{array}$ & $25 / 02 / 2011$ & $\begin{array}{l}\text { Del Mapocho al Illimani, } \\
\text { concierto de guitarra } \\
\text { clásica, } \\
\text { Museo de Arte } \\
\text { Contemporáneo Plaza (El } \\
\text { Prado) La Paz, Bolivia. }\end{array}$ & $\begin{array}{l}\text { Alejandro Escobar, } \\
\text { guitarra. }\end{array}$ \\
\hline
\end{tabular}




\begin{tabular}{|c|c|c|c|c|}
\hline $\begin{array}{l}\text { Nombre del } \\
\text { Compositor }\end{array}$ & Titulo de la obra & $\begin{array}{l}\text { Fecha de } \\
\text { Interpretación }\end{array}$ & Lugar & Intérpretes \\
\hline & $\begin{array}{l}\text { Cueca urbana (2011) para dúo de } \\
\text { guitarras. }\end{array}$ & $25 / 02 / 2011$ & $\begin{array}{l}\text { Del Mapocho al Illimani. } \\
\text { concierto de guitarra } \\
\text { clásica, Museo de Arte } \\
\text { Contemporáneo Plaza (El } \\
\text { Prado) La Paz, Bolivia. }\end{array}$ & $\begin{array}{l}\text { Dúo de guitarras Francisco } \\
\text { Liberona - Alejandro } \\
\text { Escobar. }\end{array}$ \\
\hline $\begin{array}{l}\text { Espíndola, } \\
\text { Marcelo }\end{array}$ & $\begin{array}{l}\text { Puertas adentro (2010) medios } \\
\text { electrónicos. }\end{array}$ & $15 / 10 / 2010$ & $\begin{array}{l}\text { X Festival } \\
\text { Internacional de } \\
\text { Música Electroacústica } \\
\text { Ai-Maako, Auditorio } \\
\text { Fundación Telefónica, } \\
\text { Santiago. }\end{array}$ & \\
\hline $\begin{array}{l}\text { Espinoza C., } \\
\text { Nicolás }\end{array}$ & $\begin{array}{l}\text { *Proyecto } E(2010) \text { para doce } \\
\text { guitarras eléctricas, cuatro bajos } \\
\text { eléctricos, cuatro saxofones y } \\
\text { batería. }\end{array}$ & 16 y $17 / 01 / 2011$ & $\begin{array}{l}\text { Casona Nemesio } \\
\text { Antúnez, Santiago. }\end{array}$ & $\begin{array}{l}\text { Guitarristas: } \\
\text { Diego Aguirre, Gaston } \\
\text { Apablaza, Gerson Araya, } \\
\text { Nicolás Avilés, Alonso } \\
\text { Guichard, Gabriel Feller, } \\
\text { Fernando Munizaga, } \\
\text { Francisco Pavez, Felipe } \\
\text { Peña, Christian Pérez, } \\
\text { Javier Reyes, Juan } \\
\text { Francisco Solís; } \\
\text { bajistas: Santiago } \\
\text { Astaburuaga, Vicente } \\
\text { Fabres, Patricio Rojas, } \\
\text { Alvaro San Martín; } \\
\text { saxofonistas: Rodrigo } \\
\text { Aguirre, Gabriel Barrios, } \\
\text { Sebastián López, Moris } \\
\text { El Alan; bateria: Cristian } \\
\text { Hirth; } \\
\text { dirección: Lautaro Mura. }\end{array}$ \\
\hline \multirow[t]{5}{*}{$\begin{array}{l}\text { Farías C., } \\
\text { Javier }\end{array}$} & \multirow[t]{3}{*}{$\begin{array}{l}\text { Dos dolores de patria muerta } \\
\text { (vivir sin tierra-Subiendo desde } \\
\text { abajo) (2010) para guitarra. }\end{array}$} & $26 / 10 / 2010$ & $\begin{array}{l}\text { Sala Isidora Zegers, } \\
\text { Facultad de Artes, } \\
\text { Universidad de Chile. }\end{array}$ & $\begin{array}{l}\text { Pablo González Aliaga, } \\
\text { guitarra. }\end{array}$ \\
\hline & & $28 / 10 / 2010$ & $\begin{array}{l}\text { Sala Isidora Zegers, } \\
\text { Facultad de Artes, } \\
\text { Universidad de Chile. }\end{array}$ & Felipe Celis, guitarra. \\
\hline & & $20 / 11 / 2010$ & $\begin{array}{l}\text { Concurso de Guitarra } \\
\text { Liliana Pérez Corey. }\end{array}$ & $\begin{array}{l}\text { Francisco Liberona, } \\
\text { guitarra. }\end{array}$ \\
\hline & $\begin{array}{l}\text { *Portales (2009) para saxofón y } \\
\text { percusión. }\end{array}$ & $11 / 01 / 2011$ & $\begin{array}{l}\text { XI Festival de Música } \\
\text { Contemporánea de la } \\
\text { Universidad de Chile, } \\
\text { Facultad de Artes, Sala } \\
\text { Isidora Zegers. }\end{array}$ & $\begin{array}{l}\text { Marie-Bernardette } \\
\text { Charrier, saxofón; } \\
\text { Clèment Fauconnet, } \\
\text { percusión. }\end{array}$ \\
\hline & Trastocadas (2007) para guitarra. & $22 / 01 / 2011$ & $\begin{array}{l}\text { Teatro de la Universidad } \\
\text { de Chile. }\end{array}$ & $\begin{array}{l}\text { Dúo de guitarras Orellana } \\
\text { \& Orlandini. }\end{array}$ \\
\hline
\end{tabular}




\begin{tabular}{|c|c|c|c|c|}
\hline $\begin{array}{l}\text { Nombre del } \\
\text { Compositor }\end{array}$ & Titulo de la obra & $\begin{array}{l}\text { Fecha de } \\
\text { Interpretación }\end{array}$ & Lugar & Intérpretes \\
\hline & $\begin{array}{l}\text { Concierto (2000) para cuatro } \\
\text { guitarras y orquesta. }\end{array}$ & $12 / 02 / 2011$ & $\begin{array}{l}\text { Festival de Guitarras } \\
\text { de Aschaffenburg, } \\
\text { Alemania. }\end{array}$ & $\begin{array}{l}\text { Cuarteto de Guitarras de } \\
\text { Chile: Luis Orlandini, } \\
\text { Rodrigo Guzmán, } \\
\text { Sebastián Montes y } \\
\text { Luis Mancilla; Orquesta } \\
\text { Filarmónica de Baden- } \\
\text { Baden, Pavel Baleff, } \\
\text { director. }\end{array}$ \\
\hline \multirow[t]{2}{*}{ Ferrari, Andrés } & $\begin{array}{l}\text { Optikalis } 01 \text { (2001), composición } \\
\text { audiovisual. }\end{array}$ & $26 / 10 / 2010$ & $\begin{array}{l}\text { Campos abiertos, Sede } \\
\text { Las Encinas, ciclo de } \\
\text { conciertos, Facultad de } \\
\text { Artes, Universidad de } \\
\text { Chile. }\end{array}$ & $\begin{array}{l}\text { Audiovisual con imágenes } \\
\text { 3D. }\end{array}$ \\
\hline & $\begin{array}{l}\text { Replicantes (2010) para conjunto } \\
\text { instrumental. }\end{array}$ & $12 / 01 / 2011$ & $\begin{array}{l}\text { XI Festival de Música } \\
\text { Contemporánea de la } \\
\text { Universidad de Chile, } \\
\text { Facultad de Artes, Sala } \\
\text { Isidora Zegers. }\end{array}$ & $\begin{array}{l}\text { Compañía de Música } \\
\text { Contemporánea: } \\
\text { María Fernanda Espinoza, } \\
\text { violín; Roberto Cisternas, } \\
\text { flauta; Cláudio Vasquez, } \\
\text { clarinete; Andrés Ferrari, } \\
\text { electrónica; Carlos } \\
\text { Valenzuela Ramos, } \\
\text { director. }\end{array}$ \\
\hline $\begin{array}{l}\text { Ferrari, Andrés } \\
\text { y Jorge Pepi- } \\
\text { Alos }\end{array}$ & $\begin{array}{l}\text { Gadara (pre-estreno) (2010) para } \\
\text { dos pianos. }\end{array}$ & $8 / 10 / 2010$ & $\begin{array}{l}\text { Sala Isidora Zegers, } \\
\text { Facultad de Artes, } \\
\text { Universidad de Chile. }\end{array}$ & $\begin{array}{l}\text { Jorge Pepi-Alos y Andrés } \\
\text { Ferrari. }\end{array}$ \\
\hline Filinich, Renzo & $\begin{array}{l}\text { Desierto fértil (2010) para medios } \\
\text { electroacústicos. }\end{array}$ & $13 / 10 / 2010$ & $\begin{array}{l}\text { X Festival } \\
\text { Internacional de } \\
\text { Música Electroacústica } \\
\text { Ai-Maako, Auditorio } \\
\text { Fundación Telefónica, } \\
\text { Santiago. }\end{array}$ & \\
\hline $\begin{array}{l}\text { Fuentes } \\
\text { Curaqueo, } \\
\text { Diego de la }\end{array}$ & $\begin{array}{l}\text { **Dos miniaturas para violín solo } \\
\text { (Borrador I, Borrador II). }\end{array}$ & $3 / 12 / 2010$ & $\begin{array}{l}\text { Prismas Festival } \\
\text { de Creación } \\
\text { Latinoamericana, } \\
\text { Proyecto Germina. } \\
\text { Cciones...Primaveras } \\
\text { latinoamericanas, GAM. }\end{array}$ & Iswara Silva, violín. \\
\hline $\begin{array}{l}\text { Galarce, } \\
\text { Cristián }\end{array}$ & $\begin{array}{l}\text { *Kyanq }(2010) \text { para violín, viola, } \\
\text { violoncello y piano. }\end{array}$ & $14 / 11 / 2010$ & $\begin{array}{l}\text { XX Festival de Música } \\
\text { Contemporánea, PUC, } \\
\text { Sala GAM. }\end{array}$ & $\begin{array}{l}\text { Rodolfo Mellado, } \\
\text { violín; Sergio Fresco, } \\
\text { viola; Alejandro Barría, } \\
\text { violoncello; Danilo } \\
\text { Rodríguez, piano. }\end{array}$ \\
\hline \multirow[t]{2}{*}{ Galaz, Pablo } & \multirow[t]{2}{*}{$\begin{array}{l}\text { Audiosketch (2008) para flauta, } \\
\text { clarinete, percusión, piano, violín, } \\
\text { viola y violoncello. }\end{array}$} & $23 / 10 / 2010$ & $\begin{array}{l}\text { Concierto-Bicentenario } \\
\text { en Gallus Theater de } \\
\text { Franfurt/Main, Alemania. }\end{array}$ & $\begin{array}{l}\text { Ensamble Contemporáneo, } \\
\text { Aliocha Solovera, director. }\end{array}$ \\
\hline & & $28 / 10 / 2010$ & $\begin{array}{l}\text { Concierto-Bicentenario, } \\
\text { Sala Alte Feuerwache de } \\
\text { Colonia, Alemania. }\end{array}$ & $\begin{array}{l}\text { Ensamble Contemporáneo, } \\
\text { Aliocha Solovera, director. }\end{array}$ \\
\hline
\end{tabular}




\section{$\begin{array}{llll}\text { Nombre del } & \text { Titulo de la obra } & \text { Fecha de } & \text { Lugar } \\ \text { Compositor } & \text { Interpretación } & \text { Intérpretes }\end{array}$}

\begin{tabular}{lllll}
\hline Galvez, Gabriel & $\begin{array}{l}\text { *Mi corazón se muere de vivir } \\
\text { (2010) para voz femenina, corno, } \\
\text { vibráfono y piano. }\end{array}$ & $13 / 11 / 2010$ & $\begin{array}{l}\text { XX Festival de Música } \\
\text { Contemporánea, PUC, } \\
\text { Sala GAM. }\end{array}$ & $\begin{array}{l}\text { Taller de Lejos, Gabriel } \\
\text { Galvez, director; Vanessa }\end{array}$ \\
& & & $\begin{array}{l}\text { Medo, mezzosoprano; } \\
\text { Camilo Leal, corno; Julio } \\
\text { Torres y Cristián Ramos, } \\
\text { piano. }\end{array}$ \\
\hline García, & **Nace la aurora op. $50(1978)$ & $12 / 10 / 2010$ & "Winnipeg: Música y & Ensemble Iberoamericano,
\end{tabular}

Fernando para voz y cuarteto de cuerdas (texto de Pablo Neruda).

*Lamentaciones (2010) para trío de flauta traversa, clarinete y violoncello, dedicada a Gustavo Becerra.

*Cuatro manchas sonoras (2002) para violoncello, saxofón alto, flauta y arpa.

Dos por dos para marimba y vibráfono.
Exilio", organizado por

la Asociación Música

Iberoamericana, Sala

Fürstensaal, Escuela

Superior de Música Franz

Liszt, Weimar.

15/10/2010 "Winnipeg. Música y Exilio", organizado por la Asociación Música Iberoamericana, Spinnwerk, Leipzig.

19/10/2010 "Winnipeg. Música y Exilio", organizado por la Asociación Música Iberoamericana, Sala Otto Braun, Instituto Ibero-Americano, Berlín. Conciertos didácticos, Sala América de la Biblioteca Nacional, Santiago.

$10 / 01 / 2011$

XI Festival de Música Contemporánea de la Universidad de Chile, Facultad de Artes, Sala Isidora Zegers.

03/02/2011

Música escénica para percusiones, Sala Manue Enríquez, Facultad de Música de la Universidad de Tamaulipas, Tampico, México.

04/02/2011

08/02/2011

Música escénica para percusiones, Master Class Salón de percusiones de la Universidad de Tamaulipas, Tampico, México.
Joan Pagès Valls, director;

Natasha López, soprano.

Ensemble Iberoamericano, Joan Pagès Valls, director; Natasha López, soprano.

Ensemble Iberoamericano, Joan Pagès Valls, director, Natasha López, soprano.

Elqui Espinosa Squella, flauta traversa; Lorena Vergara Castillo, clarinete; Sebastián Meza Maldonado, violoncello.

Celso López, violoncello; Miguel Villafruela, saxofón alto; Wilson Padilla, flauta; Manuel Jiménez, arpa; Aliocha Solovera, director.

Dúo de Percusiones A Dois.

Dúo de Percusiones A

Música escénica para Dúo de Percusiones A percusiones, Auditorio de Dois.

la Casa de la Marimba,

Ciudad de México. 


\begin{tabular}{|c|c|c|c|c|}
\hline $\begin{array}{l}\text { Nombre del } \\
\text { Compositor }\end{array}$ & Titulo de la obra & $\begin{array}{l}\text { Fecha de } \\
\text { Interpretación }\end{array}$ & Lugar & Intérpretes \\
\hline & & $10 / 02 / 2011$ & $\begin{array}{l}\text { Música escénica para } \\
\text { percusiones, } 2^{\circ} \text { Festival } \\
\text { de la Marimba Maestro } \\
\text { Zeferino Nandayapa en la } \\
\text { Plaza Central de Chiapas } \\
\text { de Corzo, México. }\end{array}$ & $\begin{array}{l}\text { Dúo de Percusiones A } \\
\text { Dois. }\end{array}$ \\
\hline & & $11 / 02 / 2010$ & $\begin{array}{l}\text { Música escénica para } \\
\text { percusiones, Master } \\
\text { Class, Escuela de Música } \\
\text { de la Universidad de } \\
\text { Chiapas }\end{array}$ & $\begin{array}{l}\text { Dúo de Percusiones A } \\
\text { Dois. }\end{array}$ \\
\hline & & 12/02/2011 & $\begin{array}{l}\text { Música escénica para } \\
\text { percusiones, Auditorio de } \\
\text { la Fundación Sebastián, } \\
\text { Ciudad de México. }\end{array}$ & $\begin{array}{l}\text { Dúo de Percusiones A } \\
\text { Dois. }\end{array}$ \\
\hline & & $12 / 02 / 2011$ & $\begin{array}{l}\text { Música escénica para } \\
\text { percusiones, Master } \\
\text { Class, Auditorio de la } \\
\text { Fundación Sebastian, } \\
\text { Ciudad de México. }\end{array}$ & $\begin{array}{l}\text { Dúo de Percusiones A } \\
\text { Dois. }\end{array}$ \\
\hline $\begin{array}{l}\text { García-Gracia, } \\
\text { Cecilia }\end{array}$ & $\begin{array}{l}\text { Renacimiento (2010), } \\
\text { audiovisual. }\end{array}$ & $13 / 10 / 2010$ & $\begin{array}{l}\text { X Festival } \\
\text { Internacional de } \\
\text { Música Electroacústica } \\
\text { Ai-Maako, Auditorio } \\
\text { Fundación Telefónica, } \\
\text { Santiago. } \\
\end{array}$ & \\
\hline $\begin{array}{l}\text { Godoy Frez, } \\
\text { Pablo }\end{array}$ & $\begin{array}{l}\text { **Mita, sin cambio no hay } \\
\text { evolución (2010) para piano. }\end{array}$ & $3 / 12 / 2010$ & $\begin{array}{l}\text { Prismas Festival } \\
\text { de Creación } \\
\text { Latinoamericana, } \\
\text { Proyecto Germina. } \\
\text { Cciones...Primaveras } \\
\text { latinoamericanas, GAM. }\end{array}$ & Aina Sandoval, piano. \\
\hline \multirow[t]{2}{*}{$\begin{array}{l}\text { Gómez Silva, } \\
\text { Álvaro }\end{array}$} & **Nubes (2010) para guitarras. & $29 / 11 / 2010$ & $\begin{array}{l}\text { Prismas Festival } \\
\text { de Creación } \\
\text { Latinoamericana, } \\
\text { Proyecto Germina. } \\
\text { Cciones...Primaveras } \\
\text { latinoamericanas, } \\
\text { Universidad de } \\
\text { Valparaíso. }\end{array}$ & $\begin{array}{l}\text { Consort Guitarrístico de } \\
\text { Chile: Andrés González, } \\
\text { guitarra soprano, } \\
\text { charango; Rodrigo Erazo, } \\
\text { guitarra alto; Pablo } \\
\text { Palacios, guitarra tenor; } \\
\text { Sebastián Avello, guitarra } \\
\text { bajo; Moa Edmunds, } \\
\text { guitarra contrabajo. }\end{array}$ \\
\hline & & $4 / 12 / 2010$ & $\begin{array}{l}\text { Prismas Festival } \\
\text { de Creación } \\
\text { Latinoamericana, } \\
\text { Proyecto Germina. } \\
\text { Cciones...Primaveras } \\
\text { latinoamericanas, GAM. }\end{array}$ & $\begin{array}{l}\text { Consort Guitarrístico de } \\
\text { Chile: Andrés González, } \\
\text { guitarra soprano, } \\
\text { charango; Rodrigo Erazo, } \\
\text { guitarra alto; Pablo } \\
\text { Palacios, guitarra tenor; } \\
\text { Sebastián Avello, guitarra } \\
\text { bajo; Moa Edmunds, } \\
\text { guitarra contrabajo. }\end{array}$ \\
\hline
\end{tabular}




\begin{tabular}{|c|c|c|c|c|}
\hline $\begin{array}{l}\text { Nombre del } \\
\text { Compositor }\end{array}$ & Titulo de la obra & $\begin{array}{l}\text { Fecha de } \\
\text { Interpretación }\end{array}$ & Lugar & Intérpretes \\
\hline \multirow[t]{3}{*}{$\begin{array}{l}\text { González, } \\
\text { Andrés }\end{array}$} & $\begin{array}{l}\text { Disvariaciones sobre temas de } \\
\text { Victor Jara (2010) para guitarras. }\end{array}$ & $29 / 11 / 2010$ & $\begin{array}{l}\text { Prismas Festival } \\
\text { de Creación } \\
\text { Latinoamericana, } \\
\text { Proyecto Germina. } \\
\text { Cciones...Primaveras } \\
\text { latinoamericanas, } \\
\text { Universidad de } \\
\text { Valparaíso. }\end{array}$ & $\begin{array}{l}\text { Consort Guitarrístico de } \\
\text { Chile: Andrés González, } \\
\text { guitarra soprano, } \\
\text { charango; Rodrigo Erazo, } \\
\text { guitarra alto; Pablo } \\
\text { Palacios, guitarra tenor; } \\
\text { Sebastián Avello, guitarra } \\
\text { bajo; Moa Edmunds, } \\
\text { guitarra contrabajo. }\end{array}$ \\
\hline & $\begin{array}{l}\text { **Dúo demo (2010) para guitarra, } \\
\text { charango y medios electrónicos. }\end{array}$ & $29 / 11 / 2010$ & $\begin{array}{l}\text { Prismas Festival } \\
\text { de Creación } \\
\text { Latinoamericana, } \\
\text { Proyecto Germina. } \\
\text { Cciones...Primaveras } \\
\text { latinoamericanas, } \\
\text { Universidad de } \\
\text { Valparaíso. }\end{array}$ & $\begin{array}{l}\text { Consort Guitarrístico de } \\
\text { Chile }\end{array}$ \\
\hline & $\begin{array}{l}\text { Aión (2009) para quinteto de } \\
\text { guitarras. }\end{array}$ & $12 / 01 / 2011$ & $\begin{array}{l}\text { XI Festival de Música } \\
\text { Contemporánea de la } \\
\text { Universidad de Chile, } \\
\text { Facultad de Artes, Sala } \\
\text { Isidora Zegers. }\end{array}$ & $\begin{array}{l}\text { Consort Guitarrístico de } \\
\text { Chile }\end{array}$ \\
\hline $\begin{array}{l}\text { González, } \\
\text { Francisco }\end{array}$ & Juego (2010) para dos flautas. & $13 / 10 / 2010$ & $\begin{array}{l}\text { VII Festival } \\
\text { Internacional de Música } \\
\text { Contemporánea Darwin } \\
\text { Vargas, Instituto de } \\
\text { Música de la PUCV. }\end{array}$ & $\begin{array}{l}\text { Tomás Carrasco y Rodrigo } \\
\text { López, flautas traversas. }\end{array}$ \\
\hline \multirow[t]{4}{*}{$\begin{array}{l}\text { Gorigoitía, } \\
\text { Ramón }\end{array}$} & $\begin{array}{l}\text { ** Winnipeg (2010) para } \\
\text { mezzosoprano y octeto } \\
\text { instrumental. }\end{array}$ & $12 / 10 / 2010$ & $\begin{array}{l}\text { "Winnipeg: Música y } \\
\text { Exilio", organizado por } \\
\text { la Asociación Música } \\
\text { Iberoamericana, Sala } \\
\text { Fürstensaal, Escuela } \\
\text { Superior de Música Franz } \\
\text { Liszt, Weimar. }\end{array}$ & $\begin{array}{l}\text { Ensemble Iberoamericano, } \\
\text { Joan Pagès Valls, director, } \\
\text { Carolina Krogius, } \\
\text { mezzosoprano. }\end{array}$ \\
\hline & & $15 / 10 / 2010$ & $\begin{array}{l}\text { "Winnipeg. Música y } \\
\text { Exilio", organizado por } \\
\text { la Asociación Música } \\
\text { Iberoamericana, } \\
\text { Spinnwerk, Leipzig. }\end{array}$ & $\begin{array}{l}\text { Ensemble Iberoamericano, } \\
\text { Joan Pagès Valls, director, } \\
\text { Carolina Krogius, } \\
\text { mezzosoprano. }\end{array}$ \\
\hline & & $19 / 10 / 2010$ & $\begin{array}{l}\text { "Winnipeg. Música y } \\
\text { Exilio", organizado por } \\
\text { la Asociación Música } \\
\text { Iberoamericana, } \\
\text { Sala Otto Braun, Instituto } \\
\text { Ibero-Americano, Berlín. }\end{array}$ & $\begin{array}{l}\text { Ensemble Iberoamericano, } \\
\text { Joan Pagès Valls, director, } \\
\text { Carolina Krogius, } \\
\text { mezzosoprano. }\end{array}$ \\
\hline & $\begin{array}{l}\text { Man-i-obras (2010) para } \\
\text { conjunto. }\end{array}$ & $14 / 10 / 2010$ & $\begin{array}{l}\text { VII Festival } \\
\text { Internacional de Música } \\
\text { Contemporánea Darwin } \\
\text { Vargas, Instituto de } \\
\text { Música de la PUCV. }\end{array}$ & $\begin{array}{l}\text { Ensemble E-Mex, Ramón } \\
\text { Gorigoitía, director. }\end{array}$ \\
\hline
\end{tabular}




\begin{tabular}{|c|c|c|c|c|}
\hline $\begin{array}{l}\text { Nombre del } \\
\text { Compositor }\end{array}$ & Titulo de la obra & $\begin{array}{l}\text { Fecha de } \\
\text { Interpretación }\end{array}$ & Lugar & Intérpretes \\
\hline & & $15 / 10 / 2010$ & $\begin{array}{l}\text { Sala Isidora Zegers, } \\
\text { Facultad de Artes, } \\
\text { Universidad de Chile. }\end{array}$ & $\begin{array}{l}\text { Ensemble E-Mex, Ramón } \\
\text { Gorigoitía, director. }\end{array}$ \\
\hline & $\begin{array}{l}\text { Oda al Pehuén II para } 2 \\
\text { recitantes, } 21 \text { instrumentos, } \\
\text { soporte electrónico y proyección } \\
\text { de video. }\end{array}$ & $17 / 09 / 2010$ & $\begin{array}{l}\text { Sala Alte Feuerwache de } \\
\text { Colonia, Alemania. }\end{array}$ & $\begin{array}{l}\text { Sergio Terán (saxo } \\
\text { soprano, aerófonos } \\
\text { étnicos, percusión), } \\
\text { Ulli Sdimon (recitante, } \\
\text { aerófonos étnicos } \\
\text { y percusión), Alex } \\
\text { Mora (performance } \\
\text { y percusión), Alina } \\
\text { Namunkura (recitante), } \\
\text { Ramón Gorigoitía (piano, } \\
\text { sintetizador y percusión). }\end{array}$ \\
\hline & $\begin{array}{l}\text { Variaciones canónicas (2006) } \\
\text { para dos pianos }\end{array}$ & $16 / 10 / 2010$ & $\begin{array}{l}\text { X Festival de Música } \\
\text { Contemporánea Tres } \\
\text { Cantos, Madrid, España. }\end{array}$ & $\begin{array}{l}\text { Duo Scarbó: Elena } \\
\text { Hammel y Laura Sánchez, } \\
\text { pianos. }\end{array}$ \\
\hline & $\begin{array}{l}\text { Descuajeringado I para clarinete } \\
\text { solo. }\end{array}$ & $28 / 10 / 2010$ & $\begin{array}{l}\text { Concierto-Bicentenario, } \\
\text { Sala Alte Feuerwache de } \\
\text { Colonia, Alemania. }\end{array}$ & Dante Burotto, clarinete. \\
\hline \multirow[t]{5}{*}{$\begin{array}{l}\text { Guarello, } \\
\text { Alejandro }\end{array}$} & $\begin{array}{l}\text { *Talcualtal (2010) para flauta, } \\
\text { trombón, percusión, violoncello, } \\
\text { contrabajo y medios electrónicos. }\end{array}$ & $11 / 11 / 2010$ & $\begin{array}{l}\text { XX Festival de Música } \\
\text { Contemporánea, PUC, } \\
\text { Sala GAM. }\end{array}$ & $\begin{array}{l}\text { Guillermo Lavado, } \\
\text { flauta; Héctor Montalván, } \\
\text { trombón; Gerardo Salazar, } \\
\text { percusión; Cristián } \\
\text { Gutiérrez, violoncello; } \\
\text { Carlos Arenas, contrabajo; } \\
\text { Rodrigo Cádiz, Patricio } \\
\text { de la Cuadra, electrónica; } \\
\text { Alejandro Guarello, } \\
\text { director. }\end{array}$ \\
\hline & $\begin{array}{l}\text { Fractande (2008) para cuarteto } \\
\text { de cuerdas. }\end{array}$ & $20 / 11 / 2010$ & $\begin{array}{l}\text { Teatro del Lago de } \\
\text { Frutillar. }\end{array}$ & Cuarteto Diotima. \\
\hline & Retri (2007) para flauta y piano. & $24 / 11 / 2010$ & $\begin{array}{l}\text { Semana de la Música, } \\
\text { Sala América de la } \\
\text { Biblioteca Nacional. }\end{array}$ & $\begin{array}{l}\text { Estela Bellomio, flauta } \\
\text { traversa; Fernanda Ortega, } \\
\text { piano. }\end{array}$ \\
\hline & Solitario I (1979) para clarinete. & $23 / 10 / 2010$ & $\begin{array}{l}\text { Concierto-Bicentenario } \\
\text { en Gallus Theater de } \\
\text { Franfurt/Main, Alemania }\end{array}$ & Dante Burotto, clarinete. \\
\hline & & $28 / 10 / 2010$ & $\begin{array}{l}\text { Concierto-Bicentenario, } \\
\text { Sala Alte Feuerwache de } \\
\text { Colonia, Alemania. }\end{array}$ & $\begin{array}{l}\text { Ensamble Contemporáneo, } \\
\text { Aliocha Solovera, director. }\end{array}$ \\
\hline $\begin{array}{l}\text { Guede, } \\
\text { Fernando }\end{array}$ & $\begin{array}{l}\text { *Dux comes...? II (2010) para } \\
\text { contrabajo solista, trompeta, } \\
\text { trombón, percusión y piano. }\end{array}$ & $13 / 11 / 2010$ & $\begin{array}{l}\text { XX Festival de Música } \\
\text { Contemporánea, PUC, } \\
\text { Sala GAM. }\end{array}$ & $\begin{array}{l}\text { Taller de Lejos, Fernando } \\
\text { Guede, director; Julio } \\
\text { Torres, piano. }\end{array}$ \\
\hline $\begin{array}{l}\text { Guichard } \\
\text { Concha, Alonso }\end{array}$ & $\begin{array}{l}{ }^{* *} \text { Esto (No) es un monólogo } \\
\text { (2010) para flauta. }\end{array}$ & $3 / 12 / 2010$ & $\begin{array}{l}\text { Prismas Festival } \\
\text { de Creación } \\
\text { Latinoamericana, } \\
\text { Proyecto Germina. } \\
\text { Cciones...Primaveras } \\
\text { latinoamericanas, GAM. }\end{array}$ & Stephano Labarca, flauta. \\
\hline
\end{tabular}




\begin{tabular}{|c|c|c|c|c|}
\hline $\begin{array}{l}\text { Nombre del } \\
\text { Compositor }\end{array}$ & Titulo de la obra & $\begin{array}{l}\text { Fecha de } \\
\text { Interpretación }\end{array}$ & Lugar & Intérpretes \\
\hline $\begin{array}{l}\text { Guzmán, } \\
\text { Francisco }\end{array}$ & $\begin{array}{l}\text { Vibraciones oníricas del....que? } \\
\text { (2010) para vibráfono. }\end{array}$ & $13 / 10 / 2010$ & $\begin{array}{l}\text { VII Festival } \\
\text { Internacional de Música } \\
\text { Contemporánea Darwin } \\
\text { Vargas, Instituto de } \\
\text { Música de la PUCV. }\end{array}$ & Daniel Aros, vibráfono. \\
\hline \multirow[t]{3}{*}{$\begin{array}{l}\text { Heinlein, } \\
\text { Federico }\end{array}$} & $\begin{array}{l}\text { Despedida en invierno (1939) } \\
\text { para piano. }\end{array}$ & $18 / 11 / 2010$ & $\begin{array}{l}\text { XXIV Ciclo de } \\
\text { Pianistas Jóvenes 2010, } \\
\text { Auditorium Instituto } \\
\text { Chileno Norteamericano } \\
\text { de Cultura. }\end{array}$ & Benjamín Vidal, pianista. \\
\hline & $\begin{array}{l}\text { Pastoral. Sombra de un recuerdo } \\
\text { (1986) para piano. }\end{array}$ & $18 / 11 / 2010$ & $\begin{array}{l}\text { XXIV Ciclo de } \\
\text { Pianistas Jóvenes 2010, } \\
\text { Auditorium Instituto } \\
\text { Chileno Norteamericano } \\
\text { de Cultura. }\end{array}$ & Benjamín Vidal, pianista. \\
\hline & $\begin{array}{l}\text { A orillas del rio Claro (1959) } \\
\text { para coro a cuatro voces. }\end{array}$ & $22 / 11 / 2010$ & $\begin{array}{l}\text { Sala América de la } \\
\text { Biblioteca Nacional. }\end{array}$ & $\begin{array}{l}\text { Coro Estudiantil de } \\
\text { la UMCE, Guillermo } \\
\text { Vergara, director. }\end{array}$ \\
\hline $\begin{array}{l}\text { Henríquez, } \\
\text { Álvaro }\end{array}$ & Amor violento (1991) para coro. & $7 / 10 / 2010$ & $\begin{array}{l}\text { Aula Magna de la } \\
\text { USACH. }\end{array}$ & $\begin{array}{l}\text { Coro de la USACH, } \\
\text { Santiago Marín, director. }\end{array}$ \\
\hline \multirow[t]{2}{*}{ Holmes, Bryan } & $\begin{array}{l}\text { Crepúsculo (2006) para medios } \\
\text { electrónicos. }\end{array}$ & $9 / 10 / 2010$ & $\begin{array}{l}\text { X Festival } \\
\text { Internacional de Música } \\
\text { Electroacústica Ai- } \\
\text { Maako, Teatro Municipal } \\
\text { Lord Cochrane, Valdivia. }\end{array}$ & Electrónica en 4 canales. \\
\hline & $\begin{array}{l}\text { (El otro) Atentado a Pin8 (2009) } \\
\text { para electroacústica. }\end{array}$ & $16 / 10 / 2010$ & $\begin{array}{l}\text { X Festival } \\
\text { Internacional de } \\
\text { Música Electroacústica } \\
\text { Ai-Maako, Auditorio } \\
\text { Fundación Telefónica, } \\
\text { Santiago. }\end{array}$ & \\
\hline Jara, Claudio & $\begin{array}{l}\text { *Transfiguración (2009) } \\
\text { para flauta, saxofón, piano y } \\
\text { percusión. }\end{array}$ & $13 / 01 / 2011$ & $\begin{array}{l}\text { XI Festival de Música } \\
\text { Contemporánea de la } \\
\text { Universidad de Chile, } \\
\text { Facultad de Artes, Sala } \\
\text { Isidora Zegers. }\end{array}$ & $\begin{array}{l}\text { Ensamble Próxima } \\
\text { Centauri (Francia): } \\
\text { Sylvain Millepied, } \\
\text { flauta; Marie-Bernardette } \\
\text { Charrier, saxofón; } \\
\text { Clèment Fauconnet, } \\
\text { percusión; Hilomi } \\
\text { Sacaquchi, piano. }\end{array}$ \\
\hline Jara, Marcelo & Busco (2010) para guitarra. & $8 / 10 / 2010$ & $\begin{array}{l}\text { VI Concurso de } \\
\text { Composición Luis Advis, } \\
\text { GAM. }\end{array}$ & Marcelo Jara, guitarra. \\
\hline \multirow[t]{2}{*}{ Jara, Víctor } & Te recuerdo Amanda (1968). & $5 / 10 / 2010$ & $\begin{array}{l}\text { Aula Magna Universidad } \\
\text { de Santiago de Chile. }\end{array}$ & $\begin{array}{l}\text { Coro de Cámara de la } \\
\text { UPLA, Carlos Hernández, } \\
\text { director. }\end{array}$ \\
\hline & & $12 / 10 / 2010$ & $\begin{array}{l}\text { Teatro Municipal de } \\
\text { Moron, Argentina. }\end{array}$ & $\begin{array}{l}\text { Romilio, Orellana, } \\
\text { guitarra. }\end{array}$ \\
\hline
\end{tabular}




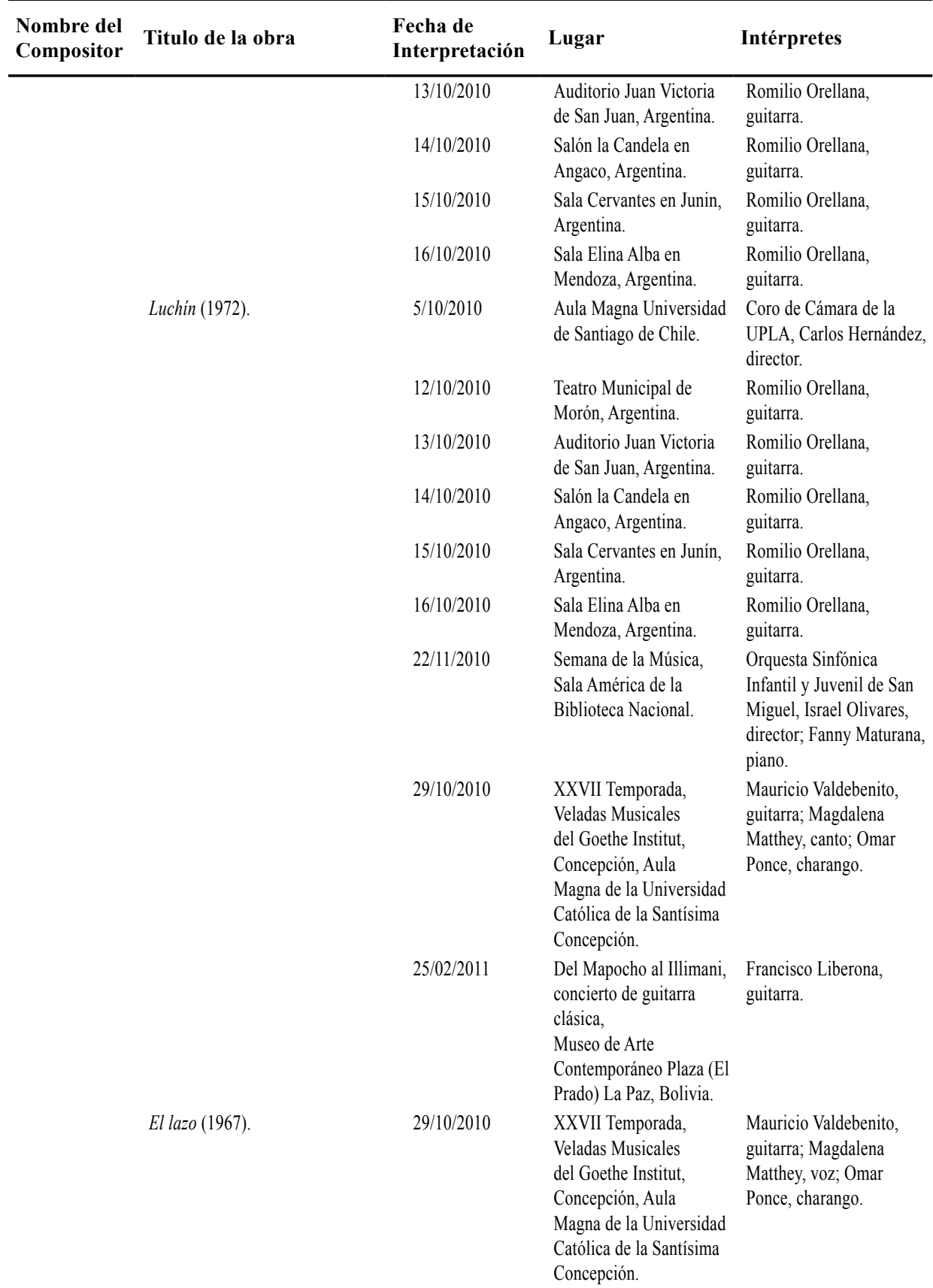




\begin{tabular}{|c|c|c|c|c|}
\hline $\begin{array}{l}\text { Nombre del } \\
\text { Compositor }\end{array}$ & Titulo de la obra & $\begin{array}{l}\text { Fecha de } \\
\text { Interpretación }\end{array}$ & Lugar & Intérpretes \\
\hline & \multirow[t]{2}{*}{ El derecho de vivir en paz (1970). } & $29 / 10 / 2010$ & $\begin{array}{l}\text { XXVII Temporada, } \\
\text { Veladas Musicales } \\
\text { del Goethe Institut, } \\
\text { Concepción, Aula } \\
\text { Magna de la Universidad } \\
\text { Católica de la Santísima } \\
\text { Concepción. }\end{array}$ & $\begin{array}{l}\text { Mauricio Valdebenito, } \\
\text { guitarra; Magdalena } \\
\text { Matthey, voz; Omar } \\
\text { Ponce, charango. }\end{array}$ \\
\hline & & $22 / 11 / 2010$ & $\begin{array}{l}\text { Semana de la Música, } \\
\text { Sala América de la } \\
\text { Biblioteca Nacional. }\end{array}$ & $\begin{array}{l}\text { Orquesta Sinfónica } \\
\text { Infantil y Juvenil de San } \\
\text { Miguel, Israel Olivares, } \\
\text { director; Fanny Maturana, } \\
\text { piano. }\end{array}$ \\
\hline & \multirow[t]{2}{*}{ Lo único que tengo (1972). } & $29 / 10 / 2010$ & $\begin{array}{l}\text { XXVII Temporada, } \\
\text { Veladas Musicales } \\
\text { del Goethe Institut, } \\
\text { Concepción, Aula } \\
\text { Magna de la Universidad } \\
\text { Católica de la Santísima } \\
\text { Concepción. }\end{array}$ & $\begin{array}{l}\text { Mauricio Valdebenito, } \\
\text { guitarra; Magdalena } \\
\text { Matthey, canto; Omar } \\
\text { Ponce, charango. }\end{array}$ \\
\hline & & $17 / 11 / 2010$ & $\begin{array}{l}\text { Aula Magna de la } \\
\text { USACH. }\end{array}$ & $\begin{array}{l}\text { Michele Millner Quinteto: } \\
\text { Michele Millner, voz; } \\
\text { Yves Cerf, saxos y } \\
\text { quena; Mael Godinat, } \\
\text { piano; Sylvain Fournier, } \\
\text { percusiones; Aurélien } \\
\text { Gattegno, flauta y quena. }\end{array}$ \\
\hline & $\begin{array}{l}\text { Poema } 15 \text { (texto Pablo Neruda) } \\
\text { (1972) }\end{array}$ & $29 / 10 / 2010$ & $\begin{array}{l}\text { XXVII Temporada, } \\
\text { Veladas Musicales } \\
\text { del Goethe Institut, } \\
\text { Concepción, Aula } \\
\text { Magna de la Universidad } \\
\text { Católica de la Santísima } \\
\text { Concepción. }\end{array}$ & $\begin{array}{l}\text { Mauricio Valdebenito, } \\
\text { guitarra; Magdalena } \\
\text { Matthey, canto; Omar } \\
\text { Ponce, charango. }\end{array}$ \\
\hline & Cuando voy al trabajo (1973). & $29 / 10 / 2010$ & $\begin{array}{l}\text { XXVII Temporada, } \\
\text { Veladas Musicales } \\
\text { del Goethe Institut, } \\
\text { Concepción, Aula } \\
\text { Magna de la Universidad } \\
\text { Católica de la Santísima } \\
\text { Concepción. }\end{array}$ & $\begin{array}{l}\text { Mauricio Valdebenito, } \\
\text { guitarra; Magdalena } \\
\text { Matthey, canto; Omar } \\
\text { Ponce, charango. }\end{array}$ \\
\hline $\begin{array}{l}\text { Jorquera } \\
\text { Aranguren, } \\
\text { Sebastián }\end{array}$ & $\begin{array}{l}* * \text { Mientras tanto (2010) para } \\
\text { violoncello. }\end{array}$ & $3 / 12 / 2010$ & $\begin{array}{l}\text { Prismas Festival } \\
\text { de Creación } \\
\text { Latinoamericana, } \\
\text { Proyecto Germina. } \\
\text { Cciones...Primaveras } \\
\text { latinoamericanas, GAM. }\end{array}$ & $\begin{array}{l}\text { Patricio Riquelme, } \\
\text { violoncello. }\end{array}$ \\
\hline
\end{tabular}




\begin{tabular}{|c|c|c|c|c|}
\hline $\begin{array}{l}\text { Nombre del } \\
\text { Compositor }\end{array}$ & Titulo de la obra & $\begin{array}{l}\text { Fecha de } \\
\text { Interpretación }\end{array}$ & Lugar & Intérpretes \\
\hline Julio, Fernando & $E \cos (2008)$ para conjunto. & $17 / 10 / 2010$ & $\begin{array}{l}\text { VII Festival } \\
\text { Internacional de Música } \\
\text { Contemporánea Darwin } \\
\text { Vargas, Instituto de } \\
\text { Música de la PUCV, } \\
\text { Teatro Auditorium } \\
\text { DUOC, Sede Viña del } \\
\text { Mar. }\end{array}$ & $\begin{array}{l}\text { Ensemble IMUS, Pablo } \\
\text { Alvarado, director. }\end{array}$ \\
\hline Kauer, Gabriel & **Distopía (2010) para guitarra. & $3 / 12 / 2010$ & $\begin{array}{l}\text { Prismas Festival } \\
\text { de Creación } \\
\text { Latinoamericana, } \\
\text { Proyecto Germina. } \\
\text { Cciones...Primaveras } \\
\text { latinoamericanas, GAM. }\end{array}$ & Sebastián Pérez, guitarra. \\
\hline Koloatic, Tomas & $\begin{array}{l}\text { *Prolegómenos (2010) para } \\
\text { cuarteto de cuerdas. }\end{array}$ & $13 / 11 / 2010$ & $\begin{array}{l}\text { XX Festival de Música } \\
\text { Contemporánea, PUC, } \\
\text { Sala GAM. }\end{array}$ & $\begin{array}{l}\text { David Núñez, Rodolfo } \\
\text { Mellado, violín; Sergio } \\
\text { Fresco, viola; Alejandro } \\
\text { Barría, violoncello. }\end{array}$ \\
\hline Lazo, Paola & $\begin{array}{l}\text { Doty Ko (2008-2010), } \\
\text { live electroacoustics. }\end{array}$ & $16 / 10 / 2010$ & $\begin{array}{l}\text { X Festival } \\
\text { Internacional de } \\
\text { Música Electroacústica } \\
\text { Ai-Maako, Auditorio } \\
\text { Fundación Telefónica, } \\
\text { Santiago. }\end{array}$ & \\
\hline \multirow[t]{5}{*}{ Leng, Alfonso } & $\begin{array}{l}\text { Andante (1905-1912) para } \\
\text { cuarteto de cuerdas. }\end{array}$ & $7 / 11 / 2010$ & $\begin{array}{l}\text { Concierto IX, "La } \\
\text { guitarra de nuestro } \\
\text { continente", Universidad } \\
\text { Andrés Bello, Campus } \\
\text { Casona de Las Condes. }\end{array}$ & $\begin{array}{l}\text { Camerata Universidad } \\
\text { Andrés Bello, Santiago } \\
\text { Meza, director. }\end{array}$ \\
\hline & & $15 / 11 / 2010$ & $\begin{array}{l}\text { Sala América de la } \\
\text { Biblioteca Nacional. }\end{array}$ & $\begin{array}{l}\text { Orquesta de Cámara del } \\
\text { Departamento de Música } \\
\text { de la UMCE, Daniel } \\
\text { Miranda, director. }\end{array}$ \\
\hline & & $17 / 04 / 2010$ & $\begin{array}{l}\text { II Concierto de la } \\
\text { temporada de la Orquesta } \\
\text { USS, Campus Bellavista } \\
\text { de USS. }\end{array}$ & $\begin{array}{l}\text { Orquesta Universidad San } \\
\text { Sebastián, Denis Kolobov, } \\
\text { director. }\end{array}$ \\
\hline & $\begin{array}{l}\text { Doloras } \mathrm{N}^{0} 1 \text { y No2 (1920) para } \\
\text { piano. }\end{array}$ & $16 / 11 / 2010$ & $\begin{array}{l}\text { XXIV Ciclo de } \\
\text { Pianistas Jóvenes 2010, } \\
\text { Auditorium Instituto } \\
\text { Chileno Norteamericano } \\
\text { de Cultura. }\end{array}$ & José Contreras, pianista. \\
\hline & $\begin{array}{l}\text { Doloras Nº y Nº } 4 \text { (1901-1914) } \\
\text { para piano. }\end{array}$ & $16 / 11 / 2010$ & $\begin{array}{l}\text { XXIV Ciclo de } \\
\text { Pianistas Jóvenes 2010, } \\
\text { Auditorium Instituto } \\
\text { Chileno Norteamericano } \\
\text { de Cultura. }\end{array}$ & $\begin{array}{l}\text { Daniela Saavedra, } \\
\text { pianista. }\end{array}$ \\
\hline
\end{tabular}




\begin{tabular}{|c|c|c|c|c|}
\hline $\begin{array}{l}\text { Nombre del } \\
\text { Compositor }\end{array}$ & Titulo de la obra & $\begin{array}{l}\text { Fecha de } \\
\text { Interpretación }\end{array}$ & Lugar & Intérpretes \\
\hline & Preludio N² (1906) para piano. & $18 / 11 / 2010$ & $\begin{array}{l}\text { XXIV Ciclo de } \\
\text { Pianistas Jóvenes 2010, } \\
\text { Auditorium Instituto } \\
\text { Chileno Norteamericano } \\
\text { de Cultura. }\end{array}$ & $\begin{array}{l}\text { Daniel Bahamondes, } \\
\text { pianista. }\end{array}$ \\
\hline & $\begin{array}{l}\text { Doloras (1901-1914) (según } \\
\text { poemas de Pedro Prado) para } \\
\text { piano. }\end{array}$ & $15 / 02 / 2011$ & $\begin{array}{l}\text { Teatro Municipal Lord } \\
\text { Cochrane, Valdivia. }\end{array}$ & Roberto Bravo, piano. \\
\hline León, Cristóbal & $\begin{array}{l}\text { **Recorrido montaña } \\
\text { fantasma }(2010) \text { para conjunto } \\
\text { instrumental. }\end{array}$ & $4 / 12 / 2010$ & $\begin{array}{l}\text { Prismas Festival } \\
\text { de Creación } \\
\text { Latinoamericana, } \\
\text { Proyecto Germina. } \\
\text { Cciones...Primaveras } \\
\text { latinoamericanas, GAM. }\end{array}$ & $\begin{array}{l}\text { Ensamble Colectivo Los } \\
\text { Musicantes: Patricio } \\
\text { Huerta, saxo alto; } \\
\text { Moris Al Alam, saxo } \\
\text { tenor; Pablo Jara, saxo } \\
\text { barítono; Felipe Machuca, } \\
\text { trompeta; Felipe Castillo, } \\
\text { trompeta; Ignacio Valle. } \\
\text { trombón;César Veas, } \\
\text { guitarra eléctrica; Claudio } \\
\text { Carrasco. batería; Felipe } \\
\text { Lolas, piano,Fabrán } \\
\text { Aguilera, bajo eléctrico, } \\
\text { Sebastián Errázuriz, } \\
\text { director. }\end{array}$ \\
\hline \multirow[t]{3}{*}{$\begin{array}{l}\text { Letelier, } \\
\text { Alfonso }\end{array}$} & $\begin{array}{l}\text { Hallazgo (1934-1942), adaptación } \\
\text { para voces femeninas. }\end{array}$ & $18 / 10 / 2010$ & $\begin{array}{l}\text { Sala de Eventos Codelco, } \\
\text { Santiago. }\end{array}$ & $\begin{array}{l}\text { Coral Femenina Viña del } \\
\text { Mar, Jessica Quezada, } \\
\text { directora. }\end{array}$ \\
\hline & $\begin{array}{l}\text { Villancico I (En los brazos de la } \\
\text { luna) (1934-1942), adaptación } \\
\text { para voces femeninas. }\end{array}$ & $18 / 10 / 2010$ & $\begin{array}{l}\text { Sala de Eventos Codelco, } \\
\text { Santiago. }\end{array}$ & $\begin{array}{l}\text { Coral Femenina Viña del } \\
\text { Mar, Jessica Quezada, } \\
\text { directora. }\end{array}$ \\
\hline & $\begin{array}{l}\text { Los vitrales de la Anunciación } \\
\text { (1949) en versión reducida con } \\
\text { órgano. }\end{array}$ & $11 / 12 / 2010$ & $\begin{array}{l}\text { Santuario de Schoenstatt } \\
\text { Agua Santa, Viña del } \\
\text { Mar. }\end{array}$ & $\begin{array}{l}\text { Coral Femenina Viña del } \\
\text { Mar, Jessica Quezada, } \\
\text { directora; Carlos } \\
\text { Caamaño, órgano. }\end{array}$ \\
\hline \multirow[t]{5}{*}{ Letelier, Miguel } & $\begin{array}{l}\text { Canciones II y III de la serie de } \\
\text { tres (1981-1982) para clarinete, } \\
\text { piano y contralto. }\end{array}$ & $13 / 10 / 2010$ & $\begin{array}{l}\text { Archivo de Música, } \\
\text { Biblioteca Nacional. }\end{array}$ & $\begin{array}{l}\text { Patricia Castro, piano; } \\
\text { Rodrigo Matamala, } \\
\text { clarinete; Carmen Luisa } \\
\text { Letelier, contralto. }\end{array}$ \\
\hline & $\begin{array}{l}\text { *Como pasa la brisa para piano } \\
\text { (2008). }\end{array}$ & $13 / 10 / 2010$ & $\begin{array}{l}\text { Archivo de Música, } \\
\text { Biblioteca Nacional. }\end{array}$ & Patricia Castro, piano. \\
\hline & $\begin{array}{l}\text { Cuatro piezas (1992) del Pequeño } \\
\text { libro para piano. }\end{array}$ & $13 / 10 / 2010$ & $\begin{array}{l}\text { Archivo de Música, } \\
\text { Biblioteca Nacional. }\end{array}$ & Patricia Castro, piano. \\
\hline & $\begin{array}{l}\text { A Violeta Parra }(1995) \text { del } \\
\text { Pequeño libro para piano. }\end{array}$ & $16 / 11 / 2010$ & Goethe Institut. & Patricia Castro, piano. \\
\hline & $\begin{array}{l}\text { Siete preludios breves (1962) para } \\
\text { guitarra. }\end{array}$ & $16 / 12 / 2010$ & $\begin{array}{l}\text { I Jornadas Guitarrísticas } \\
\text { de Coquimbo, Casa de la } \\
\text { Cultura, Coquimbo. }\end{array}$ & Luis Mancilla, guitarra. \\
\hline
\end{tabular}




\begin{tabular}{|c|c|c|c|c|}
\hline $\begin{array}{l}\text { Nombre del } \\
\text { Compositor }\end{array}$ & Titulo de la obra & $\begin{array}{l}\text { Fecha de } \\
\text { Interpretación }\end{array}$ & Lugar & Intérpretes \\
\hline $\begin{array}{l}\text { Liberona, } \\
\text { Francisco }\end{array}$ & $\begin{array}{l}\text { Fantasía sobre un tema de Violeta } \\
\text { Parra (2010) para guitarra. }\end{array}$ & $25 / 02 / 2011$ & $\begin{array}{l}\text { Del Mapocho al Illimani, } \\
\text { concierto de guitarra } \\
\text { clásica, Museo de Arte } \\
\text { Contemporáneo Plaza (El } \\
\text { Prado), La Paz-Bolivia. }\end{array}$ & $\begin{array}{l}\text { Duo de Guitarras } \\
\text { Francisco Liberona y } \\
\text { Alejandro Escobar. }\end{array}$ \\
\hline López, Cristián & $\begin{array}{l}\text { IN-certidumbres del sujeto amado } \\
\text { (2010) para cuarteto de cuerdas. }\end{array}$ & $13 / 10 / 2010$ & $\begin{array}{l}\text { VII Festival } \\
\text { Internacional de Música } \\
\text { Contemporánea Darwin } \\
\text { Vargas, Instituto de } \\
\text { Música de la PUCV. }\end{array}$ & $\begin{array}{l}\text { Cuarteto de Cuerdas } \\
\text { Antares. }\end{array}$ \\
\hline $\begin{array}{l}\text { López, } \\
\text { Mauricio }\end{array}$ & $\begin{array}{l}\text { **Esgrimista verbal (2010) para } \\
\text { clarinete bajo, saxofón, guitarra } \\
\text { eléctrica, contrabajo. }\end{array}$ & $4 / 12 / 2010$ & $\begin{array}{l}\text { Prismas Festival } \\
\text { de Creación } \\
\text { Latinoamericana, } \\
\text { Proyecto Germina. } \\
\text { Cciones...Primaveras } \\
\text { latinoamericanas, GAM. }\end{array}$ & $\begin{array}{l}\text { Santiago Bruna, clarinete } \\
\text { bajo; David Espinoza, } \\
\text { saxo tenor; Vicente } \\
\text { Fernández, guitarra } \\
\text { eléctrica; Matías Yáñez, } \\
\text { contrabajo; Javier Farías } \\
\text { Caballero, director. }\end{array}$ \\
\hline
\end{tabular}

\begin{tabular}{|c|c|c|c|c|}
\hline Manns, Patricio & $\begin{array}{l}\text { Arriba en la cordillera (1965) en } \\
\text { versión de coro. }\end{array}$ & $5 / 10 / 2010$ & $\begin{array}{l}\text { Aula Magna de la } \\
\text { USACH. }\end{array}$ & $\begin{array}{l}\text { Coro de Cámara de la } \\
\text { UPLA, Carlos Hernández, } \\
\text { director. }\end{array}$ \\
\hline $\begin{array}{l}\text { Martínez, } \\
\text { Gonzálo }\end{array}$ & $\begin{array}{l}\text { Episodios (2010) para viola y } \\
\text { piano. }\end{array}$ & $11 / 11 / 2010$ & $\begin{array}{l}\text { XX Festival de Música } \\
\text { Contemporánea, PUC, } \\
\text { Sala GAM. }\end{array}$ & $\begin{array}{l}\text { Pablo Salinas, viola; } \\
\text { Mario Feito, piano. }\end{array}$ \\
\hline
\end{tabular}

\begin{tabular}{|c|c|c|c|c|}
\hline Martínez, Jorge & $\begin{array}{l}\text { El laberinto (1984) para cuarteto } \\
\text { de guitarras. }\end{array}$ & $3 / 12 / 2010$ & $\begin{array}{l}\text { Prismas Festival } \\
\text { de Creación } \\
\text { Latinoamericana, } \\
\text { Proyecto Germina. } \\
\text { Cciones...Primaveras } \\
\text { latinoamericanas, GAM. }\end{array}$ & $\begin{array}{l}\text { Rael Valencia, Felipe Paz, } \\
\text { Sebastián Pérez, Alonso } \\
\text { Días, cuarteto de guitarras. }\end{array}$ \\
\hline \multirow[t]{3}{*}{$\begin{array}{l}\text { Matthey, } \\
\text { Gabriel }\end{array}$} & $\begin{array}{l}\text { Concierto primero (2004) para } \\
\text { guitarra y orquesta (dedicado a } \\
\text { Mauricio Valdebenito). }\end{array}$ & $26 / 11 / 2010$ & $\begin{array}{l}\text { Sala Auditorium de la } \\
\text { Facultad de Ingeniería, } \\
\text { Universidad de La } \\
\text { Serena. }\end{array}$ & $\begin{array}{l}\text { Orquesta Sinfónica de la } \\
\text { Universidad de La Serena, } \\
\text { Francisco Núñez, director; } \\
\text { Mauricio Valdebenito, } \\
\text { guitarra. }\end{array}$ \\
\hline & \multirow[t]{2}{*}{$\begin{array}{l}\text { Chilenita } \mathrm{N}^{\circ} 3 \text { para quinteto de } \\
\text { percusiones }\end{array}$} & $03 / 02 / 2011$ & $\begin{array}{l}\text { Música escénica para } \\
\text { percusiones, Sala Manuel } \\
\text { Enríquez, Facultad de } \\
\text { Música de la Universidad } \\
\text { de Tamaulipas, Tampico, } \\
\text { México. }\end{array}$ & $\begin{array}{l}\text { Dúo de Percusiones A } \\
\text { Dois y músicos invitados. }\end{array}$ \\
\hline & & $04 / 02 / 2011$ & $\begin{array}{l}\text { Música escénica } \\
\text { para percusiones, } \\
\text { Master Class, Salón } \\
\text { de percusiones de } \\
\text { la Universidad de } \\
\text { Tamaulipas, Tampico, } \\
\text { México. }\end{array}$ & $\begin{array}{l}\text { Dúo de Percusiones A } \\
\text { Dois y músicos invitados. }\end{array}$ \\
\hline
\end{tabular}




\begin{tabular}{|c|c|c|c|c|}
\hline $\begin{array}{l}\text { Nombre del } \\
\text { Compositor }\end{array}$ & Titulo de la obra & $\begin{array}{l}\text { Fecha de } \\
\text { Interpretación }\end{array}$ & Lugar & Intérpretes \\
\hline & & $08 / 02 / 2011$ & $\begin{array}{l}\text { Música escénica para } \\
\text { percusiones, Auditorio de } \\
\text { la Casa de la Marimba, } \\
\text { Ciudad de México. }\end{array}$ & $\begin{array}{l}\text { Dúo de Percusiones A } \\
\text { Dois y músicos invitados. }\end{array}$ \\
\hline & & $10 / 02 / 2011$ & $\begin{array}{l}\text { Música escénica para } \\
\text { percusiones, } 2^{\circ} \text { Festival } \\
\text { de la Marimba Maestro } \\
\text { Zeferino Nandayapa en la } \\
\text { Plaza Central de Chiapas } \\
\text { de Corzo, México. }\end{array}$ & $\begin{array}{l}\text { Dúo de Percusiones A } \\
\text { Dois y músicos invitados. }\end{array}$ \\
\hline & & $11 / 02 / 2010$ & $\begin{array}{l}\text { Música escénica para } \\
\text { percusiones, Master Class } \\
\text { Escuela de Música de la } \\
\text { Universidad de Chiapas, } \\
\text { México. }\end{array}$ & $\begin{array}{l}\text { Dúo de Percusiones A } \\
\text { Dois y músicos invitados. }\end{array}$ \\
\hline & & $12 / 02 / 2011$ & $\begin{array}{l}\text { Música escénica para } \\
\text { percusiones, Auditorio de } \\
\text { la Fundación Sebastián, } \\
\text { Ciudad de México. }\end{array}$ & $\begin{array}{l}\text { Dúo de Percusiones A } \\
\text { Dois y músicos invitados. }\end{array}$ \\
\hline & & $12 / 02 / 2011$ & $\begin{array}{l}\text { Música escénica para } \\
\text { percusiones, Master } \\
\text { Class Auditorio de la } \\
\text { Fundación Sebastián, } \\
\text { Ciudad de México. }\end{array}$ & $\begin{array}{l}\text { Dúo de Percusiones A } \\
\text { Dois y músicos invitados. }\end{array}$ \\
\hline \multirow[t]{2}{*}{$\begin{array}{l}\text { Mendoza, Juan } \\
\text { Ignacio }\end{array}$} & $\begin{array}{l}\text { Ira }(2010), 8 \text { canales } \\
\text { electroacústicos. }\end{array}$ & $7 / 10 / 2010$ & $\begin{array}{l}\text { X Festival } \\
\text { Internacional de Música } \\
\text { Electroacústica Ai- } \\
\text { Maako, Teatro Municipal } \\
\text { Lord Cochrane de } \\
\text { Valdivia. }\end{array}$ & \\
\hline & $\begin{array}{l}\text { **Dos micromúsicas (2010) para } \\
\text { contrabajo solo. }\end{array}$ & $3 / 12 / 2010$ & $\begin{array}{l}\text { Prismas Festival } \\
\text { de Creación } \\
\text { Latinoamericana, } \\
\text { Proyecto Germina. } \\
\text { Cciones...Primaveras } \\
\text { latinoamericanas, GAM. }\end{array}$ & $\begin{array}{l}\text { María Francisca } \\
\text { Moraga, Pilar Elizabeth, } \\
\text { contrabajos. }\end{array}$ \\
\hline $\begin{array}{l}\text { Meza, Juan } \\
\text { Cristóbal }\end{array}$ & $\begin{array}{l}\text { Rapsodia macabra (de la película } \\
\text { Fuga) para piano. }\end{array}$ & $15 / 02 / 2011$ & $\begin{array}{l}\text { Teatro Municipal Lord } \\
\text { Cochrane, Valdivia. }\end{array}$ & Roberto Bravo, piano. \\
\hline \multirow[t]{5}{*}{$\begin{array}{l}\text { Milla, } \\
\text { Guillermo }\end{array}$} & $\begin{array}{l}\text { Maestro cuzqueño (2003) para } \\
\text { conjunto. }\end{array}$ & $19 / 11 / 2010$ & $\begin{array}{l}\text { Centro de Extensión de } \\
\text { la Universidad Católica } \\
\text { del Maule. }\end{array}$ & Ensamble Serenata \\
\hline & & $20 / 11 / 2010$ & $\begin{array}{l}\text { Salón Balmaceda de } \\
\text { Linares. }\end{array}$ & Ensamble Serenata \\
\hline & & $21 / 11 / 2010$ & $\begin{array}{l}\text { Teatro Municipal de San } \\
\text { Clemente }\end{array}$ & Ensamble Serenata \\
\hline & Valseadito (2003) para conjunto. & $19 / 11 / 2010$ & $\begin{array}{l}\text { Centro de Extensión de } \\
\text { la Universidad Católica } \\
\text { del Maule. }\end{array}$ & Ensamble Serenata \\
\hline & & $20 / 11 / 2010$ & $\begin{array}{l}\text { Salón Balmaceda de } \\
\text { Linares. }\end{array}$ & Ensamble Serenata \\
\hline
\end{tabular}




\begin{tabular}{|c|c|c|c|c|}
\hline $\begin{array}{l}\text { Nombre del } \\
\text { Compositor }\end{array}$ & Titulo de la obra & $\begin{array}{l}\text { Fecha de } \\
\text { Interpretación }\end{array}$ & Lugar & Intérpretes \\
\hline & & $21 / 11 / 2010$ & $\begin{array}{l}\text { Teatro Municipal de San } \\
\text { Clemente }\end{array}$ & Ensamble Serenata \\
\hline $\begin{array}{l}\text { Miranda, } \\
\text { Daniel }\end{array}$ & Opta para orquesta de cámara. & $15 / 11 / 2010$ & $\begin{array}{l}\text { Sala América de la } \\
\text { Biblioteca Nacional. }\end{array}$ & $\begin{array}{l}\text { Orquesta de Cámara del } \\
\text { Departamento de Música } \\
\text { de la UMCE, Daniel } \\
\text { Miranda, director. }\end{array}$ \\
\hline \multirow[t]{6}{*}{ Mora, Mario } & $\begin{array}{l}\text { Nex (2002) para saxofón soprano } \\
\text { y medios electrónicos. }\end{array}$ & $15 / 10 / 2010$ & $\begin{array}{l}\text { X Festival } \\
\text { Internacional de } \\
\text { Música Electroacústica } \\
\text { Ai-Maako, Auditorio } \\
\text { Fundación Telefónica, } \\
\text { Santiago. }\end{array}$ & $\begin{array}{l}\text { Miguel Villafruela, } \\
\text { saxofón. }\end{array}$ \\
\hline & $\begin{array}{l}\text { *Nada (2010) para contrabajo y } \\
\text { electrónica en vivo. }\end{array}$ & $22 / 10 / 2010$ & Goethe Institut, Santiago. & $\begin{array}{l}\text { Carlos Arenas, contrabajo, } \\
\text { Mario Mora, electrónica. }\end{array}$ \\
\hline & & $26 / 10 / 2010$ & $\begin{array}{l}\text { Campos abiertos, Sede } \\
\text { Las Encinas, ciclo de } \\
\text { conciertos, Facultad de } \\
\text { Artes, Universidad de } \\
\text { Chile. }\end{array}$ & $\begin{array}{l}\text { Carlos Arenas, contrabajo, } \\
\text { Mario Mora, electrónica. }\end{array}$ \\
\hline & $\begin{array}{l}\text { Nud (1994) para flauta y } \\
\text { electrónica. }\end{array}$ & $22 / 10 / 2010$ & $\begin{array}{l}\text { Goethe Institute, } \\
\text { Santiago. }\end{array}$ & Wilson Padilla, flauta. \\
\hline & & $26 / 10 / 2010$ & $\begin{array}{l}\text { Campos abiertos, Sede } \\
\text { Las Encinas, ciclo de } \\
\text { conciertos, Facultad de } \\
\text { Artes, Universidad de } \\
\text { Chile. }\end{array}$ & Wilson Padilla, flauta. \\
\hline & $\begin{array}{l}\text { Los golpes (2010) para conjunto } \\
\text { instrumental. }\end{array}$ & $12 / 01 / 2011$ & $\begin{array}{l}\text { XI Festival de Música } \\
\text { Contemporánea de la } \\
\text { Universidad de Chile, } \\
\text { Facultad de Artes, Sala } \\
\text { Isidora Zegers. }\end{array}$ & $\begin{array}{l}\text { Compañía de Música } \\
\text { Contemporánea: } \\
\text { Roberto Cisternas, } \\
\text { flauta; Cláudio Vásquez, } \\
\text { clarinete; Violeta Mura, } \\
\text { violoncello; Simone } \\
\text { Caiafa, percusión; } \\
\text { Esteban Ravanal, piano; } \\
\text { Fabián Esparza, violín- } \\
\text { viola; Carlos Valenzuela, } \\
\text { director. }\end{array}$ \\
\hline $\begin{array}{l}\text { Morales, } \\
\text { Cristián }\end{array}$ & $\begin{array}{l}\text { *Que desorganiza todo (2010) } \\
\text { para flauta, clarinete, saxofón, } \\
\text { percusión, piano, violín y } \\
\text { violoncello. }\end{array}$ & $10 / 11 / 2010$ & $\begin{array}{l}\text { XX Festival de Música } \\
\text { Contemporánea, PUC, } \\
\text { Sala GAM. }\end{array}$ & $\begin{array}{l}\text { Taller de Música } \\
\text { Contemporánea, Pablo } \\
\text { Aranda, director. }\end{array}$ \\
\hline $\begin{array}{l}\text { Morales, Juan } \\
\text { Ignacio }\end{array}$ & $\begin{array}{l}A \_B(2010) \text { para medios } \\
\text { electroacústicos. }\end{array}$ & $16 / 10 / 2010$ & $\begin{array}{l}\text { X Festival } \\
\text { Internacional de } \\
\text { Música Electroacústica } \\
\text { Ai-Maako,Auditorio } \\
\text { Fundación Telefónica, } \\
\text { Santiago. }\end{array}$ & \\
\hline
\end{tabular}




\begin{tabular}{|c|c|c|c|c|}
\hline $\begin{array}{l}\text { Nombre del } \\
\text { Compositor }\end{array}$ & Titulo de la obra & $\begin{array}{l}\text { Fecha de } \\
\text { Interpretación }\end{array}$ & Lugar & Intérpretes \\
\hline \multirow[t]{3}{*}{$\begin{array}{l}\text { Muñoz Bravo, } \\
\text { Javier }\end{array}$} & $\begin{array}{l}\text { Credo (2010) para medios } \\
\text { electroacústicos. }\end{array}$ & $13 / 10 / 2010$ & $\begin{array}{l}\text { X Festival } \\
\text { Internacional de } \\
\text { Música Electroacústica } \\
\text { Ai-Maako, Auditorio } \\
\text { Fundación Telefónica, } \\
\text { Santiago. }\end{array}$ & \\
\hline & $\begin{array}{l}\text { **Espacios cósmicos (2010) } \\
\text { para flauta, clarinete, violín, } \\
\text { violoncello, piano. }\end{array}$ & $1 / 12 / 2010$ & $\begin{array}{l}\text { Prismas Festival } \\
\text { de Creación } \\
\text { Latinoamericana, } \\
\text { Proyecto Germina. } \\
\text { Cciones...Primaveras } \\
\text { latinoamericanas, GAM. }\end{array}$ & $\begin{array}{l}\text { Juan Pablo Aguayo, } \\
\text { flauta; Alejandro Ortiz, } \\
\text { clarinete; Elías Allendes, } \\
\text { violín; Cristián Gutiérrez, } \\
\text { violoncello; Fernanda } \\
\text { Ortega, piano; Pablo } \\
\text { Aranda, director. }\end{array}$ \\
\hline & $\begin{array}{l}\text { *La máscara de la muerte roja } \\
\text { (2009) para piano, flauta, violín, } \\
\text { violoncello, clarinete, saxo tenor, } \\
\text { contrabajo, fagot, percusión. }\end{array}$ & $10 / 01 / 2011$ & $\begin{array}{l}\text { XI Festival de Música } \\
\text { Contemporánea de la } \\
\text { Universidad de Chile, } \\
\text { Facultad de Artes, Sala } \\
\text { Isidora Zegers. }\end{array}$ & $\begin{array}{l}\text { Ensamble Taller de } \\
\text { Música Contemporánea, } \\
\text { Fernanda Ortega, piano; } \\
\text { Natalia Martorell, flauta; } \\
\text { Miguel Ángel Muñoz, } \\
\text { violín; Cristián Gutiérrez, } \\
\text { violoncello; Alejandro } \\
\text { Ortiz, clarinete; Edén } \\
\text { Carrasco, saxo tenor; } \\
\text { Carlos Arenas, contrabajo; } \\
\text { Felipe Distéfano, } \\
\text { fagot, Gerardo Salazar, } \\
\text { percusión; } \\
\text { Pablo Aranda, director. }\end{array}$ \\
\hline Núñez, Andrés & ${ }^{*}$ Deb $(2010)$ para piano. & $29 / 11 / 2010$ & $\begin{array}{l}\text { Sala América de la } \\
\text { Biblioteca Nacional. }\end{array}$ & Fernanda Ortega, piano. \\
\hline
\end{tabular}

\begin{tabular}{ll}
\hline Núñez Meneses, & ${ }^{* *}$ Caminata en el bosque... \\
Sergio & texto Elicura Chihuailaf $(2010)$ \\
& para mezzosoprano, saxofón, \\
& percusión, piano, contrabajo.
\end{tabular}

**Monólogo (2010) para soprano. 3/12/2010

\begin{tabular}{|c|c|}
\hline $\begin{array}{l}\text { Prismas Festival } \\
\text { de Creación } \\
\text { Latinoamericana, } \\
\text { Proyecto Germina. } \\
\text { Cciones...Primaveras } \\
\text { latinoamericanas, GAM. }\end{array}$ & $\begin{array}{l}\text { Copiuensamble: Vanessa } \\
\text { Rojas, mezzosoprano; } \\
\text { Isaías Zamorano, } \\
\text { saxofón; Nicolás Moreno, } \\
\text { persusión; Joy Smith, } \\
\text { piano; Carlos Arenas, } \\
\text { contrabajo; René Silva, } \\
\text { director. }\end{array}$ \\
\hline $\begin{array}{l}\text { Prismas Festival } \\
\text { de Creación }\end{array}$ & $\begin{array}{l}\text { Pilar Garrido Letelier, } \\
\text { soprano. }\end{array}$ \\
\hline
\end{tabular}

Latinoamericana,

Proyecto Germina.

Cciones...Primaveras

latinoamericanas, GAM.

\begin{tabular}{lllll}
\hline $\begin{array}{l}\text { Núñez } \\
\text { Navarrete, } \\
\text { Pedro }\end{array}$ & $\begin{array}{l}\text { Dulzura (1988) para coro, texto } \\
\text { Gabriela Mistral. }\end{array}$ & $22 / 11 / 2010$ & $\begin{array}{l}\text { Sala América de la } \\
\text { Biblioteca Nacional. }\end{array}$ & $\begin{array}{l}\text { Coro Estudiantil de } \\
\text { la UMCE, Guillermo } \\
\text { Vergara, director. }\end{array}$ \\
\hline $\begin{array}{llll}\text { Orrego-Salas, } \\
\text { Juan }\end{array}$ & $\begin{array}{l}\text { Canciones castellanas op.20 } \\
\text { (1948) para voz y conjunto } \\
\text { instrumental, textos de poetas }\end{array}$ & $17 / 11 / 2010$ & $\begin{array}{l}\text { Iglesia San Francisco, } \\
\text { españoles del Renacimiento. }\end{array}$ & $\begin{array}{l}\text { Orquesta de Cámara } \\
\text { de Chile, Juan Pablo }\end{array}$ \\
& & & & Izquierdo, director; Nora \\
& & & Miranda, voz.
\end{tabular}




\begin{tabular}{|c|c|c|c|c|}
\hline $\begin{array}{l}\text { Nombre del } \\
\text { Compositor }\end{array}$ & Titulo de la obra & $\begin{array}{l}\text { Fecha de } \\
\text { Interpretación }\end{array}$ & Lugar & Intérpretes \\
\hline & & $18 / 11 / 2010$ & $\begin{array}{l}\text { Iglesia San Ignacio, } \\
\text { Santiago. }\end{array}$ & $\begin{array}{l}\text { Orquesta de Cámara } \\
\text { de Chile, Juan Pablo } \\
\text { Izquierdo, director; Nora } \\
\text { Miranda, voz. }\end{array}$ \\
\hline & & $19 / 11 / 2010$ & $\begin{array}{l}\text { Iglesia María Madre de } \\
\text { Misericordia, Santiago. }\end{array}$ & $\begin{array}{l}\text { Orquesta de Cámara } \\
\text { de Chile, Juan Pablo } \\
\text { Izquierdo, director; Nora } \\
\text { Miranda, voz. }\end{array}$ \\
\hline & & $20 / 11 / 2010$ & $\begin{array}{l}\text { Iglesia San Ignacio, } \\
\text { Santiago. }\end{array}$ & $\begin{array}{l}\text { Orquesta de Cámara } \\
\text { de Chile, Juan Pablo } \\
\text { Izquierdo, director; Nora } \\
\text { Miranda, voz. }\end{array}$ \\
\hline & & $20 / 11 / 2010$ & $\begin{array}{l}\text { Universidad Federico } \\
\text { Santa María, Valparaíso. }\end{array}$ & $\begin{array}{l}\text { Orquesta de Cámara } \\
\text { de Chile, Juan Pablo } \\
\text { Izquierdo, director; Nora } \\
\text { Miranda, voz. }\end{array}$ \\
\hline Ortega, Sergio & $\begin{array}{l}\text { Lonquén (1979) para soprano y } \\
\text { conjunto. }\end{array}$ & $13 / 10 / 2010$ & $\begin{array}{l}\text { VII Festival } \\
\text { Internacional de Música } \\
\text { Contemporánea Darwin } \\
\text { Vargas, Instituto de } \\
\text { Música de la PUCV. }\end{array}$ & $\begin{array}{l}\text { Orquesta Andina, Félix } \\
\text { Cárdenas, director; Maysa } \\
\text { López, soprano. }\end{array}$ \\
\hline \multirow[t]{2}{*}{$\begin{array}{l}\text { Osses Alvarado, } \\
\text { Bárbara }\end{array}$} & **Sin título (2010) para piano. & $30 / 11 / 2010$ & $\begin{array}{l}\text { Prismas Festival } \\
\text { de Creación } \\
\text { Latinoamericana, } \\
\text { Proyecto Germina. } \\
\text { Cciones...Primaveras } \\
\text { latinoamericanas, GAM. }\end{array}$ & Edwin Godoy, piano. \\
\hline & **La llamada (2010) para corno. & $3 / 12 / 2010$ & $\begin{array}{l}\text { Prismas Festival } \\
\text { de Creación } \\
\text { Latinoamericana, } \\
\text { Proyecto Germina. } \\
\text { Cciones...Primaveras } \\
\text { latinoamericanas, GAM. }\end{array}$ & Alonso Pescio, corno. \\
\hline \multirow[t]{3}{*}{ Osorio, Daniel } & $\begin{array}{l}\text { Zikkus-P (2010) para piano y } \\
\text { medios electrónicos. }\end{array}$ & $7 / 10 / 2010$ & $\begin{array}{l}\text { X Festival } \\
\text { Internacional de Música } \\
\text { Electroacústica Ai- } \\
\text { Maako, Teatro Municipal } \\
\text { Lord Cochrane de } \\
\text { Valdivia. }\end{array}$ & Fernanda Ortega, piano. \\
\hline & $\begin{array}{l}\text { La ciudad (2010) para soprano, } \\
\text { flauta dulce, clarinete, guitarra, } \\
\text { violín y violoncello. }\end{array}$ & $10 / 11 / 2010$ & $\begin{array}{l}\text { XX Festival de Música } \\
\text { Contemporánea, PUC, } \\
\text { Sala GAM. }\end{array}$ & $\begin{array}{l}\text { Taller de Música } \\
\text { Contemporánea, Pablo } \\
\text { Aranda, director; Nancy } \\
\text { Gómez, soprano. }\end{array}$ \\
\hline & L-ein (2006-2008) para piano. & $29 / 11 / 2010$ & $\begin{array}{l}\text { Sala América de la } \\
\text { Biblioteca Nacional. }\end{array}$ & Fernanda Ortega, piano. \\
\hline
\end{tabular}




\begin{tabular}{|c|c|c|c|c|}
\hline $\begin{array}{l}\text { Nombre del } \\
\text { Compositor }\end{array}$ & Titulo de la obra & $\begin{array}{l}\text { Fecha de } \\
\text { Interpretación }\end{array}$ & Lugar & Intérpretes \\
\hline & Nayra (2010) para conjunto. & $10 / 01 / 2011$ & $\begin{array}{l}\text { XI Festival de Música } \\
\text { Contemporánea de la } \\
\text { Universidad de Chile, } \\
\text { Facultad de Artes, Sala } \\
\text { Isidora Zegers. }\end{array}$ & $\begin{array}{l}\text { Ensamble Taller de } \\
\text { Música Contemporánea, } \\
\text { Paola Muñoz, flauta } \\
\text { dulce; Nancy Gómez, voz; } \\
\text { Diego Castro, guitarra; } \\
\text { Miguel Ángel Muñoz, } \\
\text { violín; Cristián Gutiérrez, } \\
\text { violoncello; Alejandro } \\
\text { Ortiz, clarinete; } \\
\text { Pablo Aranda, director. }\end{array}$ \\
\hline Otondo, Felipe & $\begin{array}{l}\text { Pacifico (2010), } \\
\text { audiovisual/estéreo. }\end{array}$ & $13 / 10 / 2010$ & $\begin{array}{l}\text { X Festival } \\
\text { Internacional de } \\
\text { Música Electroacústica } \\
\text { Ai-Maako, Auditorio } \\
\text { Fundación Telefónica, } \\
\text { Santiago. }\end{array}$ & \\
\hline $\begin{array}{l}\text { Pájaro Araya, } \\
\text { Claudio }\end{array}$ & Mitimaes (2010) para guitarra. & $29 / 11 / 2010$ & $\begin{array}{l}\text { Prismas Festival } \\
\text { de Creación } \\
\text { Latinoamericana, } \\
\text { Proyecto Germina. } \\
\text { Cciones...Primaveras } \\
\text { latinoamericanas, } \\
\text { Universidad de } \\
\text { Valparaíso. }\end{array}$ & $\begin{array}{l}\text { Consort Guitarrístico de } \\
\text { Chile. }\end{array}$ \\
\hline \multirow[t]{3}{*}{$\begin{array}{l}\text { Parra Cancino, } \\
\text { Juan }\end{array}$} & $\begin{array}{l}\text { GeoAves (2008) para flauta } \\
\text { bassett y computadora. }\end{array}$ & $9 / 10 / 2010$ & $\begin{array}{l}\text { X Festival } \\
\text { Internacional de Música } \\
\text { Electroacústica Ai- } \\
\text { Maako, Teatro Municipal } \\
\text { Lord Cochrane, Valdivia. }\end{array}$ & \\
\hline & & $14 / 10 / 2010$ & $\begin{array}{l}\text { X Festival } \\
\text { Internacional de } \\
\text { Música Electroacústica } \\
\text { Ai-Maako, Auditorio } \\
\text { Fundación Telefónica, } \\
\text { Santiago. }\end{array}$ & \\
\hline & $\begin{array}{l}\text { KVSwalk_Solo (2010) para } \\
\text { computadora y medios } \\
\text { electrónicos. }\end{array}$ & $9 / 10 / 2010$ & $\begin{array}{l}\text { X Festival } \\
\text { Internacional de Música } \\
\text { Electroacústica Ai- } \\
\text { Maako, Teatro Municipal } \\
\text { Lord Cochrane, Valdivia. }\end{array}$ & \\
\hline \multirow[t]{2}{*}{ Parra, Violeta } & $\begin{array}{l}\text { Run run se fue pa'l norte (1966) } \\
\text { en versión de coro. }\end{array}$ & $5 / 10 / 2010$ & $\begin{array}{l}\text { Aula Magna Universidad } \\
\text { de Santiago de Chile. }\end{array}$ & $\begin{array}{l}\text { Coro de Cámara de la } \\
\text { UPLA, Carlos Hernández, } \\
\text { director. }\end{array}$ \\
\hline & $\begin{array}{l}\text { La jardinera (1950-1954) en } \\
\text { versión de coro. }\end{array}$ & $7 / 10 / 2010$ & $\begin{array}{l}\text { Aula Magna de la } \\
\text { Universidad de de } \\
\text { USACH. }\end{array}$ & $\begin{array}{l}\text { Coro de la USACH, } \\
\text { Santiago Marín, director. }\end{array}$ \\
\hline
\end{tabular}




\begin{tabular}{|c|c|c|c|c|}
\hline $\begin{array}{l}\text { Nombre del } \\
\text { Compositor }\end{array}$ & Titulo de la obra & $\begin{array}{l}\text { Fecha de } \\
\text { Interpretación }\end{array}$ & Lugar & Intérpretes \\
\hline & \multirow[t]{3}{*}{ Gracias a la vida (1966). } & $14 / 10 / 2010$ & $\begin{array}{l}\text { Festival Internacional } \\
\text { Cervantino de } \\
\text { Guanajuato, México. }\end{array}$ & $\begin{array}{l}\text { BAFONA, Leticia } \\
\text { Lizama, directora. }\end{array}$ \\
\hline & & $22 / 11 / 2010$ & $\begin{array}{l}\text { Semana de la Música, } \\
\text { Sala América de la } \\
\text { Biblioteca Nacional. }\end{array}$ & $\begin{array}{l}\text { Orquesta Sinfónica } \\
\text { Infantil y Juvenil de San } \\
\text { Miguel, Israel Olivares, } \\
\text { director; Fanny Maturana, } \\
\text { piano. }\end{array}$ \\
\hline & & $22 / 11 / 2010$ & $\begin{array}{l}\text { Sala América de la } \\
\text { Biblioteca Nacional. }\end{array}$ & $\begin{array}{l}\text { Coro Estudiantil de } \\
\text { la UMCE, Guillermo } \\
\text { Vergara, director. }\end{array}$ \\
\hline & Volver a los diecisiete (1966). & $14 / 10 / 2010$ & $\begin{array}{l}\text { Festival Internacional } \\
\text { Cervantino de } \\
\text { Guanajuato, México, }\end{array}$ & BAFONA \\
\hline & \multirow[t]{2}{*}{$\begin{array}{l}\text { Cinco Anticuecas (ca.1957) para } \\
\text { guitarra. }\end{array}$} & $20 / 10 / 2010$ & $\begin{array}{l}\text { Ciclo Guitarrístico, } \\
\text { Instituto Cervantes } \\
\text { de Manchester, Reino } \\
\text { Unido. }\end{array}$ & $\begin{array}{l}\text { Mauricio Valdebenito, } \\
\text { guitarra. }\end{array}$ \\
\hline & & $21 / 10 / 2010$ & $\begin{array}{l}\text { Universidad John Moores } \\
\text { de Liverpool, Reino } \\
\text { Unido. }\end{array}$ & $\begin{array}{l}\text { Mauricio Valdebenito, } \\
\text { guitarra. }\end{array}$ \\
\hline & \multirow[t]{2}{*}{$\begin{array}{l}\text { Qué he sacado con quererte } \\
\text { (1964-1965) en versión de coro } \\
\text { y piano. }\end{array}$} & $21 / 10 / 2010$ & $\begin{array}{l}\text { Santuario de la } \\
\text { Innmaculada Concepción, } \\
\text { La Granja. }\end{array}$ & $\begin{array}{l}\text { Coro de la USACH, } \\
\text { Santiago Marín, director; } \\
\text { Patricio Valenzuela, piano }\end{array}$ \\
\hline & & $30 / 10 / 2010$ & $\begin{array}{l}\text { XVII Festival Nacional } \\
\text { de Coros de Chile, San } \\
\text { Antonio. }\end{array}$ & $\begin{array}{l}\text { Coro de la USACH, } \\
\text { Santiago Marín, director; } \\
\text { Patricio Valenzuela, piano }\end{array}$ \\
\hline & $\begin{array}{l}\text { Anticueca } \mathrm{N}^{0} 1 \text { (ca. 1957), } \\
\text { Anticueca } \mathrm{N}^{0} 2(\text { ca. 1957), } \\
\text { Anticueca } \mathrm{N}^{\circ} 5 \text { (ca.1957) para } \\
\text { guitarra. }\end{array}$ & $29 / 10 / 2010$ & $\begin{array}{l}\text { XXVII Temporada, } \\
\text { Veladas Musicales } \\
\text { del Goethe Institut, } \\
\text { Concepción, Aula } \\
\text { Magna de la Universidad } \\
\text { Católica de la Santísima } \\
\text { Concepción. }\end{array}$ & $\begin{array}{l}\text { Mauricio Valdebenito, } \\
\text { guitarra. }\end{array}$ \\
\hline & $\begin{array}{l}\text { El gavilán (1959) para voz } \\
\text { femenina, charango y guitarra. }\end{array}$ & $29 / 10 / 2010$ & $\begin{array}{l}\text { Concierto de Música } \\
\text { Latinoamericana, } \\
\text { Instituto Chileno-Alemán } \\
\text { de Concepción, Aula } \\
\text { Magna de la Universidad } \\
\text { Católica de la Santísima } \\
\text { Concepción. }\end{array}$ & $\begin{array}{l}\text { Madgalena Matthey, voz; } \\
\text { Omar Ponce, charango, } \\
\text { Mauricio Valdebenito, } \\
\text { guitarra. }\end{array}$ \\
\hline $\begin{array}{l}\text { Parra Violeta/ } \\
\text { Eduardo Vila }\end{array}$ & Casamiento de negros (1953) & $22 / 11 / 2010$ & $\begin{array}{l}\text { Sala América de la } \\
\text { Biblioteca Nacional. }\end{array}$ & $\begin{array}{l}\text { Coro Estudiantil de } \\
\text { la UMCE, Guillermo } \\
\text { Vergara, director. }\end{array}$ \\
\hline $\begin{array}{l}\text { Parra Violeta/ } \\
\text { Luis Advis }\end{array}$ & $\begin{array}{l}\text { El amor (2006) arreglo para coro } \\
\text { femenino de Fernando Ortiz. }\end{array}$ & $18 / 10 / 2010$ & $\begin{array}{l}\text { Sala de Eventos Codelco, } \\
\text { Santiago. }\end{array}$ & $\begin{array}{l}\text { Coral Femenina Viña del } \\
\text { Mar, Jessica Quezada, } \\
\text { directora. }\end{array}$ \\
\hline
\end{tabular}




\begin{tabular}{|c|c|c|c|c|}
\hline $\begin{array}{l}\text { Nombre del } \\
\text { Compositor }\end{array}$ & Titulo de la obra & $\begin{array}{l}\text { Fecha de } \\
\text { Interpretación }\end{array}$ & Lugar & Intérpretes \\
\hline Pedrotti, Italo & $\begin{array}{l}\text { Vuelo de pájaros (1990), versión } \\
\text { para charango y guitarra. }\end{array}$ & $29 / 10 / 2010$ & $\begin{array}{l}\text { XXVII Temporada, } \\
\text { Veladas Musicales } \\
\text { del Goethe Institut, } \\
\text { Concepción, Aula } \\
\text { Magna de la Universidad } \\
\text { Católica de la Santísima } \\
\text { Concepción. }\end{array}$ & $\begin{array}{l}\text { Omar Ponce, charango; } \\
\text { Mauricio Valdebenito, } \\
\text { guitarra. }\end{array}$ \\
\hline $\begin{array}{l}\text { Peña Herrera, } \\
\text { Jorge }\end{array}$ & $\begin{array}{l}\text { **Lucero del atardecer }(2010) \\
\text { para clarinete, saxofón, trombón, } \\
\text { piano, viola, contrabajo. }\end{array}$ & $30 / 11 / 2010$ & $\begin{array}{l}\text { Prismas Festival } \\
\text { de Creación } \\
\text { Latinoamericana, } \\
\text { Proyecto Germina. } \\
\text { Cciones...Primaveras } \\
\text { latinoamericanas, GAM. }\end{array}$ & $\begin{array}{l}\text { Copiuensamble: Francisco } \\
\text { San Ramín, clarinete; } \\
\text { David Espinoza, saxofón; } \\
\text { Héctor Beldar, trombón; } \\
\text { Emilio Ovalle, piano; } \\
\text { Cynthia Díaz, viola; } \\
\text { Héctor Leyton, contrabajo; } \\
\text { Sebastián Ramírez, } \\
\text { director. }\end{array}$ \\
\hline \multirow[t]{4}{*}{$\begin{array}{l}\text { Pepi-Alos, } \\
\text { Jorge y Andrés } \\
\text { Ferrari }\end{array}$} & $\begin{array}{l}\text { Gadara (2010) para ensamble y } \\
\text { electrónica en tiempo real. }\end{array}$ & $8 / 10 / 2010$ & $\begin{array}{l}\text { Sala Isidora Zegers, } \\
\text { Facultad de Artes, } \\
\text { Universidad de Chile. }\end{array}$ & $\begin{array}{l}\text { Compañía de Música } \\
\text { Contemporánea, } \\
\text { María Fernanda Espinoza, } \\
\text { violín; Roberto Cisternas, } \\
\text { flauta; Cláudio Vasquez, } \\
\text { clarinete; Violeta Mura, } \\
\text { violoncello; Pedro } \\
\text { Portales, saxofón; } \\
\text { Fabián Esparza, violín- } \\
\text { viola; Andrés Ferrari } \\
\text { y electrónica; Carlos } \\
\text { Valenzuela, director. }\end{array}$ \\
\hline & & $29 / 10 / 2010$ & Goethe Institut, Santiago. & $\begin{array}{l}\text { Compañía de Música } \\
\text { Contemporánea, } \\
\text { María Fernanda Espinoza, } \\
\text { violín; Roberto Cisternas, } \\
\text { flauta; Cláudio Vasquez, } \\
\text { clarinete; Violeta Mura, } \\
\text { violoncello; Pedro } \\
\text { Portales, saxofón; } \\
\text { Fabián Esparza, violín- } \\
\text { viola; Andrés Ferrari, } \\
\text { electrónica; Carlos } \\
\text { Valenzuela, director. }\end{array}$ \\
\hline & & $12 / 01 / 2011$ & $\begin{array}{l}\text { XI Festival de Música } \\
\text { Contemporánea de la } \\
\text { Universidad de Chile, } \\
\text { Facultad de Artes, Sala } \\
\text { Isidora Zegers. }\end{array}$ & $\begin{array}{l}\text { Compañía de Música } \\
\text { Contemporánea, } \\
\text { Carlos Valenzuela, } \\
\text { director. }\end{array}$ \\
\hline & $\begin{array}{l}\text { *Esse Est Percipi (2010) para } \\
\text { flauta, clarinete, dos violines, } \\
\text { violoncello, percusión y piano. }\end{array}$ & $8 / 11 / 2010$ & $\begin{array}{l}\text { XX Festival de Música } \\
\text { Contemporánea, PUC, } \\
\text { Sala GAM. }\end{array}$ & $\begin{array}{l}\text { Ensamble Contemporáneo, } \\
\text { Aliocha Solovera, } \\
\text { director; Jorge Pepi Alos, } \\
\text { piano. }\end{array}$ \\
\hline
\end{tabular}




\begin{tabular}{|c|c|c|c|c|}
\hline $\begin{array}{l}\text { Nombre del } \\
\text { Compositor }\end{array}$ & Titulo de la obra & $\begin{array}{l}\text { Fecha de } \\
\text { Interpretación }\end{array}$ & Lugar & Intérpretes \\
\hline \multirow[t]{2}{*}{$\begin{array}{l}\text { Peralta, } \\
\text { Alejandro }\end{array}$} & \multirow[t]{2}{*}{$\begin{array}{l}\text { Canción y Ostinato (2010) para } \\
\text { guitarra. }\end{array}$} & $28 / 10 / 2010$ & $\begin{array}{l}\text { Sala Isidora Zegers, } \\
\text { Facultad de Artes, } \\
\text { Universidad de Chile. }\end{array}$ & Italo Accini, guitarra. \\
\hline & & $29 / 10 / 2010$ & $\begin{array}{l}\text { Auditorium Cirilo } \\
\text { Vila, Facultad de Artes, } \\
\text { Universidad de Chile. }\end{array}$ & $\begin{array}{l}\text { Moisés Bobadilla, } \\
\text { guitarra. }\end{array}$ \\
\hline Pérez, Carlos & $\begin{array}{l}\text { Tres piezas chilenas (refalosa, } \\
\text { entonación y cueca) (2009) para } \\
\text { cuarteto de guitarras. }\end{array}$ & $6 / 12 / 2010$ & $\begin{array}{l}\text { Sala América de la } \\
\text { Biblioteca Nacional. }\end{array}$ & $\begin{array}{l}\text { Cuarteto Universitario } \\
\text { de Guitarras del } \\
\text { Departamento de Música } \\
\text { de la UMCE, María Luz } \\
\text { López, directora. }\end{array}$ \\
\hline \multirow[t]{3}{*}{$\begin{array}{l}\text { Peréz Freire, } \\
\text { Osman }\end{array}$} & $\begin{array}{l}\text { Ay ay ay (1937) en versión para } \\
\text { soprano y orquesta ssinfónica. }\end{array}$ & $11 / 10 / 2010$ & $\begin{array}{l}\text { Parque Bustamante, } \\
\text { Instituto Cultural de } \\
\text { Providencia. }\end{array}$ & $\begin{array}{l}\text { Orquesta Sinfónica } \\
\text { de Chile, David Levi, } \\
\text { director; Cristina } \\
\text { Gallardo-Domâs, soprano. }\end{array}$ \\
\hline & $\begin{array}{l}\text { Copihues rojos (1940) en versión } \\
\text { para soprano y orquesta sinfónica. }\end{array}$ & $\begin{array}{l}11,12 \\
13 / 10 / 2010\end{array}$ & $\begin{array}{l}\text { Parque Bustamante, } \\
\text { Instituto Cultural de } \\
\text { Providencia. }\end{array}$ & $\begin{array}{l}\text { Orquesta Sinfónica } \\
\text { de Chile, David Levi, } \\
\text { director; Cristina } \\
\text { Gallardo-Domâs, soprano. }\end{array}$ \\
\hline & $\begin{array}{l}\text { La tranquera- canción (1937) } \\
\text { para guitarra. }\end{array}$ & $16 / 12 / 2010$ & $\begin{array}{l}\text { I Jornadas Guitarrísticas } \\
\text { de Coquimbo, Casa de la } \\
\text { Cultura, Coquimbo. }\end{array}$ & Ricardo Acevedo, guitarra. \\
\hline $\begin{array}{l}\text { Pérez Massad, } \\
\text { Tomás }\end{array}$ & $\begin{array}{l}\text { **Viento nortino (2010) para } \\
\text { guitarra. }\end{array}$ & $3 / 12 / 2010$ & $\begin{array}{l}\text { Prismas Festival } \\
\text { de Creación } \\
\text { Latinoamericana, } \\
\text { Proyecto Germina. } \\
\text { Cciones...Primaveras } \\
\text { latinoamericanas, GAM. }\end{array}$ & Rael Valencia, guitarra. \\
\hline Pertout, Adrián & $\begin{array}{l}\text { Le petit Agneau (2009) } \\
\text { composición para medios } \\
\text { electroacústicos. }\end{array}$ & $13 / 10 / 2010$ & $\begin{array}{l}\text { X Festival } \\
\text { Internacional de } \\
\text { Música Electroacústica } \\
\text { Ai-Maako, Auditorio } \\
\text { Fundación Telefónica, } \\
\text { Santiago. }\end{array}$ & \\
\hline \multirow[t]{2}{*}{$\begin{array}{l}\text { Pinto d'Aguiar } \\
\text { Montt, Felipe }\end{array}$} & \multirow[t]{2}{*}{$\begin{array}{l}\text { Litoral (2010) para conjunto de } \\
\text { guitarras. }\end{array}$} & $13 / 10 / 2010$ & $\begin{array}{l}\text { VII Festival } \\
\text { Internacional de Música } \\
\text { Contemporánea Darwin } \\
\text { Vargas, Instituto de } \\
\text { Música de la PUCV. }\end{array}$ & $\begin{array}{l}\text { Consort Guitarrístico de } \\
\text { Chile. }\end{array}$ \\
\hline & & $29 / 11 / 2010$ & $\begin{array}{l}\text { Prismas Festival } \\
\text { de Creación } \\
\text { Latinoamericana, } \\
\text { Proyecto Germina. } \\
\text { Cciones...Primaveras } \\
\text { latinoamericanas, } \\
\text { Universidad de } \\
\text { Valparaíso. }\end{array}$ & $\begin{array}{l}\text { Consort Guitarrístico de } \\
\text { Chile. }\end{array}$ \\
\hline
\end{tabular}




\begin{tabular}{|c|c|c|c|c|}
\hline $\begin{array}{l}\text { Nombre del } \\
\text { Compositor }\end{array}$ & Titulo de la obra & $\begin{array}{l}\text { Fecha de } \\
\text { Interpretación }\end{array}$ & Lugar & Intérpretes \\
\hline \multirow[t]{3}{*}{$\begin{array}{l}\text { Ponce Valdivia, } \\
\text { Omar }\end{array}$} & $\begin{array}{l}\text { Flor y espina (huayno altiplánico) } \\
\text { (2002) para charango. }\end{array}$ & $29 / 10 / 2010$ & $\begin{array}{l}\text { XXVII Temporada, } \\
\text { Veladas Musicales } \\
\text { del Goethe Institut, } \\
\text { Concepción, Aula } \\
\text { Magna de la Universidad } \\
\text { Católica de la Santísima } \\
\text { Concepción. }\end{array}$ & Omar Ponce, charango. \\
\hline & $\begin{array}{l}\text { Libre golondrina (2004) para } \\
\text { charango. }\end{array}$ & $29 / 10 / 2010$ & $\begin{array}{l}\text { XXVII Temporada, } \\
\text { Veladas Musicales } \\
\text { del Goethe Institut, } \\
\text { Concepción, Aula } \\
\text { Magna de la Universidad } \\
\text { Católica de la Santísima } \\
\text { Concepción. }\end{array}$ & Omar Ponce, charango. \\
\hline & $\begin{array}{l}\text { Sikurmarka (pueblos de los } \\
\text { Sikuris) Sikuri y Kacharpaya } \\
\text { (2009) para charango. }\end{array}$ & $29 / 10 / 2010$ & $\begin{array}{l}\text { XXVII Temporada, } \\
\text { Veladas Musicales } \\
\text { del Goethe Institut, } \\
\text { Concepción, Aula } \\
\text { Magna de la Universidad } \\
\text { Católica de la Santísima } \\
\text { Concepción. }\end{array}$ & Omar Ponce, charango. \\
\hline Pozo, Javier & $\begin{array}{l}\text { A la búsqueda del ocaso infinito } \\
\text { (2010) para piano. }\end{array}$ & $17 / 10 / 2010$ & $\begin{array}{l}\text { VII Festival } \\
\text { Internacional de Música } \\
\text { Contemporánea Darwin } \\
\text { Vargas, Instituto de } \\
\text { Música de la PUCV. }\end{array}$ & Alexandra Aubert, piano. \\
\hline $\begin{array}{l}\text { Puelma, } \\
\text { Roberto }\end{array}$ & $\begin{array}{l}\text { *Concierto (1940) para violín y } \\
\text { orquesta. }\end{array}$ & 15 y $16 / 10 / 2010$ & $\begin{array}{l}\text { Teatro de la Universidad } \\
\text { de Chile. }\end{array}$ & $\begin{array}{l}\text { Orquesta Sinfónica de } \\
\text { Chile, Francisco Rettig, } \\
\text { director; Alberto Dourthé, } \\
\text { violín. }\end{array}$ \\
\hline $\begin{array}{l}\text { Rafart Arruyo, } \\
\text { Francisco }\end{array}$ & $\begin{array}{l}\text { **Inefable (2010) para conjunto } \\
\text { instrumental. }\end{array}$ & $4 / 12 / 2010$ & $\begin{array}{l}\text { Prismas Festival } \\
\text { de Creación } \\
\text { Latinoamericana, } \\
\text { Proyecto Germina. } \\
\text { Cciones...Primaveras } \\
\text { latinoamericanas, GAM. }\end{array}$ & $\begin{array}{l}\text { Ensamble Colectivo Los } \\
\text { Musicantes: } \\
\text { Patricio Huerta, saxo } \\
\text { alto; Moris Al Alam, saxo } \\
\text { tenor, Pablo Jara, saxo } \\
\text { barítono; Felipe Machuca, } \\
\text { trompeta; Felipe Castillo, } \\
\text { trompeta; Ignacio Valle, } \\
\text { trombón; César Veas, } \\
\text { guitarra eléctrica; Claudio } \\
\text { Carrasco, batería; Felipe } \\
\text { Lolas, piano; Fabián } \\
\text { Aguilera, bajo eléctrico; } \\
\text { Sebastián Errazuriz, } \\
\text { director. }\end{array}$ \\
\hline $\begin{array}{l}\text { Ramírez, } \\
\text { Hernán }\end{array}$ & Trío No3 op. 138 (2008). & $17 / 10 / 2010$ & $\begin{array}{l}\text { VII Festival } \\
\text { Internacional de Música } \\
\text { Contemporánea Darwin } \\
\text { Vargas, Instituto de } \\
\text { Música de la PUCV. }\end{array}$ & $\begin{array}{l}\text { Trío Clásico: Cristián } \\
\text { González, violín; Eduardo } \\
\text { Simpson, violoncello y } \\
\text { Alexandra Aubert, piano. }\end{array}$ \\
\hline
\end{tabular}




\begin{tabular}{|c|c|c|c|c|}
\hline $\begin{array}{l}\text { Nombre del } \\
\text { Compositor }\end{array}$ & Titulo de la obra & $\begin{array}{l}\text { Fecha de } \\
\text { Interpretación }\end{array}$ & Lugar & Intérpretes \\
\hline & $\begin{array}{l}\text { *Catarsis op.106 (1997) para } \\
\text { orquesta sinfónica. }\end{array}$ & $22 / 10 / 2010$ & $\begin{array}{l}\text { Teatro Municipal de La } \\
\text { Serena. }\end{array}$ & $\begin{array}{l}\text { Orquesta Sinfónica de la } \\
\text { Universidad de La Serena, } \\
\text { David Handel, director } \\
\text { invitado. }\end{array}$ \\
\hline $\begin{array}{l}\text { Ramírez } \\
\text { Zamorano, } \\
\text { Sebastián }\end{array}$ & $\begin{array}{l}\text { **Nuestro reencuentro }(2010) \\
\text { para clarinete, saxofón, viola, } \\
\text { trombón, piano, contrabajo. }\end{array}$ & $30 / 11 / 2010$ & $\begin{array}{l}\text { Prismas Festival } \\
\text { de Creación } \\
\text { Latinoamericana, } \\
\text { Proyecto Germina. } \\
\text { Cciones...Primaveras } \\
\text { latinoamericanas, GAM. }\end{array}$ & $\begin{array}{l}\text { Copiuensamble: Francisco } \\
\text { San Ramín, clarinete; } \\
\text { David Espinoza, saxofón; } \\
\text { Héctor Beldar, trombón; } \\
\text { Emilio Ovalle, piano; } \\
\text { Cynthia Díaz, viola; } \\
\text { Héctor Leyton, contrabajo; } \\
\text { Sebastián Ramírez, } \\
\text { director. }\end{array}$ \\
\hline \multirow[t]{3}{*}{$\begin{array}{l}\text { Rañilao, } \\
\text { Francisco }\end{array}$} & $\begin{array}{l}\text { Fuerzas naturales (2010) para } \\
\text { flauta y conjunto. }\end{array}$ & $29 / 10 / 2010$ & Goethe Institut, Santiago. & $\begin{array}{l}\text { Compañía de Música } \\
\text { Contemporánea: } \\
\text { María Fernanda Espinoza, } \\
\text { violín: Roberto Cisternas, } \\
\text { flauta; Claudio Vasquez, } \\
\text { clarinete; Violeta Mura, } \\
\text { violoncello; Simone } \\
\text { Caiafa, percusión, Esteban } \\
\text { Ravanal, piano; Fabián } \\
\text { Esparza, violín-viola; } \\
\text { Carlos Valenzuela Ramos, } \\
\text { director. }\end{array}$ \\
\hline & & $9 / 11 / 2010$ & $\begin{array}{l}\text { XX Festival de Música } \\
\text { Contemporánea, PUC, } \\
\text { Sala GAM. }\end{array}$ & $\begin{array}{l}\text { Compañía de Música } \\
\text { Contemporánea, } \\
\text { Carlos Valenzuela Ramos, } \\
\text { director. }\end{array}$ \\
\hline & & $12 / 01 / 2011$ & $\begin{array}{l}\text { XI Festival de Música } \\
\text { Contemporánea de la } \\
\text { Universidad de Chile, } \\
\text { Facultad de Artes, Sala } \\
\text { Isidora Zegers. }\end{array}$ & $\begin{array}{l}\text { Compañía de Música } \\
\text { Contemporánea, Carlos } \\
\text { Valenzuela, director. }\end{array}$ \\
\hline $\begin{array}{l}\text { Recabarren, } \\
\text { Natalie }\end{array}$ & $\begin{array}{l}\text { Wünelfe ül (Romanceada del } \\
\text { lucero), Llamekán (2005) para } \\
\text { voz y trompes. }\end{array}$ & $18 / 10 / 2010$ & $\begin{array}{l}\text { Sala de Eventos Codelco, } \\
\text { Santiago. }\end{array}$ & $\begin{array}{l}\text { Coral Femenina Viña del } \\
\text { Mar, Jessica Quezada, } \\
\text { directora; Alejandra } \\
\text { Solís, Marcelle Orellana } \\
\text { y Valentina Chamorro, } \\
\text { trompes. }\end{array}$ \\
\hline Reyes, Enrique & $\begin{array}{l}\text { Waifai (2010) para piano y } \\
\text { músico-actor. }\end{array}$ & $15 / 10 / 2010$ & $\begin{array}{l}\text { VII Festival } \\
\text { Internacional de Música } \\
\text { Contemporánea Darwin } \\
\text { Vargas, Instituto de } \\
\text { Música de la PUCV. }\end{array}$ & $\begin{array}{l}\text { Patricia Escobar, piano; } \\
\text { Enrique Reyes, músico- } \\
\text { actor. }\end{array}$ \\
\hline \multirow[t]{2}{*}{$\begin{array}{l}\text { Rodríguez, } \\
\text { Felipe }\end{array}$} & $\begin{array}{l}\text { "Estudio (2010) para piano y } \\
\text { electrónica en vivo. }\end{array}$ & $22 / 10 / 2010$ & Goethe Institut, Santiago. & $\begin{array}{l}\text { Danilo Rodríguez, piano; } \\
\text { Diego Ridolfi, electrónica. }\end{array}$ \\
\hline & $\begin{array}{l}\text { *Estudio (2010) para viola de } \\
\text { gamba y electrónica en vivo. }\end{array}$ & $22 / 10 / 2010$ & Goethe Institut, Santiago. & $\begin{array}{l}\text { Felipe Rodríguez, viola } \\
\text { da gamba; Diego Ridolfi, } \\
\text { electrónica. }\end{array}$ \\
\hline
\end{tabular}




\begin{tabular}{|c|c|c|c|c|}
\hline $\begin{array}{l}\text { Nombre del } \\
\text { Compositor }\end{array}$ & Titulo de la obra & $\begin{array}{l}\text { Fecha de } \\
\text { Interpretación }\end{array}$ & Lugar & Intérpretes \\
\hline & & $26 / 10 / 2010$ & $\begin{array}{l}\text { Campos abiertos, Sede } \\
\text { Las Encinas, ciclo de } \\
\text { conciertos, Facultad de } \\
\text { Artes, Universidad de } \\
\text { Chile. }\end{array}$ & $\begin{array}{l}\text { Felipe Rodríguez, viola } \\
\text { da gamba; Diego Ridolfi, } \\
\text { electrónica. }\end{array}$ \\
\hline \multirow[t]{4}{*}{$\begin{array}{l}\text { Rosenmann } \\
\text { Taub, Mauricio }\end{array}$} & $\begin{array}{l}\text { *Madam Czerny }(2007-2008) \\
\text { para piano. }\end{array}$ & $20 / 03 / 2010$ & $\begin{array}{l}\text { "Neue Musik für } \\
\text { eine Metropole"/ } \\
\text { "Kulturhauptstadt Europa } \\
\text { RUHR" } \\
\text { Recklinghausen, } \\
\text { Bürgerhaus Süd, } \\
\text { Alemania. }\end{array}$ & $\begin{array}{l}\text { Martin von der Heydt, } \\
\text { piano. }\end{array}$ \\
\hline & & $5 / 09 / 2010$ & $\begin{array}{l}\text { Centro Evangélico de } \\
\text { Remagen-Oberwinter, } \\
\text { Alemania. }\end{array}$ & Nenad Lecic, piano. \\
\hline & & 19/09/2010 & $\begin{array}{l}\text { Bechstein-Centrum de } \\
\text { Düsseldorf/Stilwerk }\end{array}$ & $\begin{array}{l}\text { Martin von der Heydt, } \\
\text { piano. }\end{array}$ \\
\hline & & $26 / 11 / 2010$ & $\begin{array}{l}\text { Museo Folkwang de } \\
\text { Essen. }\end{array}$ & $\begin{array}{l}\text { Martin von der Heydt, } \\
\text { piano. }\end{array}$ \\
\hline \multirow[t]{3}{*}{$\begin{array}{l}\text { Salinas, } \\
\text { Horacio }\end{array}$} & $\begin{array}{l}\text { Suite del tiempo ausente (1987) } \\
\text { para guitarra. }\end{array}$ & $20 / 10 / 2010$ & $\begin{array}{l}\text { Ciclo Guitarrístico, } \\
\text { Instituto Cervantes } \\
\text { de Manchester, Reino } \\
\text { Unido. }\end{array}$ & $\begin{array}{l}\text { Mauricio Valdebenito, } \\
\text { guitarra. }\end{array}$ \\
\hline & & $21 / 10 / 2010$ & $\begin{array}{l}\text { Universidad John Moores } \\
\text { de Liverpool, Reino } \\
\text { Unido. }\end{array}$ & $\begin{array}{l}\text { Mauricio Valdebenito, } \\
\text { guitarra. }\end{array}$ \\
\hline & Danza en tres tiempos (1988). & $29 / 10 / 2010$ & $\begin{array}{l}\text { XXVII Temporada, } \\
\text { Veladas Musicales } \\
\text { del Goethe Institut, } \\
\text { Concepción, Aula } \\
\text { Magna de la Universidad } \\
\text { Católica de la Santísima } \\
\text { Concepción. }\end{array}$ & $\begin{array}{l}\text { Mauricio Valdebenito, } \\
\text { guitarra. }\end{array}$ \\
\hline \multirow[t]{8}{*}{$\begin{array}{l}\text { Sánchez, Juan } \\
\text { Antonio }\end{array}$} & Tonada por despedida (2002). & $12 / 10 / 2010$ & $\begin{array}{l}\text { Teatro Municipal de } \\
\text { Moron, Argentina. }\end{array}$ & $\begin{array}{l}\text { Romilio Orellana, } \\
\text { guitarra. }\end{array}$ \\
\hline & & $13 / 10 / 2010$ & $\begin{array}{l}\text { Auditorio Juan Victoria } \\
\text { de San Juan, Argentina. }\end{array}$ & $\begin{array}{l}\text { Romilio Orellana, } \\
\text { guitarra. }\end{array}$ \\
\hline & & $14 / 10 / 2010$ & $\begin{array}{l}\text { Salón la Candela en } \\
\text { Angaco, Argentina. }\end{array}$ & $\begin{array}{l}\text { Romilio Orellana, } \\
\text { guitarra. }\end{array}$ \\
\hline & & $15 / 10 / 2010$ & $\begin{array}{l}\text { Sala Cervantes en Junín, } \\
\text { Argentina. }\end{array}$ & $\begin{array}{l}\text { Romilio Orellana, } \\
\text { guitarra. }\end{array}$ \\
\hline & & $16 / 10 / 2010$ & $\begin{array}{l}\text { Sala Elina Alba en } \\
\text { Mendoza, Argentina. }\end{array}$ & $\begin{array}{l}\text { Romilio Orellana, } \\
\text { guitarra. }\end{array}$ \\
\hline & & $17 / 10 / 2010$ & $\begin{array}{l}\text { Berazategui, Buenos } \\
\text { Aires, Argentina. }\end{array}$ & $\begin{array}{l}\text { Romilio Orellana, } \\
\text { guitarra. }\end{array}$ \\
\hline & & $19 / 11 / 2010$ & $\begin{array}{l}\text { Centro de Extensión de } \\
\text { la Universidad Católica } \\
\text { del Maule. }\end{array}$ & Ensamble Serenata. \\
\hline & & $20 / 11 / 2010$ & $\begin{array}{l}\text { Salón Balmaceda de } \\
\text { Linares. }\end{array}$ & Ensamble Serenata. \\
\hline
\end{tabular}




\begin{tabular}{|c|c|c|c|c|}
\hline $\begin{array}{l}\text { Nombre del } \\
\text { Compositor }\end{array}$ & Titulo de la obra & $\begin{array}{l}\text { Fecha de } \\
\text { Interpretación }\end{array}$ & Lugar & Intérpretes \\
\hline & \multirow{3}{*}{ Cueca yuxtapuesta para guitarra. } & $21 / 11 / 2010$ & $\begin{array}{l}\text { Teatro Municipal de San } \\
\text { Clemente }\end{array}$ & Ensamble Serenata. \\
\hline & & $13 / 10 / 2010$ & $\begin{array}{l}\text { Auditorio Juan Victoria } \\
\text { de San Juan, Argentina. }\end{array}$ & $\begin{array}{l}\text { Romilio Orellana, } \\
\text { guitarra. }\end{array}$ \\
\hline & & $14 / 10 / 2010$ & $\begin{array}{l}\text { Salón la Candela en } \\
\text { Angaco, Argentina. }\end{array}$ & $\begin{array}{l}\text { Romilio Orellana, } \\
\text { guitarra. }\end{array}$ \\
\hline & \multirow{4}{*}{$\begin{array}{l}\text { El plazo del ángel (2002) para } \\
\text { guitarra. }\end{array}$} & $15 / 10 / 2010$ & $\begin{array}{l}\text { Sala Cervantes en Junín, } \\
\text { Argentina. }\end{array}$ & $\begin{array}{l}\text { Romilio Orellana, } \\
\text { guitarra. }\end{array}$ \\
\hline & & $16 / 10 / 2010$ & $\begin{array}{l}\text { Sala Elina Alba en } \\
\text { Mendoza, Argentina. }\end{array}$ & $\begin{array}{l}\text { Romilio Orellana, } \\
\text { guitarra. }\end{array}$ \\
\hline & & $29 / 10 / 2010$ & $\begin{array}{l}\text { Auditorium Cirilo Vila, } \\
\text { Facultad de Artes, } \\
\text { Universidad de Chile. }\end{array}$ & Xavier Barrera, guitarra. \\
\hline & & $29 / 10 / 2010$ & $\begin{array}{l}\text { XXVII Temporada, } \\
\text { Veladas Musicales } \\
\text { del Goethe Institut, } \\
\text { Concepción, Aula } \\
\text { Magna de la Universidad } \\
\text { Católica de la Santísima } \\
\text { Concepción. }\end{array}$ & $\begin{array}{l}\text { Mauricio Valdebenito, } \\
\text { guitarra. }\end{array}$ \\
\hline & $\begin{array}{l}\text { *Rin del adiós (2010) para dúo } \\
\text { de guitarras. }\end{array}$ & $22 / 01 / 2011$ & $\begin{array}{l}\text { Teatro de la Universidad } \\
\text { de Chile. }\end{array}$ & Dúo Orellana \& Orlandini. \\
\hline & $\begin{array}{l}\text { *Sirilla del nuevo día (2010) para } \\
\text { dúo de guitarras. }\end{array}$ & $22 / 01 / 2011$ & $\begin{array}{l}\text { Teatro de la Universidad } \\
\text { de Chile. }\end{array}$ & Dúo Orellana \& Orlandini. \\
\hline Sandoval, Aina & $\begin{array}{l}\text { **Corre que te pillo (2010) para } \\
\text { violín. }\end{array}$ & $3 / 12 / 2010$ & $\begin{array}{l}\text { Prismas Festival } \\
\text { de Creación } \\
\text { Latinoamericana, } \\
\text { Proyecto Germina. } \\
\text { Cciones...Primaveras } \\
\text { latinoamericanas, GAM. }\end{array}$ & Alvaro Meza, violín. \\
\hline \multirow[t]{2}{*}{$\begin{array}{l}\text { Santa Cruz, } \\
\text { Domingo }\end{array}$} & $\begin{array}{l}\text { Cinco piezas para orquesta de } \\
\text { cuerdas op. } 14 \text { (extracto), Grave } \\
\text { movido con sencillez, Inquieto y } \\
\text { doloroso, Algo movido (1937). }\end{array}$ & $15 / 11 / 2010$ & $\begin{array}{l}\text { Sala América de la } \\
\text { Biblioteca Nacional. }\end{array}$ & $\begin{array}{l}\text { Orquesta de Cámara del } \\
\text { Departamento de Música } \\
\text { de la UMCE, Daniel } \\
\text { Miranda, director. }\end{array}$ \\
\hline & $\begin{array}{l}\text { Preludios dramáticos (1946) para } \\
\text { orquesta. }\end{array}$ & 15 y $16 / 11 / 2010$ & $\begin{array}{l}\text { Teatro Municipal de } \\
\text { Santiago. }\end{array}$ & $\begin{array}{l}\text { Orquesta Filarmónica } \\
\text { de Santiago, Julio } \\
\text { Doggenweilwer, director. }\end{array}$ \\
\hline $\begin{array}{l}\text { Santibáñez, } \\
\text { Gonzalo }\end{array}$ & $\begin{array}{l}\text { **Monólogo (2010) para } \\
\text { contrabajo. }\end{array}$ & $4 / 12 / 2010$ & $\begin{array}{l}\text { Prismas Festival } \\
\text { de Creación } \\
\text { Latinoamericana, } \\
\text { Proyecto Germina. } \\
\text { Cciones...Primaveras } \\
\text { latinoamericanas, GAM. }\end{array}$ & $\begin{array}{l}\text { Francisca Moraga, } \\
\text { contrabajo. }\end{array}$ \\
\hline
\end{tabular}




\begin{tabular}{|c|c|c|c|c|}
\hline $\begin{array}{l}\text { Nombre del } \\
\text { Compositor }\end{array}$ & Titulo de la obra & $\begin{array}{l}\text { Fecha de } \\
\text { Interpretación }\end{array}$ & Lugar & Intérpretes \\
\hline Schuller, Karla & **lxl (2010) para coro fonético. & $4 / 12 / 2010$ & $\begin{array}{l}\text { Prismas Festival } \\
\text { de Creación } \\
\text { Latinoamericana, } \\
\text { Proyecto Germina. } \\
\text { Cciones...Primaveras } \\
\text { latinoamericanas, GAM. }\end{array}$ & $\begin{array}{l}\text { Coro Juan Bustamante: } \\
\text { Fernanda Campos, Carla } \\
\text { Gaete, Karla Güettner, } \\
\text { Pilar Lizama, José } \\
\text { Antonio Luna, Ramiro } \\
\text { Molina, Ricardo Muñoz, } \\
\text { Claudio Orellana, Camila } \\
\text { Pérez, Rodrigo Rivera, } \\
\text { Soledad Salinas. }\end{array}$ \\
\hline
\end{tabular}

\begin{tabular}{ll}
\hline Schumacher, & El espejo de Alicia (2009), \\
Federico & composición electroacústica.
\end{tabular}

$16 / 10 / 2010$

X Festival

Internacional de

Música Electroacústica

Ai-Maako, Auditorio

Fundación Telefónica, Santiago.

\begin{tabular}{ll}
\hline Silva Cruzatt, & ${ }^{* *}$ Efimer (2010) para flauta, \\
Lautaro & clarinete, violín, violoncello, \\
& piano.
\end{tabular}

$1 / 12 / 2010$

Prismas Festival

\section{de Creación}

Latinoamericana,

Proyecto Germina.

Cciones...Primaveras

latinoamericanas, GAM.

$\begin{array}{ll}26 \text { y 27/11/2010 } & \begin{array}{l}\text { Teatro de la Universidad } \\ \text { de Chile. }\end{array}\end{array}$

\begin{tabular}{ll}
\hline $\begin{array}{l}\text { Silva Ponce, } \\
\text { René }\end{array}$ & $\begin{array}{l}\text { **Tirana (2010) para tuba y } \\
\text { orquesta. }\end{array}$ \\
& \\
& **Pido venganza por el valiente!! \\
& (2010), texto Francisco Pezoa, \\
& para tenor, fagot, saxofón, \\
& percusión, piano, contrabajo.
\end{tabular}

$2 / 12 / 2010$ para tenor, fagot, saxofón, percusion, piano, contrabjo.
Prismas Festival de Creación Latinoamericana, Proyecto Germina. Cciones...Primaveras latinoamericanas, GAM.

\begin{tabular}{|c|c|c|c|c|}
\hline \multirow[t]{3}{*}{$\begin{array}{l}\text { Solovera, } \\
\text { Aliocha }\end{array}$} & $\begin{array}{l}\text { Blue Bubbles (2010) para } \\
\text { ensamble. }\end{array}$ & $23 / 10 / 2010$ & $\begin{array}{l}\text { Gallus Theater de } \\
\text { Frankfurt/Main, } \\
\text { Alemania. }\end{array}$ & $\begin{array}{l}\text { Ensamble Contemporáneo, } \\
\text { Aliocha Solovera, director. }\end{array}$ \\
\hline & & $28 / 10 / 2010$ & $\begin{array}{l}\text { Concierto-Bicentenario, } \\
\text { Sala Alte Feuerwache de } \\
\text { Colonia, Alemania. }\end{array}$ & $\begin{array}{l}\text { Ensamble Contemporáneo, } \\
\text { Aliocha Solovera, director. }\end{array}$ \\
\hline & $\begin{array}{l}\text { A cuatro (2006) para cuarteto de } \\
\text { saxofones. }\end{array}$ & $29 / 10 / 2010$ & $\begin{array}{l}\text { Sala Isidora Zegers, } \\
\text { Facultad de Artes, } \\
\text { Universidad de Chile. }\end{array}$ & $\begin{array}{l}\text { Isaías Zamorano, saxofón } \\
\text { alto; Fabián Morales, } \\
\text { saxofón alto;Gabriel } \\
\text { Barrios, saxofón tenor; } \\
\text { Marcos Contreras, saxofón } \\
\text { barítono. }\end{array}$ \\
\hline
\end{tabular}

\section{Copiuensamble: Natalia Martorelli, flauta; Alejandro Ortiz, clarinete;} Miguel Ángel Muñoz, violín; Isidora Edwards, violoncello; Fernanda Ortega, piano; Pablo Aranda, director. Orquesta Sinfónica de Chile, Michael Morgan, director; Carlos Herrera, tuba.

Copiuensamble: César Sepúlveda, tenor; Jorge Espinoza, fagot; Isaías Zamorano, saxofón; Nicolás Moreno, percusión, Joy Smith, piano; Carlos Arenas, contrabajo; René Silva P., director. 


\begin{tabular}{|c|c|c|c|c|}
\hline $\begin{array}{l}\text { Nombre del } \\
\text { Compositor }\end{array}$ & Titulo de la obra & $\begin{array}{l}\text { Fecha de } \\
\text { Interpretación }\end{array}$ & Lugar & Intérpretes \\
\hline Soro, Enrique & $\begin{array}{l}\text { Andante appassionato (1899) } \\
\text { para orquesta de cuerdas. }\end{array}$ & 7 y $9 / 12 / 2010$ & $\begin{array}{l}\text { Teatro Municipal de } \\
\text { Santiago. }\end{array}$ & $\begin{array}{l}\text { Orquesta Filarmónica de } \\
\text { Santiago, Rani Calderón, } \\
\text { director. }\end{array}$ \\
\hline Soto, Ignacio & Ktarsis (2010) para percusión. & $17 / 10 / 2010$ & $\begin{array}{l}\text { VII Festival } \\
\text { Internacional de Música } \\
\text { Contemporánea Darwin } \\
\text { Vargas, Instituto de } \\
\text { Música de la PUCV. }\end{array}$ & $\begin{array}{l}\text { Ensamble de Percusión } \\
\text { PUCV, José Díaz, director. }\end{array}$ \\
\hline Soublette, Silvia & $\begin{array}{l}\text { Lluvia (1945) para coro femenino, } \\
\text { texto Juana de Ibarbouru. }\end{array}$ & $18 / 10 / 2010$ & $\begin{array}{l}\text { Sala de Eventos Codelco, } \\
\text { Santiago. }\end{array}$ & $\begin{array}{l}\text { Coral Femenina Viña del } \\
\text { Mar, Jessica Quezada, } \\
\text { directora. }\end{array}$ \\
\hline $\begin{array}{l}\text { Springinsfeld, } \\
\text { Jorge }\end{array}$ & $\begin{array}{l}\text { Mambo (1996) para flauta y } \\
\text { piano. }\end{array}$ & $12 / 01 / 2011$ & $\begin{array}{l}\text { XI Festival de Música } \\
\text { Contemporánea de la } \\
\text { Universidad de Chile, } \\
\text { Facultad de Artes, Sala } \\
\text { Isidora Zegers. }\end{array}$ & $\begin{array}{l}\text { Wilson Padilla, flauta, } \\
\text { Jorge Pepi Alos, piano. }\end{array}$ \\
\hline \multirow[t]{6}{*}{$\begin{array}{l}\text { Stuardo, } \\
\text { Marcelo }\end{array}$} & $\begin{array}{l}\text { Aires nuevos para marimba y } \\
\text { cajón peruano. }\end{array}$ & $03 / 02 / 2011$ & $\begin{array}{l}\text { Música escénica para } \\
\text { percusiones, Sala Manuel } \\
\text { Enríquez, Facultad de } \\
\text { Música de la Universidad } \\
\text { de Tamaulipas, Tampico, } \\
\text { México. }\end{array}$ & $\begin{array}{l}\text { Dúo de Percusiones A } \\
\text { Dois. }\end{array}$ \\
\hline & & $04 / 02 / 2011$ & $\begin{array}{l}\text { Música escénica } \\
\text { para percusiones, } \\
\text { Master Class, Salón } \\
\text { de percusiones de } \\
\text { la Universidad de } \\
\text { Tamaulipas, Tampico, } \\
\text { México. }\end{array}$ & $\begin{array}{l}\text { Dúo de Percusiones A } \\
\text { Dois. }\end{array}$ \\
\hline & & 08/02/2011 & $\begin{array}{l}\text { Música escénica para } \\
\text { percusiones, Auditorio de } \\
\text { la Casa de la Marimba, } \\
\text { Ciudad de México. }\end{array}$ & $\begin{array}{l}\text { Dúo de Percusiones A } \\
\text { Dois. }\end{array}$ \\
\hline & & $10 / 02 / 2011$ & $\begin{array}{l}\text { Música escénica para } \\
\text { percusiones, } 2^{\circ} \text { Festival } \\
\text { de la Marimba Maestro } \\
\text { Zeferino Nandayapa en la } \\
\text { Plaza Central de Chiapas } \\
\text { de Corzo, México. }\end{array}$ & $\begin{array}{l}\text { Dúo de Percusiones A } \\
\text { Dois. }\end{array}$ \\
\hline & & $11 / 02 / 2011$ & $\begin{array}{l}\text { Música escénica para } \\
\text { percusiones, Master } \\
\text { Class, Escuela de Música } \\
\text { de la Universidad de } \\
\text { Chiapas }\end{array}$ & $\begin{array}{l}\text { Dúo de Percusiones A } \\
\text { Dois. }\end{array}$ \\
\hline & & $12 / 02 / 2011$ & $\begin{array}{l}\text { Música escénica para } \\
\text { percusiones, Auditorio de } \\
\text { la Fundación Sebastián, } \\
\text { Ciudad de México. }\end{array}$ & $\begin{array}{l}\text { Dúo de Percusiones A } \\
\text { Dois. }\end{array}$ \\
\hline
\end{tabular}




\begin{tabular}{|c|c|c|c|c|}
\hline $\begin{array}{l}\text { Nombre del } \\
\text { Compositor }\end{array}$ & Titulo de la obra & $\begin{array}{l}\text { Fecha de } \\
\text { Interpretación }\end{array}$ & Lugar & Intérpretes \\
\hline & & $12 / 02 / 2011$ & $\begin{array}{l}\text { Música escénica para } \\
\text { percusiones, Master } \\
\text { Class, Auditorio de la } \\
\text { Fundación Sebastian, } \\
\text { Ciudad de México. }\end{array}$ & $\begin{array}{l}\text { Dúo de Percusiones A } \\
\text { Dois. }\end{array}$ \\
\hline $\begin{array}{l}\text { Ugarte, Edgard } \\
\text { "Galo" }\end{array}$ & $\begin{array}{l}\text { **Órganon (2010) para conjunto } \\
\text { instrumental. }\end{array}$ & $4 / 12 / 2010$ & $\begin{array}{l}\text { Prismas Festival } \\
\text { de Creación } \\
\text { Latinoamericana, } \\
\text { Proyecto Germina. } \\
\text { Cciones...Primaveras } \\
\text { latinoamericanas, GAM. }\end{array}$ & $\begin{array}{l}\text { Ensamble Colectivo Los } \\
\text { Musicantes: } \\
\text { Patricio Huerta, saxo } \\
\text { alto; Moris Al Alam, saxo } \\
\text { tenor; Pablo Jara, saxo } \\
\text { barítono; Felipe Machuca } \\
\text { trompeta; Felipe Castillo, } \\
\text { trompeta; Ignacio Valle, } \\
\text { trombón; César Veas, } \\
\text { guitarra eléctrica; Claudio } \\
\text { Carrasco, batería; Felipe } \\
\text { Lolas, piano; Fabián } \\
\text { Aguilera, bajo eléctrico; } \\
\text { Sebastián Errazuriz, } \\
\text { director. }\end{array}$ \\
\hline \multirow[t]{3}{*}{$\begin{array}{l}\text { Valdebenito, } \\
\text { Mauricio }\end{array}$} & $\begin{array}{l}\text { La Cruz de Mayo (2005), para } \\
\text { conjunto. }\end{array}$ & $19 / 11 / 2010$ & $\begin{array}{l}\text { Centro de Extensión de } \\
\text { la Universidad Católica } \\
\text { del Maule. }\end{array}$ & Ensamble Serenata. \\
\hline & & $20 / 11 / 2010$ & $\begin{array}{l}\text { Salón Balmaceda de } \\
\text { Linares. }\end{array}$ & Ensamble Serenata. \\
\hline & & $21 / 11 / 2010$ & $\begin{array}{l}\text { Teatro Municipal de San } \\
\text { Clemente }\end{array}$ & Ensamble Serenata. \\
\hline $\begin{array}{l}\text { Vargas, } \\
\text { Leonardo }\end{array}$ & $\begin{array}{l}\text { **Jardines de la memoria }(2010) \\
\text { para ensamble. }\end{array}$ & $4 / 12 / 2010$ & $\begin{array}{l}\text { Prismas Festival } \\
\text { de Creación } \\
\text { Latinoamericana, } \\
\text { Proyecto Germina. } \\
\text { Cciones...Primaveras } \\
\text { latinoamericanas, GAM. }\end{array}$ & $\begin{array}{l}\text { Ensamble Colectivo Los } \\
\text { Musicantes: Patricio } \\
\text { Huerta, saxo alto; } \\
\text { Moris Al Alam. saxo } \\
\text { tenor; Pablo Jara, saxo } \\
\text { barítono; Felipe Machuca } \\
\text { trompeta; Felipe Castillo, } \\
\text { trompeta; Ignacio Valle, } \\
\text { trombón; César Veas, } \\
\text { guitarra eléctrica; Claudio } \\
\text { Carrasco, batería; Felipe } \\
\text { Lolas, piano; Fabián } \\
\text { Aguilera, bajo eléctrico; } \\
\text { Sebastián Errazuriz, } \\
\text { director. }\end{array}$ \\
\hline $\begin{array}{l}\text { Vásquez, } \\
\text { Cristián }\end{array}$ & $\begin{array}{l}\text { Iluminación del tiempo (2006) } \\
\text { para flauta, violín. viola, } \\
\text { violoncello, piano y percusión. }\end{array}$ & $9 / 11 / 2010$ & $\begin{array}{l}\text { XX Festival de Música } \\
\text { Contemporánea, PUC, } \\
\text { Sala GAM. }\end{array}$ & $\begin{array}{l}\text { Compañía de Música } \\
\text { Contemporánea, Carlos } \\
\text { Valenzuela Ramos, } \\
\text { director }\end{array}$ \\
\hline $\begin{array}{l}\text { Vega, Ricardo y } \\
\text { Chiste }\end{array}$ & $\begin{array}{l}\text { Interés por el conflicto (2010), } \\
\text { improvisación audiovisual. }\end{array}$ & $13 / 10 / 2010$ & $\begin{array}{l}\text { X Festival Ai-Maako, } \\
\text { Auditorio Fundación } \\
\text { Telefónica, Santiago. }\end{array}$ & \\
\hline
\end{tabular}




\begin{tabular}{lllll}
\hline $\begin{array}{l}\text { Nombre del } \\
\text { Compositor }\end{array}$ & Titulo de la obra & $\begin{array}{l}\text { Fecha de } \\
\text { Interpretación }\end{array}$ & Lugar & Intérpretes \\
\hline Venegas, Alexis & $\begin{array}{l}\text { Pie de cueca chorizo y tranquila } \\
\text { (2010) para guitarra. }\end{array}$ & $7 / 10 / 2010$ & $\begin{array}{l}\text { VI Concurso de } \\
\text { Composición Luis Advis, } \\
\text { GAM. }\end{array}$ & Alexis Venegas, guitarra. \\
& & & & \\
\hline
\end{tabular}

\begin{tabular}{|c|c|c|c|c|}
\hline $\begin{array}{l}\text { Vera Rivera, } \\
\text { Santiago }\end{array}$ & $\begin{array}{l}\text { Anagogística (1986) para } \\
\text { guitarra. }\end{array}$ & $26 / 10 / 2010$ & $\begin{array}{l}\text { Auditorio del Instituto } \\
\text { de Chile, presentación } \\
\text { pública del CD. }\end{array}$ & Luis Orlandini, guitarra. \\
\hline & $\begin{array}{l}\text { *Celosiátika I (Universus) (2010) } \\
\text { para orquesta. }\end{array}$ & $12 / 11 / 2010$ & $\begin{array}{l}\text { Teatro Municipal de La } \\
\text { Serena. }\end{array}$ & $\begin{array}{l}\text { Orquesta Sinfónica de } \\
\text { la Universidad de La } \\
\text { Serena, Víctor Hugo Toro, } \\
\text { director. }\end{array}$ \\
\hline $\begin{array}{l}\text { Vergara, Juan } \\
\text { Pablo }\end{array}$ & $\begin{array}{l}\text { *Regando el tiempo con tinta } \\
\text { (2010) para flauta, trompeta, } \\
\text { percusión, piano, violín, } \\
\text { violoncello y contrabajo. }\end{array}$ & $9 / 11 / 2010$ & $\begin{array}{l}\text { XX Festival de Música } \\
\text { Contemporánea, PUC, } \\
\text { Sala GAM. }\end{array}$ & $\begin{array}{l}\text { Compañía de Música } \\
\text { Contermporánea, Carlos } \\
\text { Valenzuela Ramos, } \\
\text { director. }\end{array}$ \\
\hline \multirow[t]{5}{*}{$\begin{array}{l}\text { Vila Castro, } \\
\text { Cirilo }\end{array}$} & $\begin{array}{l}\text { Rapsodia chilensis (1986) para } \\
\text { piano. }\end{array}$ & $16 / 11 / 2010$ & Goethe Institut, Santiago. & Patricia Castro, piano. \\
\hline & Hojas de otoño (1984) para flauta. & $24 / 11 / 2010$ & $\begin{array}{l}\text { Sala América de la } \\
\text { Biblioteca Nacional. }\end{array}$ & $\begin{array}{l}\text { Estela Bellomio, flauta } \\
\text { traversa. }\end{array}$ \\
\hline & $\begin{array}{l}\text {...Y una flor para ésta y otras } \\
\text { primaveras (1987) para flauta. }\end{array}$ & $24 / 11 / 2010$ & $\begin{array}{l}\text { Sala América de la } \\
\text { Biblioteca Nacional. }\end{array}$ & $\begin{array}{l}\text { Estela Bellomio, flauta } \\
\text { traversa. }\end{array}$ \\
\hline & $\begin{array}{l}\text { Poema }(1965 / \text { rev. } 1980) \text { para } \\
\text { piano. }\end{array}$ & $29 / 11 / 2010$ & $\begin{array}{l}\text { Sala América de la } \\
\text { Biblioteca Nacional. }\end{array}$ & Fernanda Ortega, piano. \\
\hline & $\begin{array}{l}\text { **Secuencia Momentos (1969) } \\
\text { para cuarteto de cuerdas, obra } \\
\text { dedicada "A Gustavo Becerra, } \\
\text { maestro/ al Cuarteto del } \\
\text { Conservatorio". }\end{array}$ & $13 / 01 / 2011$ & $\begin{array}{l}\text { XI Festival de Música } \\
\text { Contemporánea de la } \\
\text { Universidad de Chile, } \\
\text { Facultad de Artes, Sala } \\
\text { Isidora Zegers. }\end{array}$ & $\begin{array}{l}\text { Ensamble ViktoriaQuartett } \\
\text { Berlin: } \\
\text { Álvaro Parra, violín; } \\
\text { Gabriel Adorján, violín; } \\
\text { Daniel Röhn, viola; } \\
\text { Christopher Jepson, } \\
\text { violoncello. }\end{array}$ \\
\hline \multirow[t]{3}{*}{ Wang, Patricio } & $\begin{array}{l}\text { El naufragio (2008) para conjunto } \\
\text { (clarinete Sib, saxo tenor, guitarra } \\
\text { eléctrica, bajo eléctrico y piano). }\end{array}$ & $15 / 10 / 2010$ & $\begin{array}{l}\text { VII Festival } \\
\text { Internacional de Música } \\
\text { Contemporánea Darwin } \\
\text { Vargas, Instituto de } \\
\text { Música de PUCV. }\end{array}$ & $\begin{array}{l}\text { Ensemble Universidad de } \\
\text { Valparaíso. }\end{array}$ \\
\hline & $\begin{array}{l}\text { Extractos de vocis informis } \\
\text { (2008), adaptación para la Coral } \\
\text { Femenina Viña del Mar. }\end{array}$ & $18 / 10 / 2010$ & $\begin{array}{l}\text { Sala de Eventos Codelco, } \\
\text { Santiago. }\end{array}$ & $\begin{array}{l}\text { Coral Femenina Viña del } \\
\text { Mar, Jessica Quezada, } \\
\text { directora. }\end{array}$ \\
\hline & $\begin{array}{l}\text { **Then the Old Woman (de la } \\
\text { obra Vocis informis) (2010) para } \\
\text { soprano. }\end{array}$ & $30 / 11 / 2010$ & $\begin{array}{l}\text { Prismas Festival } \\
\text { de Creación } \\
\text { Latinoamericana, } \\
\text { Proyecto Germina. } \\
\text { Cciones...Primaveras } \\
\text { latinoamericanas, GAM. }\end{array}$ & Carolina Matus, soprano. \\
\hline
\end{tabular}




\begin{tabular}{|c|c|c|c|c|}
\hline $\begin{array}{l}\text { Nombre del } \\
\text { Compositor }\end{array}$ & Titulo de la obra & $\begin{array}{l}\text { Fecha de } \\
\text { Interpretación }\end{array}$ & Lugar & Intérpretes \\
\hline \multirow[t]{2}{*}{ Yau, Rodrigo } & $\begin{array}{l}\text { **Curro (2010) para conjunto de } \\
\text { guitarras. }\end{array}$ & $29 / 11 / 2010$ & $\begin{array}{l}\text { Prismas Festival } \\
\text { de Creación } \\
\text { Latinoamericana, } \\
\text { Proyecto Germina. } \\
\text { Cciones...Primaveras } \\
\text { latinoamericanas, } \\
\text { Universidad de } \\
\text { Valparaíso. }\end{array}$ & $\begin{array}{l}\text { Consort Guitarrístico de } \\
\text { Chile: Andrés González, } \\
\text { guitarra soprano, } \\
\text { charango; Rodrigo Erazo, } \\
\text { guitarra alto; Pablo } \\
\text { Palacios, guitarra tenor, } \\
\text { Sebastián Avello, guitarra } \\
\text { bajo; Moa Edmunds, } \\
\text { guitarra contrabajo. }\end{array}$ \\
\hline & & $4 / 12 / 2010$ & $\begin{array}{l}\text { Prismas Festival } \\
\text { de Creación } \\
\text { Latinoamericana, } \\
\text { Proyecto Germina. } \\
\text { Cciones...Primaveras } \\
\text { latinoamericanas, GAM. }\end{array}$ & $\begin{array}{l}\text { Consort Guitarrístico de } \\
\text { Chile. }\end{array}$ \\
\hline \multirow[t]{7}{*}{ Zamora, Carlos } & $\begin{array}{l}\text { Un fugitivo irlandés (2008) para } \\
\text { soprano y orquesta. }\end{array}$ & $5 / 10 / 2010$ & $\begin{array}{l}\text { XIII Festival de Música } \\
\text { Chilena Contemporánea } \\
\text { de la Universidad Austral } \\
\text { de Chile, Aula Magna. }\end{array}$ & $\begin{array}{l}\text { Orquesta de Cámara de } \\
\text { la Universidad Austral } \\
\text { de Chile, } \\
\text { Carlos Zamora, director; } \\
\text { Cecilia Barrientos, } \\
\text { soprano. }\end{array}$ \\
\hline & $\begin{array}{l}\text { Vocalise (2010) para soprano y } \\
\text { piano. }\end{array}$ & $5 / 10 / 2010$ & $\begin{array}{l}\text { XIII Festival de Música } \\
\text { Chilena Contemporánea } \\
\text { de la Universidad Austral } \\
\text { de Chile, Aula Magna. }\end{array}$ & $\begin{array}{l}\text { Cecilia Barrientos, } \\
\text { soprano; Ximena Cabello, } \\
\text { piano. }\end{array}$ \\
\hline & $\begin{array}{l}\text { Victor Jara Sinfónico (2006) } \\
\text { (Plegaria a un labrador, Que } \\
\text { saco rogar al cielo, El aparecido, } \\
\text { El derecho de vivir en paz). }\end{array}$ & $7 / 10 / 2010$ & $\begin{array}{l}\text { Aula Magna de la } \\
\text { USACH. }\end{array}$ & $\begin{array}{l}\text { Coro de la USACH, } \\
\text { Santiago Marín, director; } \\
\text { Patricio Valenzuela, piano. }\end{array}$ \\
\hline & & $21 / 10 / 2010$ & $\begin{array}{l}\text { Santuario de la } \\
\text { Inmaculada Concepción, } \\
\text { La Granja. }\end{array}$ & $\begin{array}{l}\text { Coro de la USACH, } \\
\text { Santiago Marín, director; } \\
\text { Patricio Valenzuela, piano. }\end{array}$ \\
\hline & & $30 / 10 / 2010$ & $\begin{array}{l}\text { XVII Festival Nacional } \\
\text { de Coros de Chile, San } \\
\text { Antonio. }\end{array}$ & $\begin{array}{l}\text { Coro de la USACH, } \\
\text { Santiago Marín, director; } \\
\text { Patricio Valenzuela, piano. }\end{array}$ \\
\hline & & $9 / 12 / 2010$ & $\begin{array}{l}\text { Teatro Nescafé de las } \\
\text { Artes. }\end{array}$ & $\begin{array}{l}\text { Orquesta Sinfónica } \\
\text { Estudiantil Región } \\
\text { Metropolitana, } \\
\text { Felipe Hidalgo, director; } \\
\text { BAFONA, Leticia } \\
\text { Lizama, directora. }\end{array}$ \\
\hline & & 2/01/2011 & $\begin{array}{l}\text { Quinta Vergara, Ilustre } \\
\text { Municipalidad de Viña } \\
\text { del Mar. }\end{array}$ & $\begin{array}{l}\text { Orquesta Sinfónica } \\
\text { Estudiantil Región } \\
\text { Metropolitana, Felipe } \\
\text { Hidalgo, director; } \\
\text { BAFONA, Leticia } \\
\text { Lizama, directora. }\end{array}$ \\
\hline
\end{tabular}




\begin{tabular}{|c|c|c|c|c|}
\hline $\begin{array}{l}\text { Nombre del } \\
\text { Compositor }\end{array}$ & Titulo de la obra & $\begin{array}{l}\text { Fecha de } \\
\text { Interpretación }\end{array}$ & Lugar & Intérpretes \\
\hline & $\begin{array}{l}\text { Quinteto de vientos } \mathrm{N}^{0} 1(1995), \\
\mathrm{N}^{0} 2(1999), \mathrm{N}^{0} 3(2000) .\end{array}$ & $31 / 10 / 2010$ & $\begin{array}{l}\text { Centro Cultural } \\
\text { ANAHUAC, Cerro San } \\
\text { Cristóbal, Santiago. }\end{array}$ & $\begin{array}{l}\text { Alumnos de la cátedra de } \\
\text { Música de Cámara de la } \\
\text { Facultad de Artes de la } \\
\text { Universidad de Chile. }\end{array}$ \\
\hline & $\begin{array}{l}\text { Movimiento de sonata (2007) } \\
\text { para flauta dulce y guitarra. }\end{array}$ & $12 / 11 / 2010$ & $\begin{array}{l}\text { Festival Entrecuerdas, } \\
\text { Valdivia. }\end{array}$ & Dúo Divertimento. \\
\hline & $\begin{array}{l}\text { Tres visiones de un sikuris } \\
\text { atacameño (1999) para orquesta. }\end{array}$ & $13 / 11 / 2010$ & $\begin{array}{l}\text { Transmisión vía satélite } \\
\text { de versión pregrabada } \\
\text { para conmemorar } \\
\text { el aniversario de la } \\
\text { revolución mexicana, } \\
\text { Zócalo de Ciudad de } \\
\text { México. }\end{array}$ & $\begin{array}{l}\text { Orquesta de la provincia } \\
\text { Marga-Marga, Luis José } \\
\text { Recart, director. }\end{array}$ \\
\hline & & $2 / 12 / 2010$ & $\begin{array}{l}\text { Centro de Eventos } \\
\text { del Casino, Dreams, } \\
\text { Valdivia. }\end{array}$ & $\begin{array}{l}\text { Orquesta de Cámara } \\
\text { de Valdivia, Cristobal } \\
\text { Urrutia, director. }\end{array}$ \\
\hline & $\begin{array}{l}\text { *Misa Brevis (2009) para } \\
\text { soprano, coro femenino y } \\
\text { orquesta de cuerdas. }\end{array}$ & $14 / 11 / 2010$ & $\begin{array}{l}\text { XX Festival de Música } \\
\text { Contemporánea, PUC, } \\
\text { Sala GAM. }\end{array}$ & $\begin{array}{l}\text { Cecilia Barrientos, } \\
\text { soprano, coro Ad-Hoc y } \\
\text { Orquesta Marga Marga, } \\
\text { Carlos Zamora, director }\end{array}$ \\
\hline $\begin{array}{l}\text { Zamora, } \\
\text { Segundo y } \\
\text { Sergio Sauvalle }\end{array}$ & $\begin{array}{l}\text { Adiós Santiago querido arreglo } \\
\text { para guitarra (1994). }\end{array}$ & $25 / 02 / 2011$ & $\begin{array}{l}\text { Del Mapocho al Illimani, } \\
\text { concierto de guitarra } \\
\text { clásica., Museo de Arte } \\
\text { Contemporáneo Plaza (El } \\
\text { Prado), La Paz-Bolivia. }\end{array}$ & $\begin{array}{l}\text { Alejandro Escobar, } \\
\text { guitarra. }\end{array}$ \\
\hline
\end{tabular}

